مدخل مقترح لمراجعة القيمة الحالية كأحد مقاييس القيمة العادلة فى إطار المعايير الدولية للمراجعة - دراسة ميدانية

\author{
د. عبدالحميد احمد احمد شاهين \\ أستاذ مساعد المحاسبة والمراجعة \\ كلية التجارة - جامعة مدينة السادات
}


مدخل مقترح لمراجعة القيمة الحالية كأحد مقاييس القيمة العادلة فى إطار المعايير الدولية

للمراجعة - دراسة ميدانية

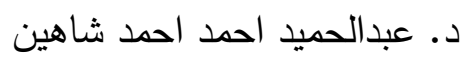

يهدف البحث إلى إجراء دراسة تحليلية للقيمة الحالية للتدفقات النقدية المستقبلية المتوقعة كمنهج

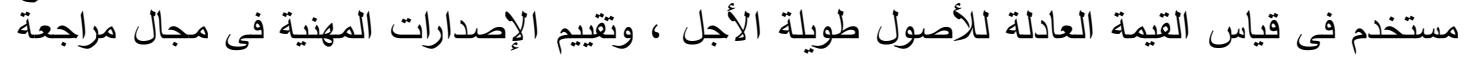

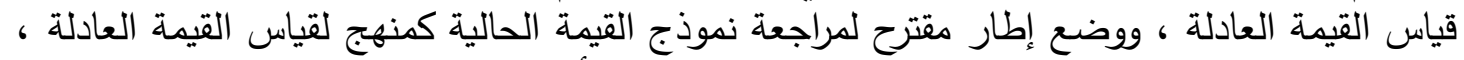

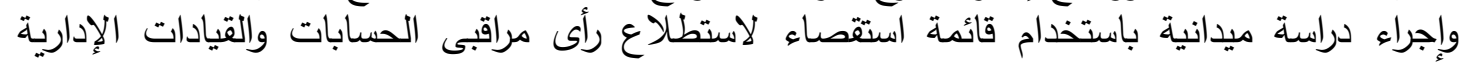

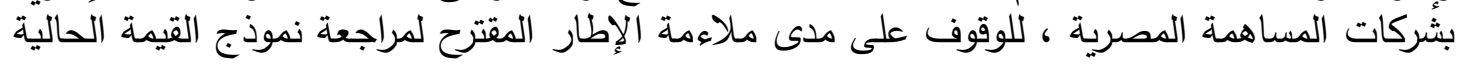

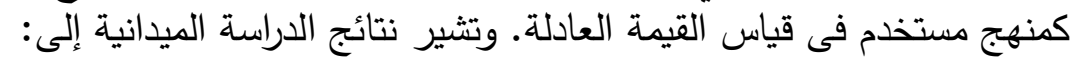

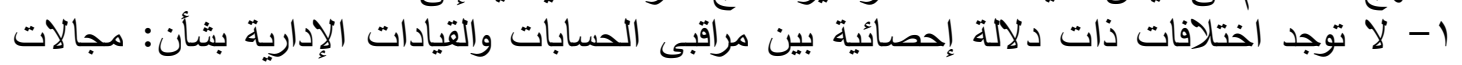

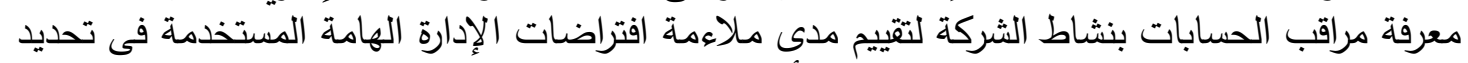

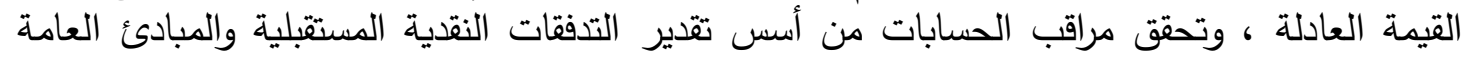
والعوامل المؤثرة فى تحديد سعر خصم التدفقات ومعدل الخصم التصد المستخدم فى تحديد القيمة الحالية للتدفقات النقدية المستقبلية. ץ- يوجد اختلافات ذات دلاتلة إحصائية بين مراقبى الحسابات والقيادات الإدارية بشأن تحقق مراقب

Abstract:

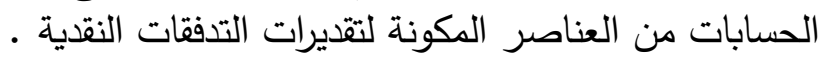

The research aims to conduct an analytical study to the present value of the future cash flows expected as a used way in measuring the fair value of long-term assets, and evaluation professional versions in the field of audit fair value measurement, and establish a framework proposal to audit of the present value model of a method for measuring fair value, and conduct a field study using the questionnaire of survey the poll auditors and administrative leaders Egyptian Shareholding Companies, to stand on the appropriateness of the proposed framework to audit the present value model as a way of used in the fair value measurement.

The results of the field study to:

1 - There are no statistically significant differences between the auditors and administrative leaders on: areas of knowledge of the auditor actively company to evaluate the appropriateness of the significant management assumptions used in determining fair value, and the auditor substantive of the basis of estimating future cash flows and general principles and influencing factors in determining the discount rate of future cash flows and the discount rate used in determining the present value of future cash flows.

2- There are statistically significant differences between the auditors and administrative leaders on the auditor substantive of estimates of the cash flows projections. 
مدخل مقترح لمراجعة القيمة الحالية كأحد مقاييس القيمة العادلة فى إطار المعايير

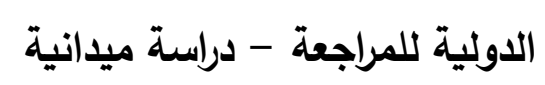

د. عبدالحميد احمد احمد شاهين (")

$$
\text { أولا : الإطار العام للبحث }
$$

1/1 - 1/ دوافع ومشكلة البحث:

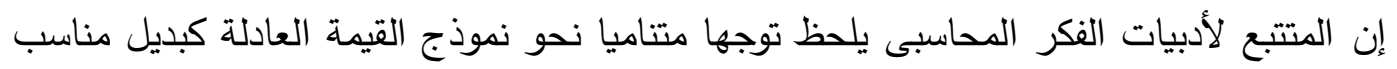

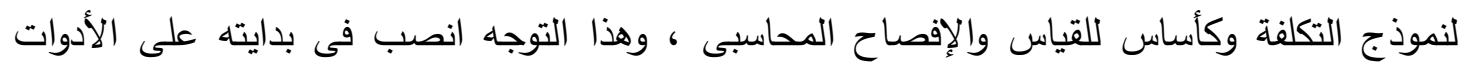
المالية (Financial Instruments) ، ثم شمل الأصول الملموسة كالاستثمار العقارى والأصول

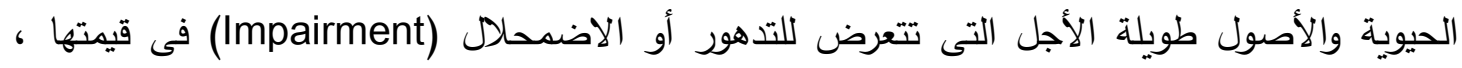

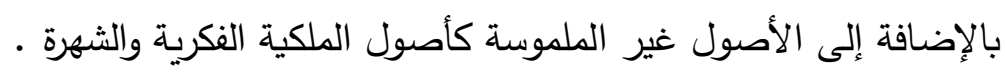
وقد أكد (2010) Pannes and Delfavero على انه بالرغم من ان محاسبة القيمة العادلة لا

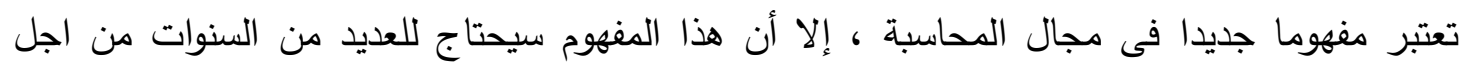

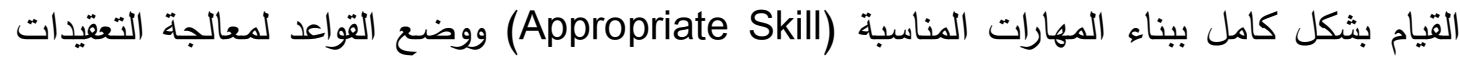

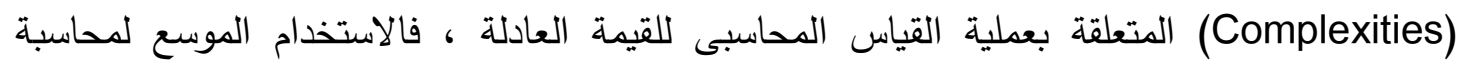

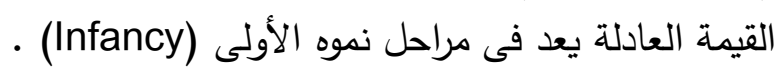

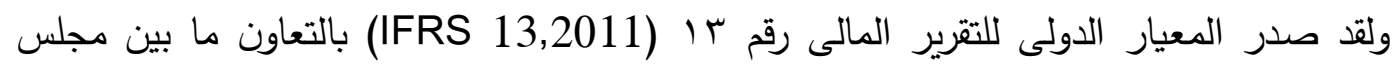

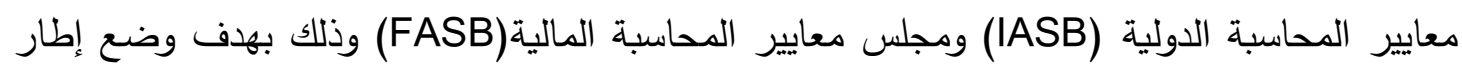

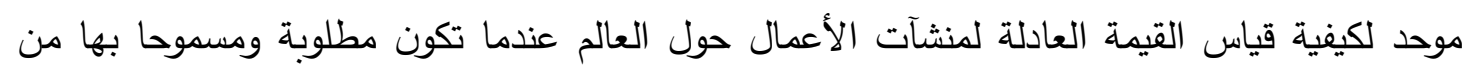

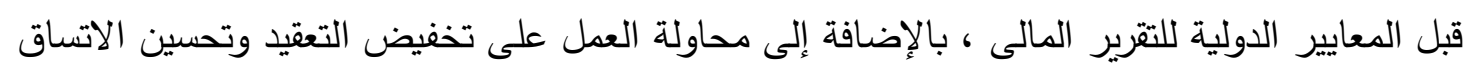
(Improve Consistency)

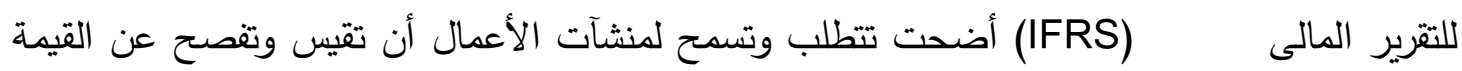

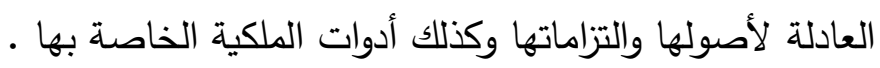




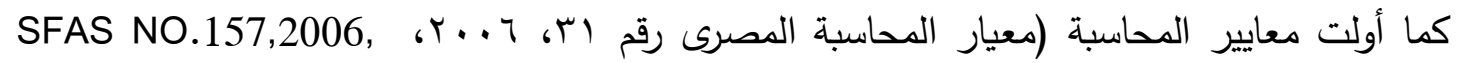

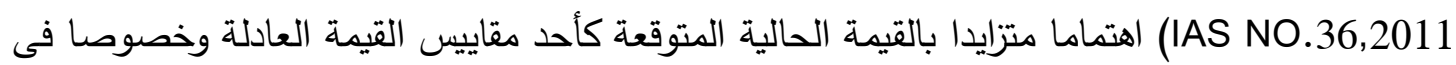
ظل غياب سوق نشطة للأصل محل القياس. وتتاول كلا من Bell and Griffin (2012) التحديات التى تواجه كل من واضعى المعايير والممارسين والمستخدمين ومراقبى الحسابات ، والمتعلقة بحالة عدم

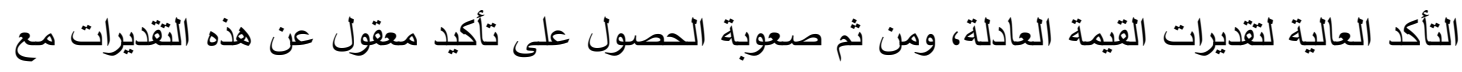
وجود مستوى عال من الارتياب المتأصل فى عملية القياس Uncertainty)

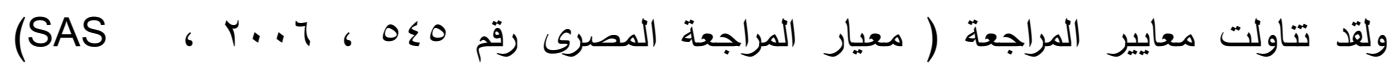

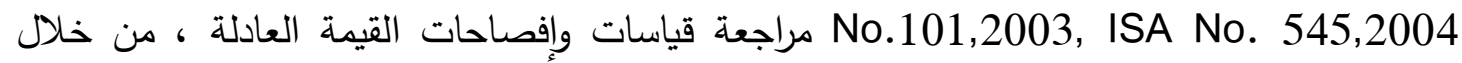
توفير إرشادات لمراقبى الحسابات حول عملية المراجعة ، وعلى وجه الخصوص اعتبارات المراجعة ماتهات المتعلقة بالقياس والإفصاح عن الأصول والالتزامات وعناصر محددة من حقوق الملكية المعروضة أو

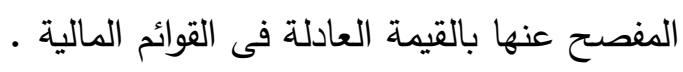
ولقد ورد بتقارير التفتيش لمجلس مراقبة شركات المحاسبة العامة (PCAOB) أن السبب الأساسى لعيى

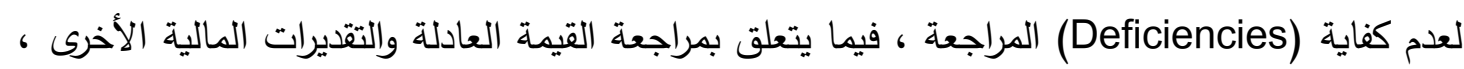

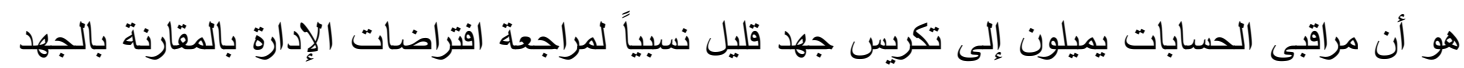

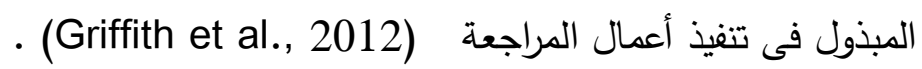
كما أكد (2008) Carprntier, et al. أن الاتجاه الحالى للمعايير الدولية (IFRS) ومبادئ المحاسبة المقبولة عموما (GAAP) هو بوضوح لصالح قياس القيمة العادلة ، والقراء والمحللون للبيانات

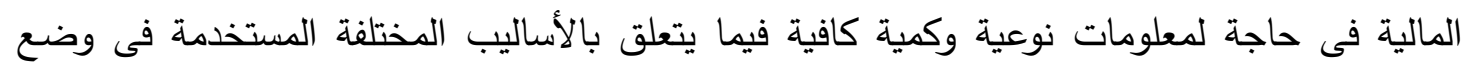
افتراضات للمتغيرات المرتبطة بأصول لا يتوفر لها سوق نشطة أو لأصول متشابهة أو سوق غير نشطة فئة

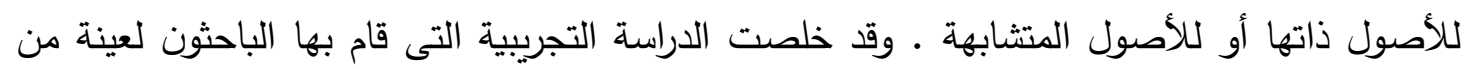
ثلاثة وأربعين من خبراء التقييم لتقييم أحد الاستثمارات اعتمادا على نفس المبادئ التئ التوجيهية والمعايير

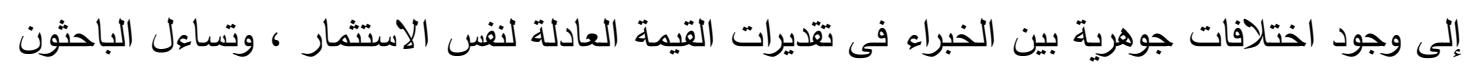

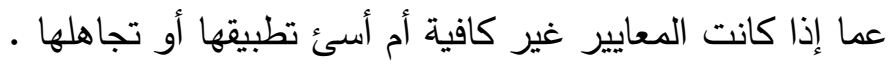

وبناءً على ما تقدم ، يرى الباحث ان أولى دوافع هذا البحث تتمثل فى ان معايير المراجعة المعنية

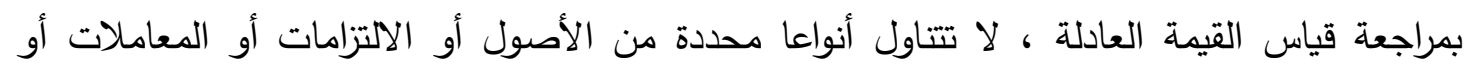

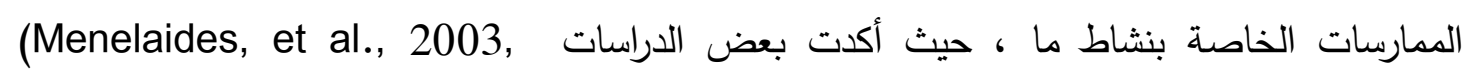
عدم فعالية معايير المراجعة الحالية فى توجيه وإرشاد مراقبى Pannese and Delfavero, 2010) الحسابات نحو التحقق من القياس المحاسبى للقيمة العادلة ، وحاجة تلك المعايير إلى المزيد من الإيضاح والتقصيل للربط بين إجراءات المراجعة وبنود القوائم المالية التى يتم قياسها بالقيمة العادلة . 


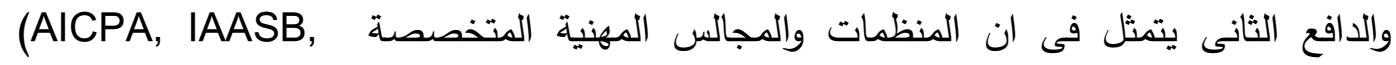

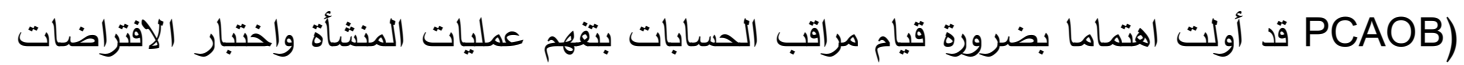

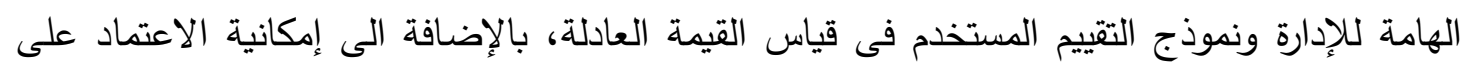

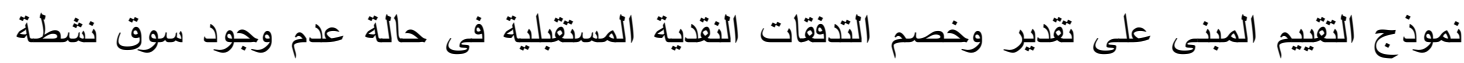

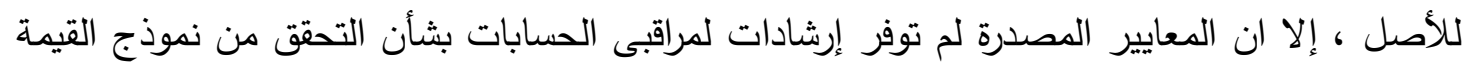

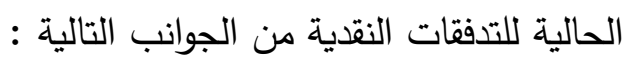

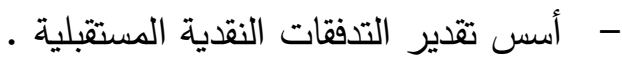
- - العناصر المكونة لتقديرات التدفقات النقدية . - - المبادئ والعوامل المؤثرة فى تحديد سعر خصم التدفقات النقدية .

أما الدافع الثالث فيتمثل فى الطبيعة المعقدة لنموذج القيمة الحالية للتدفقات النقدية المستقبلية فيما

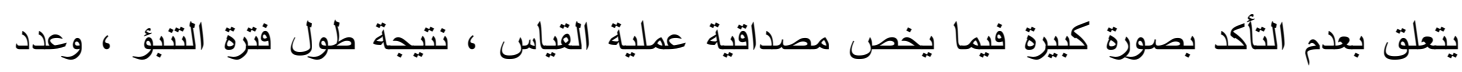

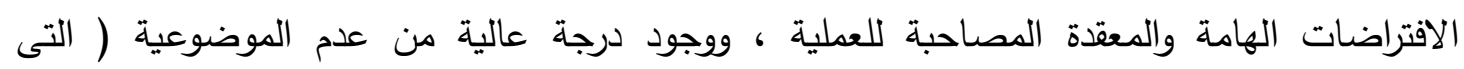

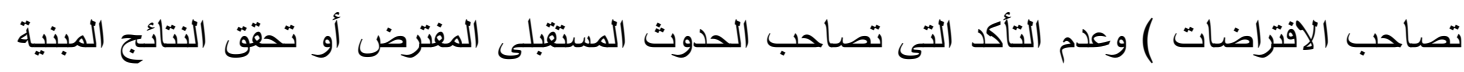

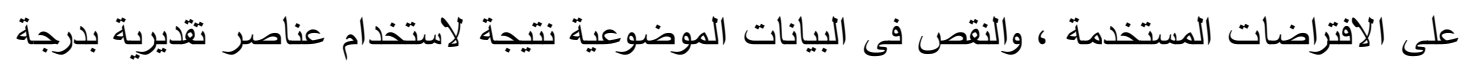

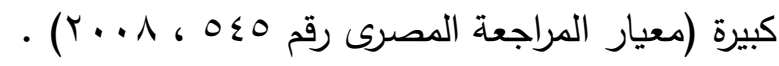

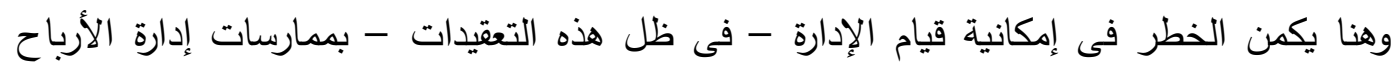

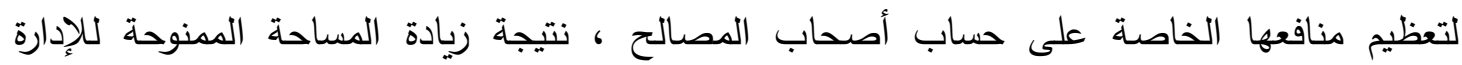

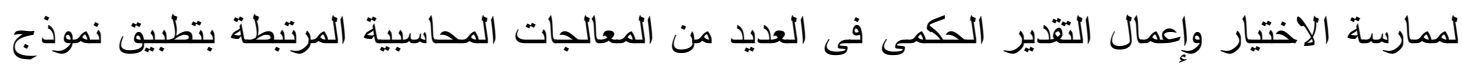
القيمة الحالية كمدل لقياس القيمة العادلة .

والدافع الرابع يتمثل فى ان زيادة استخدام محاسبة القيمة العادلة يثكل تحديا لمراقبى الحسابات ،

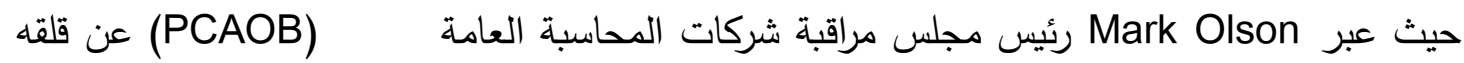

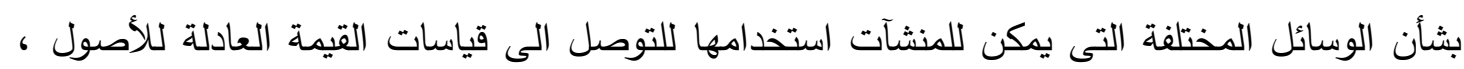

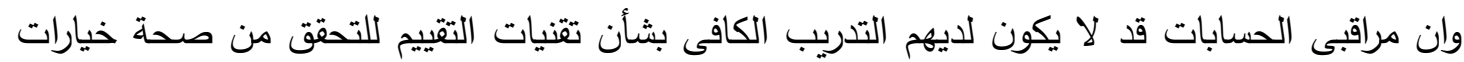

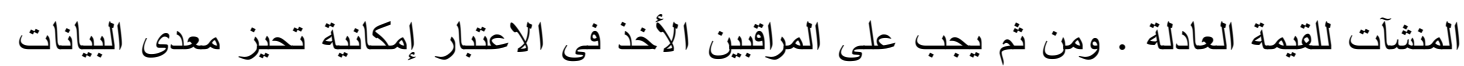

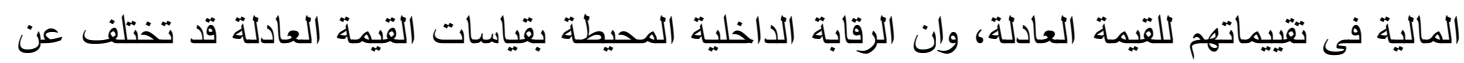

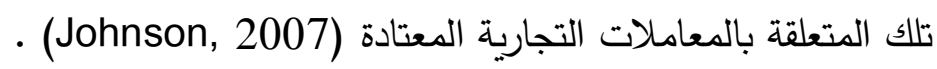

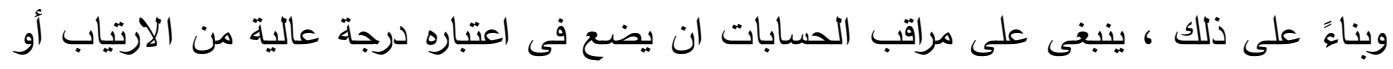

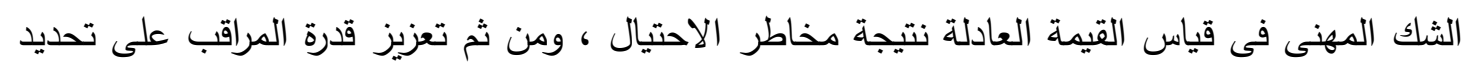

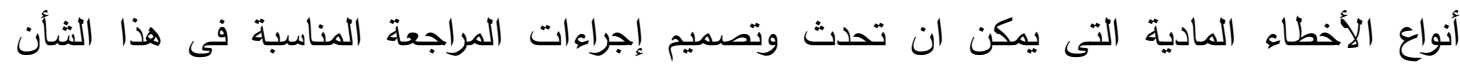
. (PCAOB, 2009) 
وبناءً على ما تقدم ، ونظرا لان نموذج القيمة الحالية للتدفقات النقدية يعد أحد المداخل الأساسية

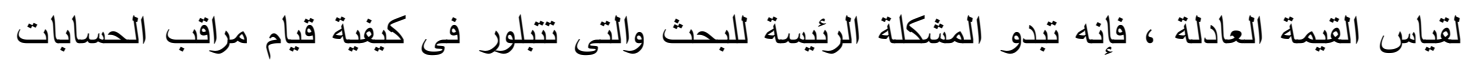
بمراجعة الافتراضات الهامة للإدارة ونموذج التقييم المستخدم فى قياس القيمة العادلة للحصول على لئى أدلة

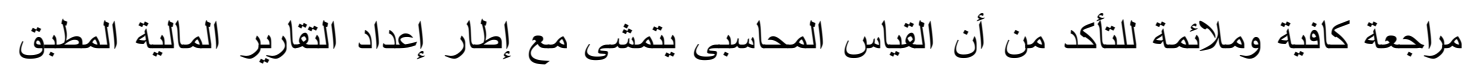

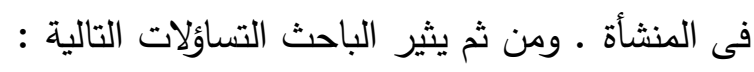
1- ما هى طبيعة المشاكل المتعلقة بنموذج القيمة الحالية للتدفقات النقدية المستقبلية والتى قد تؤثر على مصداقية القياس المحاسبى للقيمة العادلة ؟. ץ- وهل المعايير الدولية لمراجعة القياس المحاسبى للقيمة العادلة تعد كافية لإرشاد مراقبى الحسابات

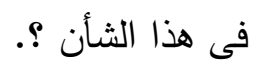
r- وهل يمكن لمراقبى الحسابات التحقق من وإبداء الرأى فى مدى ملاءمة افتراضات الإدارة فيما يتعلق بمقدار وتوقيت ومعدل خصم التدفقات النقدية المستقبلية ؟.

\section{: r/l}

يسعى الباحث إلى الإجابة عن التساؤلات السابقة بما يسهم فى تحقيق الأهداف التالية:

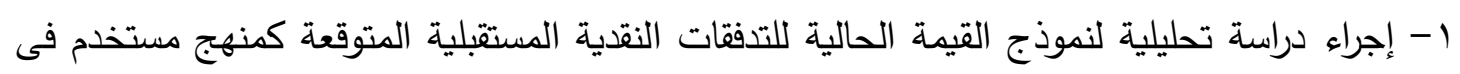

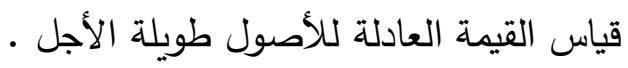

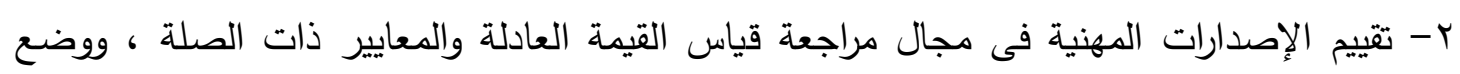
إطار مقترح لمراجعة نموذج القيمة الحالية لتتمشى عملية قياس القيمة العادلة مع إطار إعداد

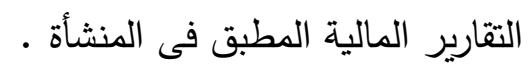
r- إجراء دراسة ميدانية من خلال استقراء فكر مراقبى الحسابات والقيادات الإدارية بشركات المساهمة المصرية ، للوقوف على مدى ملاعمة الإطار الفكرى المقترح لمراجعة نموذج القيمة الحالية كمنهج

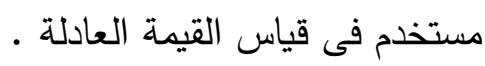

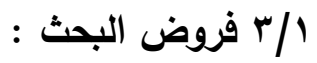

$$
\begin{aligned}
& \text { لتحقيق أهداف البحث ، قام الباحث بصياغة فروض البحث على النحو التالى : }
\end{aligned}
$$

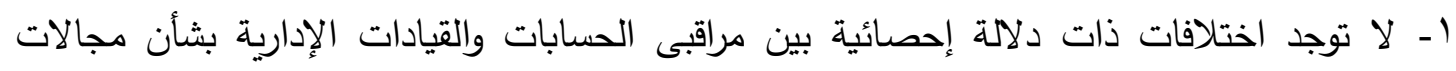

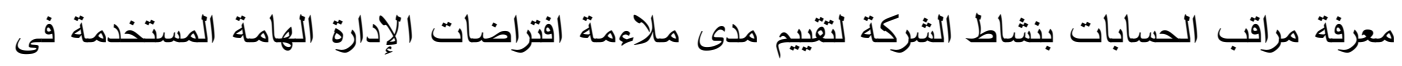
تحديد القيمة العادلة . معربه

r - لا توجد اختلافات ذات دلالة إحصائية بين مراقبى الحسابات والقيادات الإدارية بشأن تحقق مراقب

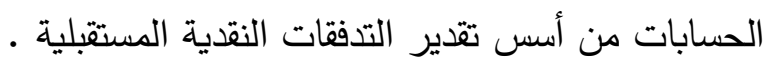

r- لا توجد اختلافات ذات دلالة إحصائية بين مراقبى الحسابات والقيادات الإدارية بشأن تحقق مراقب

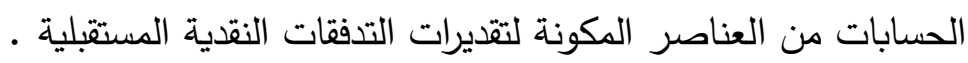


ع ـ ل لا توجد اختلافات ذات دلالة إحصائية بين مراقبى الحسابات والقيادات الإدارية بشأن تحقق مراقب

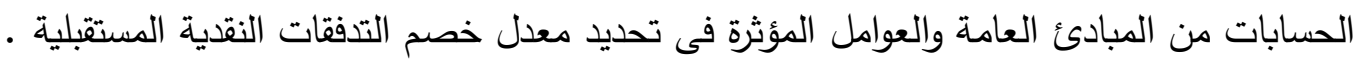
هـ ـ لا توجد اختلافات ذات دلالة إحصائية بين مراقبى الحسابات والقيادات الإدارية بشأن تحقق مراقب الحسابات من معدل الخصم المستخدم فى تحديد القيمة الحالية للتدفقات النقدية المستقبلية.

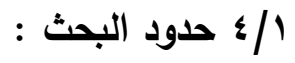

تتمثل حدود البحث فى إجراء دراسة تحليلية لنموذج القيمة الحالية للتدفقات النقدية المستقبلية كمنهج لقياس القيمة العادلة للأصول طويلة الأجل وذلك فى إطار معايير المحاسبة الدولية والأمريكية والمصرية .

كما اقتصر البحث على تقييم الإصدارات المهنية - الدولية والأمريكية والمصرية -المعنية بمراجعة قياس القيمة العادلة ، وإجراء دراسة ميدانية لاستطلاع أراء كل من مراقبى الحسابات والقيادات الإدارية

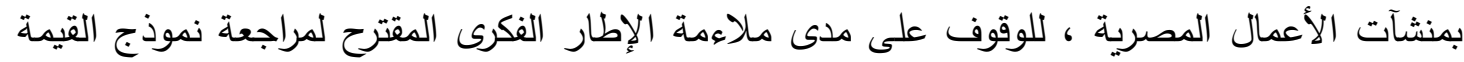
الحالية كأحد مقاييس القيمة العادلة ـ : 1/ أهمية البحث

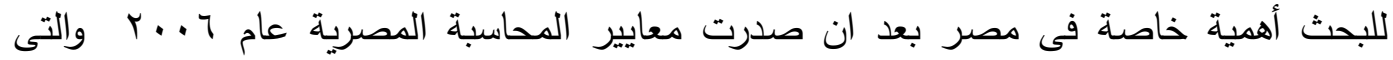
تتاولت فى بعض هذه المعايير أسس القياس المحاسبى للقيمة العادلة باستخدام القيمة الحالية للتدفقات التهات

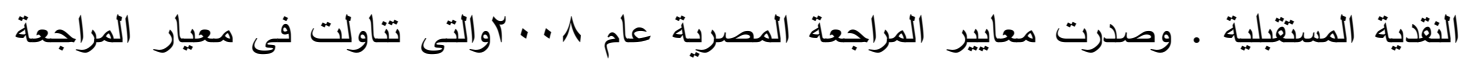

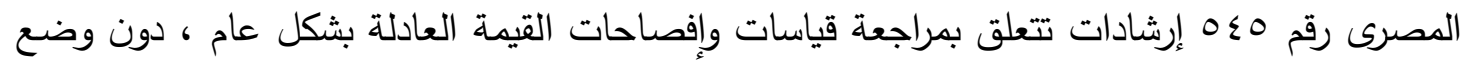
إجراءات تفصيلية تتعلق بمراجعة النموذج المستخدم فى قياس القيمة العادلة . كما ان للبحث أهمية خاصة لمراقبى الحسابات ، نظرا لان مراجعة النموذج المستخدم فى قياس القيمة العادلة ، يسهم بشكل ايجابى فى تضييق فجوة التوقعات بين الدور المرتقب لمراقب الحسابات وكافة

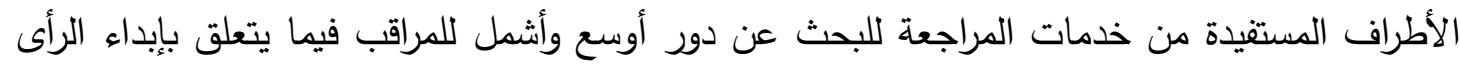
عن نماذج القياس المحاسبى للقيمة العادلة ، بالإضافة إلى الحد من مخاطر التحريف الجوهرى للحقائق

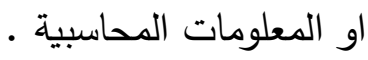
هذا بالإضافة الى ان البحث فى عمومه يعد بمثابة دعوة فكرية مفتوحة للمنظمات المهنية المتخصصة ، للمساهمة فى تعديل معيار المراجعة الدولى والمصرى رقم 0 ؛ـ ليشمل جوانب المراجعة

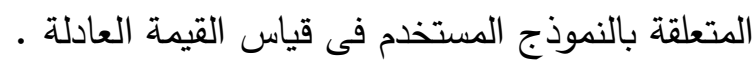

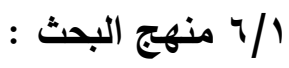

اعتمد الباحث على المنهج الاستتباطى فى صياغة مشكلة البحث وتحديد أهدافه وفروضه وتحديد

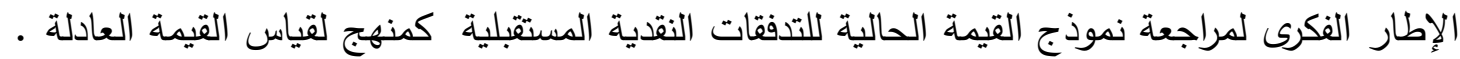


بينما اعتمد الباحث على المنهج الاستقرائى فى الدراسة الميدانية لاستطلاع آراء مراقبى الحسابات والقيادات الإدارية ، للوقوف على مدى ملاءمة الإطار الفكرى المقترح لمراجعة نموذج القيمة الحالية . : خطة البحث V/ لتحقيق أهداف البحث واختبار مدى صحة فروضه تم تقسيم بقية البحث على النحو التالى : ثانيا : عرض وتحليل الدراسات السابقة .

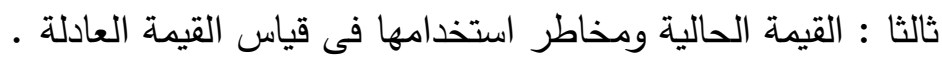
رابعا : الإطار الفكرى لمراجعة القيمة الحالية كمدخل لقياس القيمة العادلة .

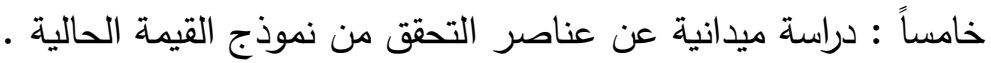

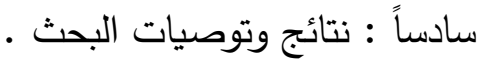

ثانيا : عرض وتحليل الدراسات السابقة

تتاولت بعض الدراسات (الأجنبية بصفة خاصة) مراجعة القياس والإفصاح المحاسبى عن القيمة

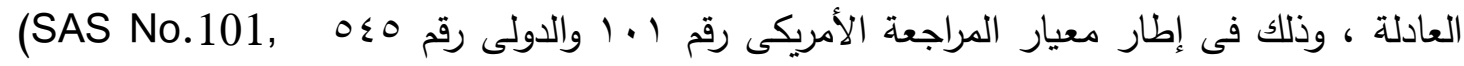
(2003, ISA No. 545, 2004 ، ويمكن عرض بعض أهم الدراسات فى هذا للشأن على النحو : الموضح فيما يلى :

: Menelaides, et al. (2003) (1/ 1/

استهدفت الدراسة عرض وتحليل الدور الموسع لمراقب الحسابات فى مجال مراجعة القياس

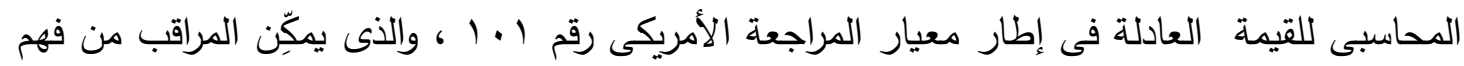

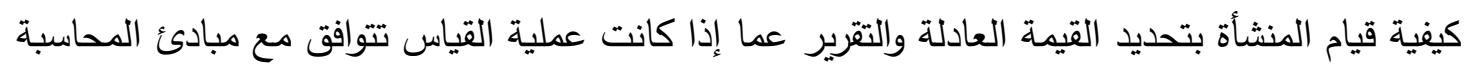
المقبولة قبولا عاما (GAAP) ، مع ضرورة قيام المراقب بتقييم مخاطر التحريف الهام فى قياسات وإفصاحات القيمة العادلة المعدة بواسطة إدارة المنشأة.

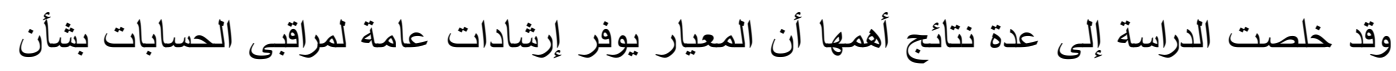

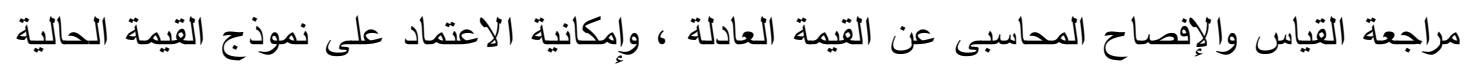

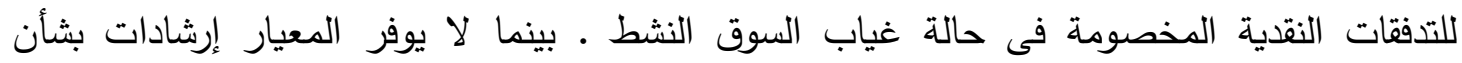
مراجعة أنواع محددة من الأصول أو الالتزامات أو عناصر حقوق الملكية أو المعاملات أو الممارسات الخاصة بصناعة ما.

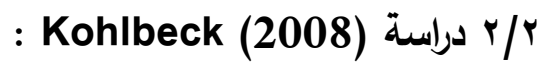

استهدفت الدراسة التحقق من مدى توافر خاصيتى الملاعمة والمصداقية فى نموذج القيمة العادلة ،

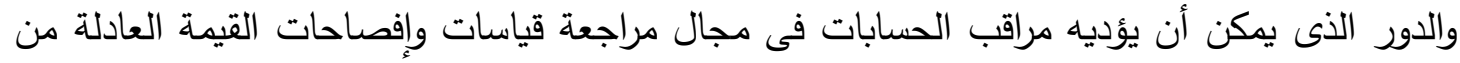

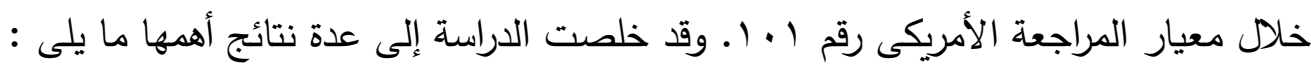


1- قدرة نموذج القيمة العادلة فى تحقيق خاصية الملاءمة بتوفير المعلومات المؤثرة على القرارات الاقتصادية للمستخدمين.

ץ- إن خاصية المصداقية أو الاعتمادية محل شك (Suspect) ، وخاصة عندما تكون القيمة العادلة محددة على أساس افتراضات غير قائمة على معلومات السوق. حيث يتم القياس بناءً على التقدير

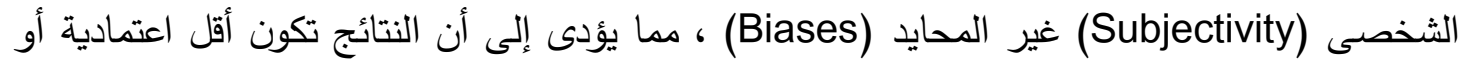
مصداقية أو موثوقية (reliability). ז- إن إلزام مراقبى الحسابات بمراجعة القياس والإفصاح المحاسبى عن القيمة العادلة يمكن أن يحسن

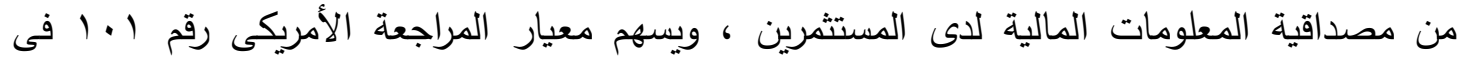
تحقيق هذا الغرض.

: IAASB (2008) دراسة

استهدفت الدراسة الوقوف على التحديات التى تواجه المحاسبين والمراجعين فى مجال التقييم

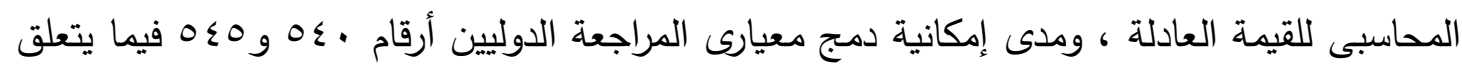

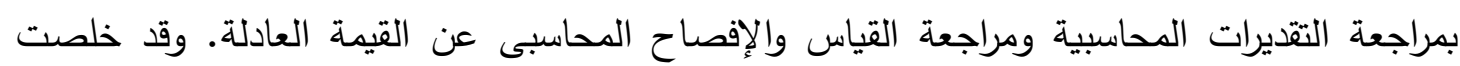

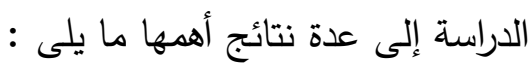
1- إن طبيعة وموثوقية المعلومات المتاحة للإدارة لاعم عملية التقييم المحاسبى للقيمة العادلة تختلف على نطاق واسع ، ويعد هذا من أهم التحديات التى تواجه المحاسبين والمراجعين لتأثير ذلك على درجة

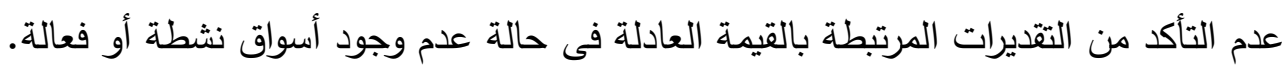

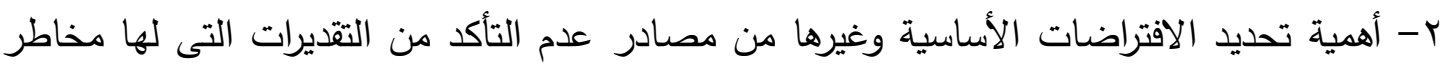

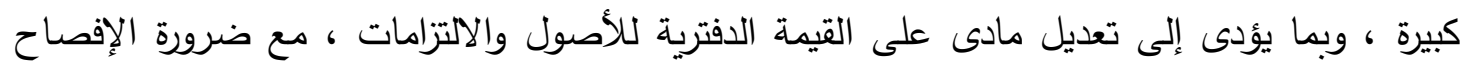

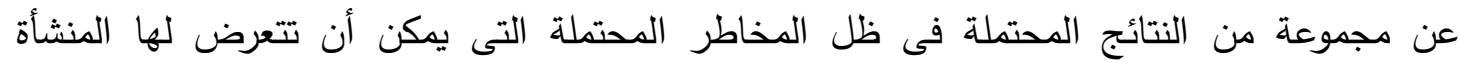
وسياسات وإجراءات إدارة المخاطر والأساليب المستخدمة لقياس المخاطر وموقف مراقب الحسابات من تلك المخاطر .

: PCAOB (2009) (براسة

استهدفت الدراسة الوقوف على مشاكل مراجعة قياسات القيمة العادلة فى حالة عدم وجود سوق نشطة للأصل أو للأصول المتشابهة أو عدم القدرة على الحصول على الأسعار المشتقة للأصول ذاتها

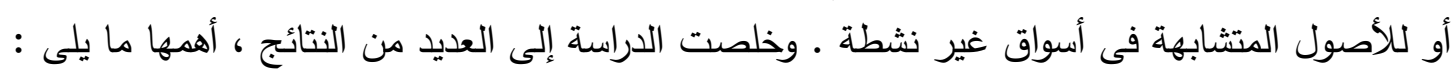
1 - تتوع إجراءات المراجعة بدرجة كبيرة فى الطبيعة والتوقيت والمدى بسبب تباين قياسات القيمة العادلة ما بين البسيط والنماذج المعقدة. ץ- إن الاختبارات الأساسية التى يقوم بعملها مراقبو الحسابات بخصوص عملية قياس القيمة العادلة ، من الممكن أن تتضمن؛ اختبار الافتراضات الهامة للإدارة واختبار نموذج التقييم والبيانات الأساسية ، 
تطوير تقديرات مستقلة للقيمة العادلة بغرض تعزيز وتأييد قياس القيمة العادلة بواسطة المنشأة ، ومراجعة الأحداث والصفقات اللاحقة.

\section{: Pannese and Delfavero (2010)}

استهدفت الدراسة الوقوف على التحديات التى تواجه مراقبى الحسابات لمراجعة القياس المحاسبى

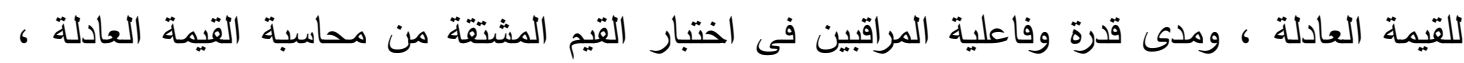

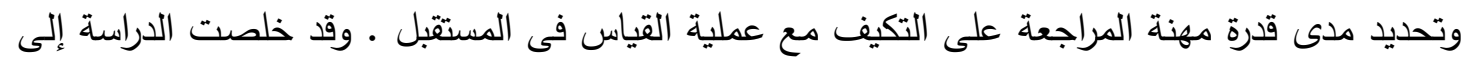

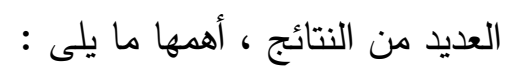
1- على الرغم من أن معايير محاسبة القيمة العادلة قد تم إصدارها من أجل تحسين منفعة المعلومات فى القوائم المالية ، إلا أن هناك بدون شك إمكانية لتحمل مراقبى الحسابات المسئولية للتصدى لأعمال المراجعة فى هذا الثأن. r- إن مجلس معايير المحاسبة المالية (FASB) ومجلس مراقبة شركات المحاسبة العامة (PCAOB) ومجلس معايير المحاسبة الدولية (IASB) لم يتوقعوا تماما النتائج المترتبة من الاستخدام الموسع لمحاسبة القيمة العادلة على مهنة المراجعة. r- يجب توفير إشارات تحذيرية (A warning sign) بأن الوقت ما زال مبكرا أكثر مما ينبغى لتفعيل

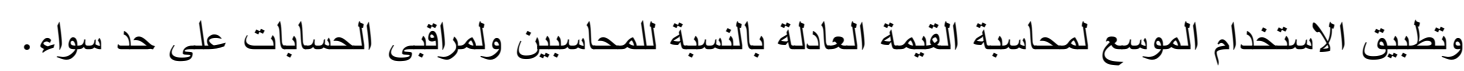

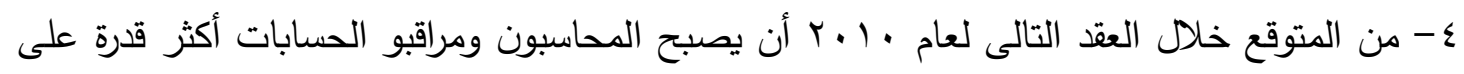

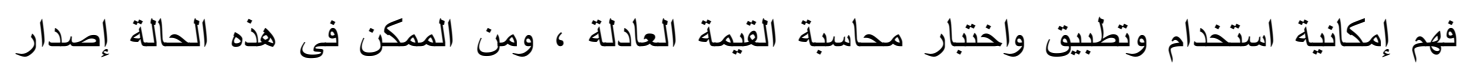
معايير دولية للمراجعة أكثر كفاءة فى هذا الثأن.

: Kumarasiri (2011) التحداس

استهدفت الدراسة الوقوف على التحديات التى تواجه مراقبى الحسابات وخاصة فى الدول النامية ،

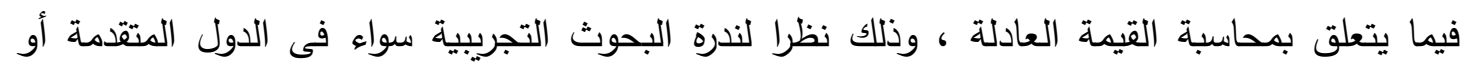
النامية. وتتاولت الدراسة وجهات نظر عينة من مراقبى الحسابات - 107 مراقب حسابات بمكاتب لنباء

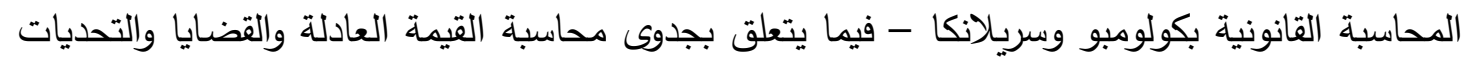

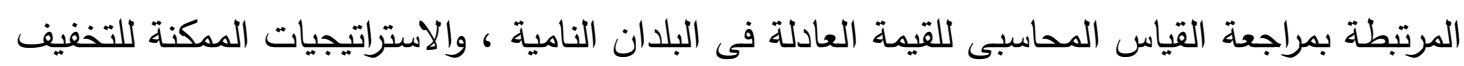

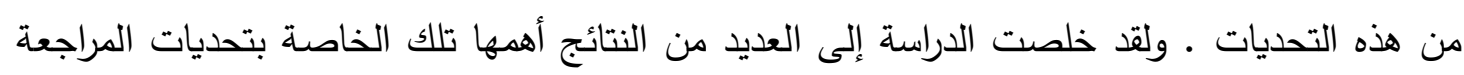

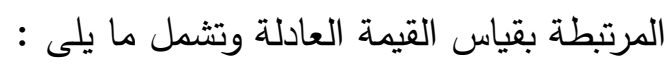
ا- إن التحقق من قياسات القيمة العادلة ومراجعة التقارير المالية المعدة وفقا لها أكثر تعقيدا من

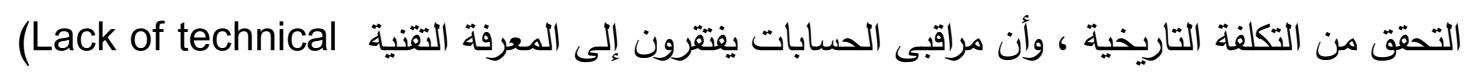
knowledge) 
ץ- إن التقنيات المستخدمة للتحقق من قياسات القيمة العادلة تختلف وفقا للصناعات المتعددة ، وان معظم الأصول والالتزامات ذات الصلة - بعملية القياس - لا يتم تداولها فى أسواق نشطة.

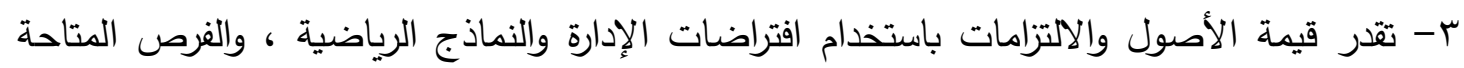

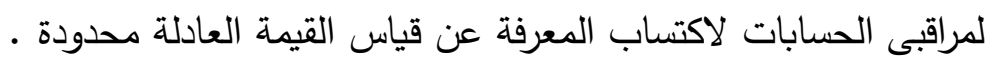
ع - إن قياسات القيمة العادلة كثيرا ما تتضمن تقديرات الأحداث والظروف المستقبلية ( قيمة وتوقيت التدفقات النقدية ومعدلات الخصم ).

: Backof, et al. (2012) دراسة استهدفت الدراسة تحديد ما إذا كانت طريقة عرض الأدلة المقدمة لمراقبى الحسابات - بواسطة

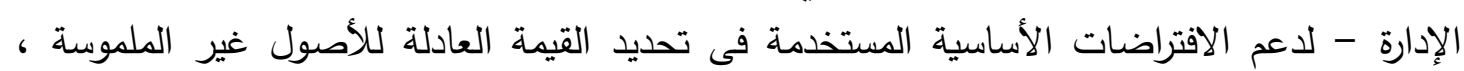

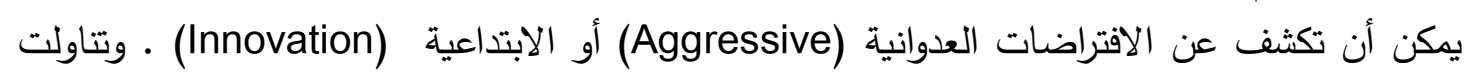

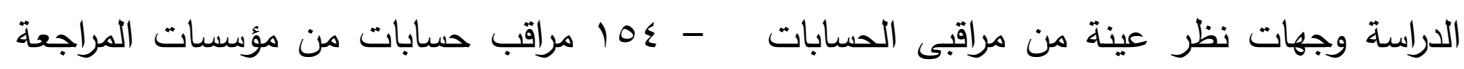

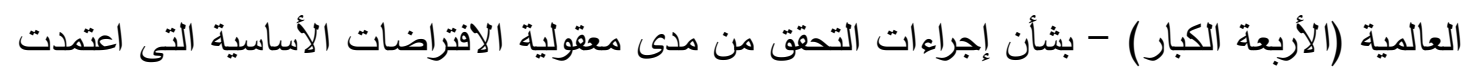

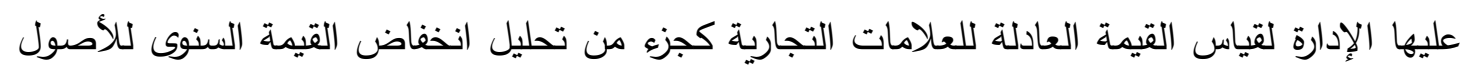

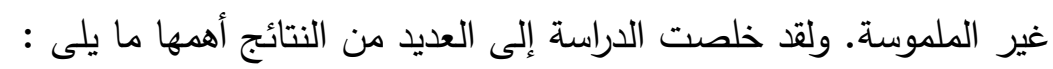

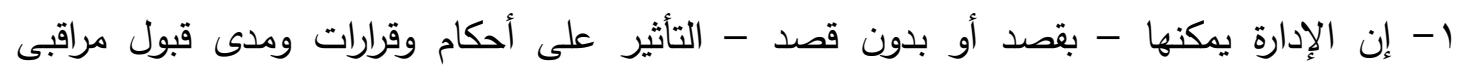

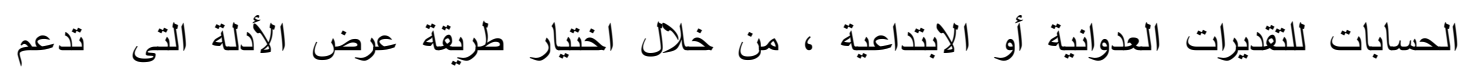

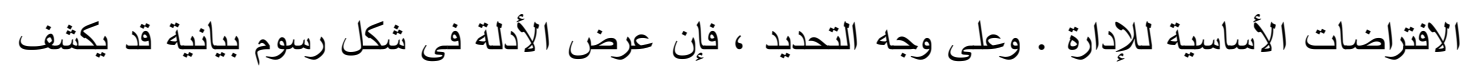

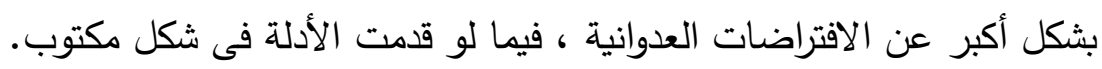

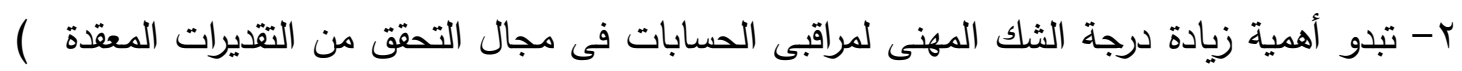

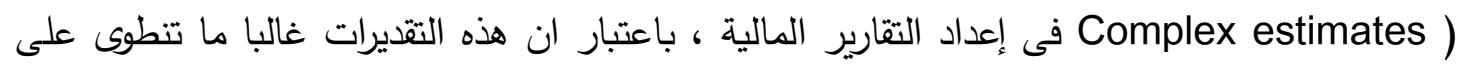
النظر فى تقنيات معقدة التقييم (Complicated valuation techniques) والافتراضات المترابطة باعتي والأحداث والظروف المستقبلية.

: Maksymov, et al. (2012) دراسة استهدفت الدراسة تحديد آثار كل من : إطار الإجراءات (Procedure frame) وإجراءات التحقق

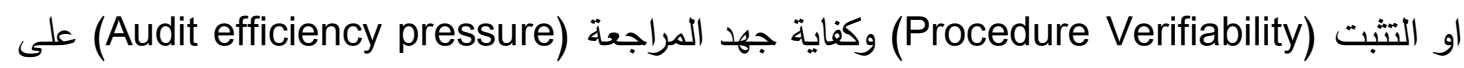
تخطيط مراجعات القيمة العادلة ـ وتتاولت الدراسة وجهات نظر عينة من مراقبى الحسابات - 9 ؛ من من

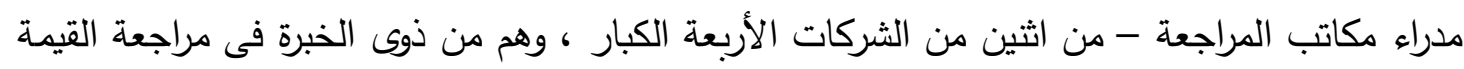

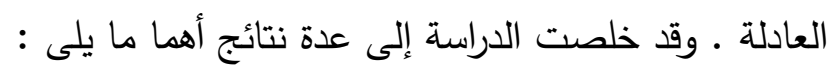

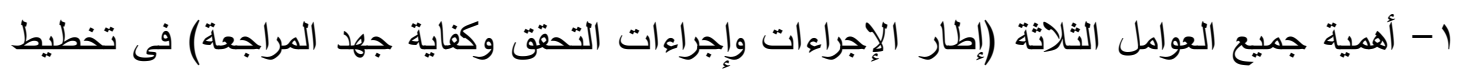

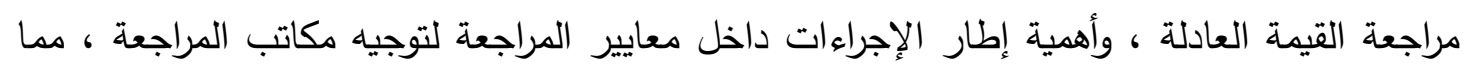
يؤثر فى نهاية المطاف على كفاءة وفاعلية المراجعة فى الكثف عن الأخطاء المادية للقيمة العادلة . 
ץ- إن إطار الإجراءات ( معايير المراجعة المعنية بالقيمة العادلة ) وكفاية جهد المراجعة يؤثران بشكل معنوى هام على أحكام المراجعين فى عملية التخطيط ، كما يوجد تفاعل معنوى بين الإطار وإجراءات - التحقق من مان ץ- إن إطار الإجراءات وجهد المراجعة لا يؤثران على تقييم مراقب الحسابات لخطر المراجعة المحقق وأن المراقبين لا يدركون كيفية تأثير الإطار والجهد على أحكامهر ، مما يبرز أهمية قيام المراقبين بتخصيص جهد المراجعة لمختلف الإجراءات الرامية إلى تقييم معقولية تقديرات الإدارة للقيمة العادلة ـ لإنيل

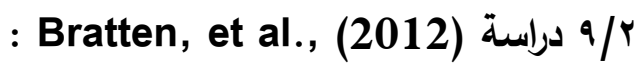

استهدفت الدراسة تحديد المتغيرات أو العوامل التى تئثر على جودة أحكام المراجعة فيما يتعلق

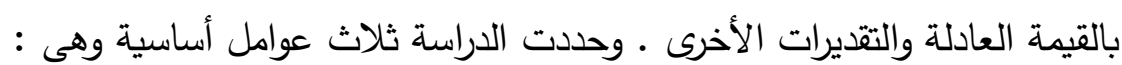

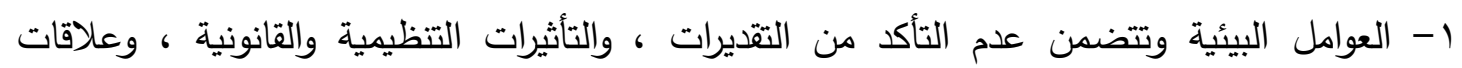

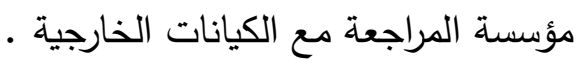

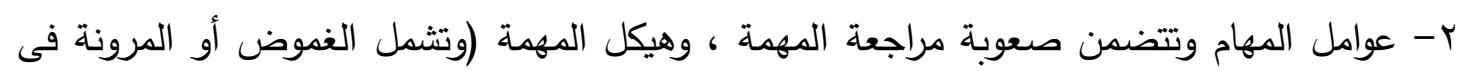

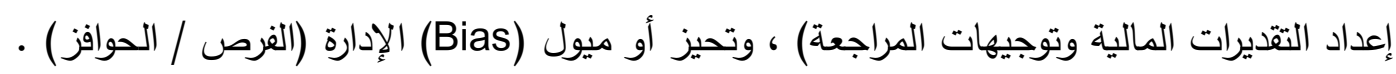

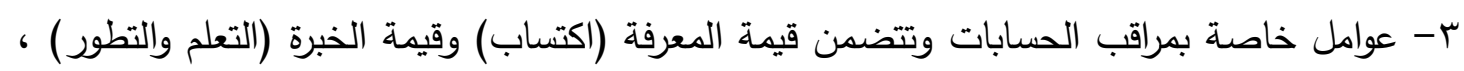

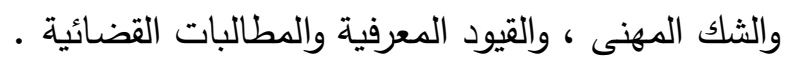
وقد خلصت الدراسة النظرية لعدة نتائج أهمها ما يلى : والئ 1- إن غالبية أوجه القصور فى مراجعة القيمة العادلة والتقديرات الأخرى ، إنما يعزى إلى التى التأثيرات التفاعلية بين العوامل الأساسية الثلاثة ، فقد يكون سبب عدم وجود الثك المهنى من خلال التفاعل بين

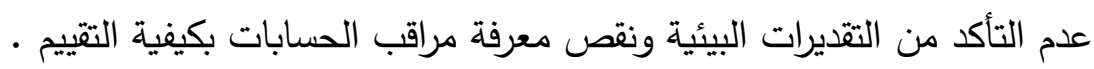

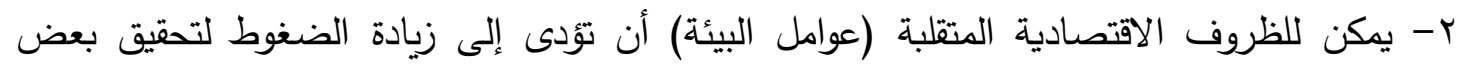

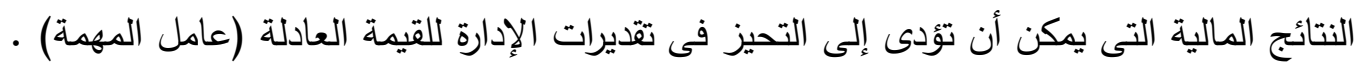

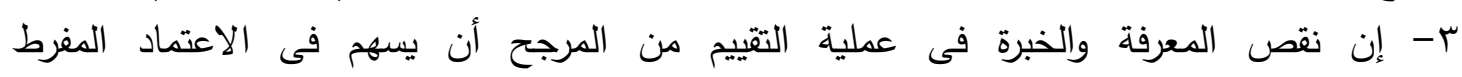
على تقديرات الإدارة ، مما يتطلب ضرورة تعزيز تتمية مهارات التفكير الناقد لمراجعة التهنة (Overreliance) القيمة العادلة . وبناءً على ما تقدم ، يمكن للباحث عرض أهم النتائج المستخلصة من تحليل الدراسات السابقة فيما يلي ا - أجمعت الدراسات السابقة على إمكانية الاعتماد على نموذج القيمة الحالية المتوقعة كمنهج لقياس

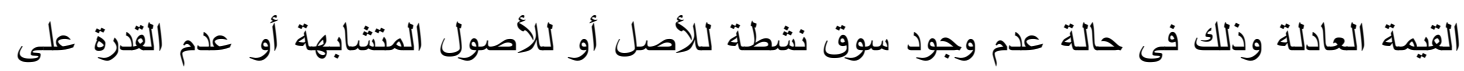
الحصول على الأسعار المشتقة للأصول ذاتها أو للأصول المتثابهة فى أسواق غير نشئ نشطة. 
ץ- اهتمت معظم الدراسات السابقة بعرض وتحليل أهم ما ورد بمعايير المراجعة الأمريكية والدولية بشأن مجالات اهتمام مراقب الحسابات بمراجعة القياس والإفصاح المحاسبى عن القيمة العادلة للأصول بصفة عامة . ץ- أبرزت معظم الدراسات أهمية مراجعة واختبار الافتراضات الهامة للإدارة ونموذج التثييم والبيانات

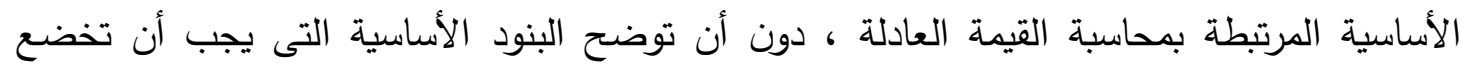

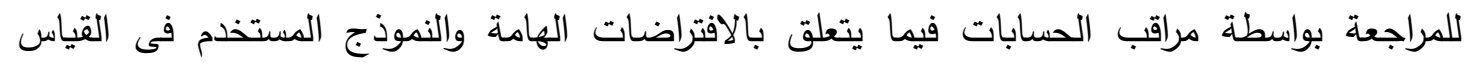
المحاسبى للقيمة العادلة .

ومما تقدم يرى الباحث إمكانية استخدام نموذج القيمة الحالية للتدفقات النقدية المستقبلية كمدخل لقياس القيمة العادلة للأصول التى لا تتوافر لها سوق نشطة ، ومن ثم تبدو أهمية عرض الجوانب التبانبة

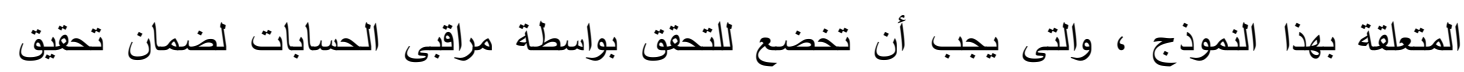
المصداقية والموثوقية فى المعلومات المحاسبية المعدة وفقا لهذا النموذج كمدخل لقياس القيمة العادلة . وهذا ما توضحه الدراسة التحليلية التالية .

ثالثا : القيمة الحالية ومخاطر استخد/مها فى قياس القيمة العادلة

يعتبر نموذج القيمة الحالية للتدفقات النقدية المستقبلية المتوقعة أحد أهم المقاييس التى يمكن

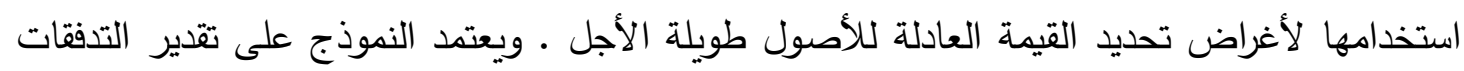

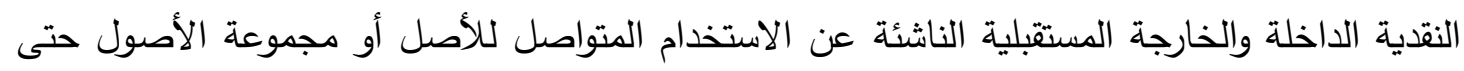

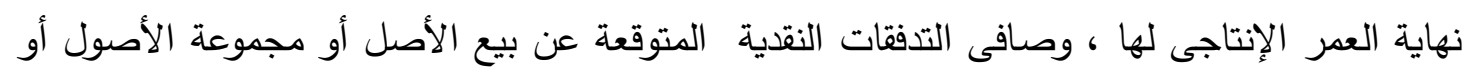
التصرف فيها فى نهاية عمرها الإنتاجى، وتحديد القيمة الحالية لصافى التدفقات النقدية المستقبلية

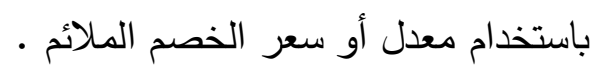
ونظرا لأن نموذج القيمة الحالية كمدخل للتثييم يعتمد على وضع افتم التراضات عن مستوى التدفقات

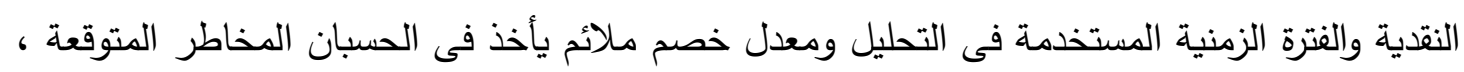

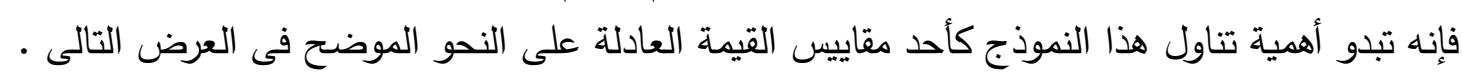

ب/ أهمية قياس القيمة العادلة للأصول :

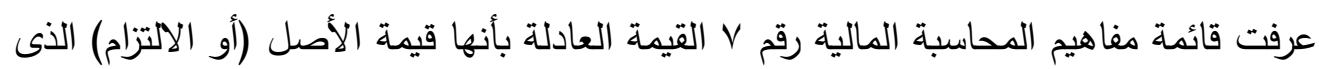

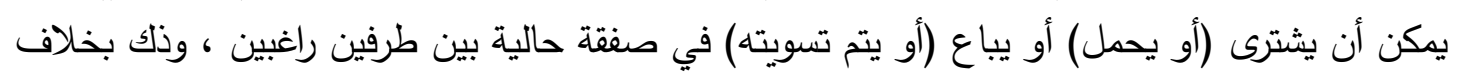

البيع الجبرى أو التصفية (SFAC No.7, 2000). (liability) as the amount at which that asset (or liability) could be bought (or 
incurred) or sold (or settled) in a current transaction between willing parties , that is, other than in a forced or liquidation sale

وتناول معيار المحاسبة المصرى رقم اب تعريف القيمة العادلة بأنها المبلغ الذى يمكن الحصول عليه

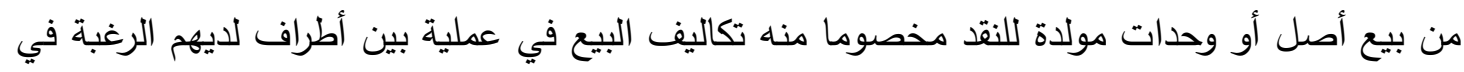
التبادل وعلى بينة من الحقائق و يتعاملان بإرادة حرة ، كما حدد المعيار مفهوم القيمة الاستردادية

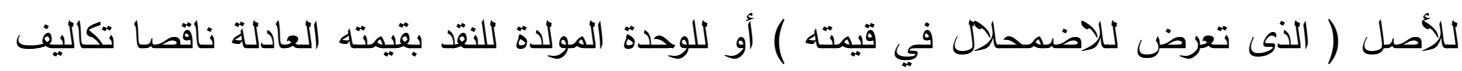

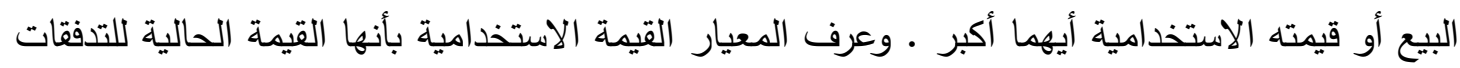

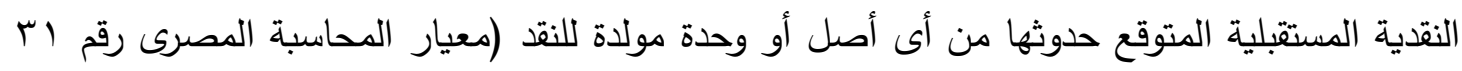
.$(r+1.7$ ،

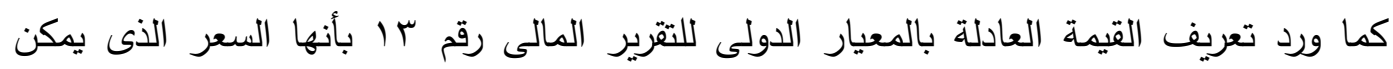

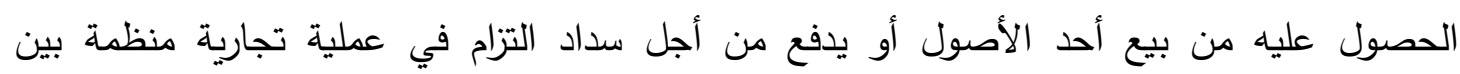

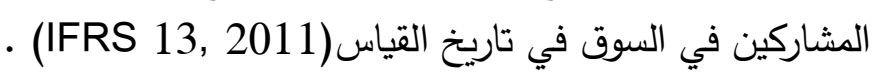
The price that would be received to sell as asset or paid to transfer a liability in an orderly transaction between market participants at the measurement date .

ولقد تتاولت دراسة (2002) . Don, et al المقارنة بين مجموعة من الدول (استراليا ، إنجلترا ،

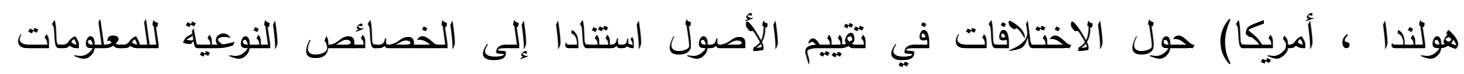

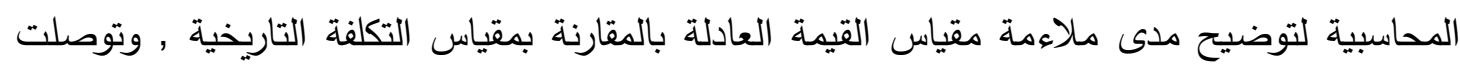

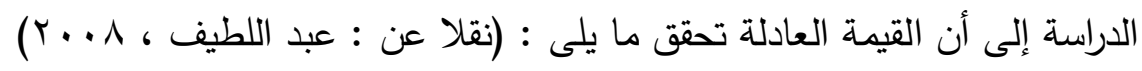

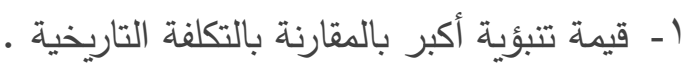
r- توفير المعلومات الملائمة المؤثرة على قرارات المستثمرين والدائنين والدحللين وغيرهم. r- تدعم خاصية الاتساق (consistency) والاستقرار والثبات وعدم تغيير السياسات والإجراءات من

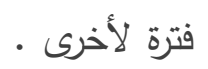

ع - تحسين المحتوى الإعلامى للقوائم المالية ومن ثم زيادة درجة مصداقية وشفافية هذه القوائم .

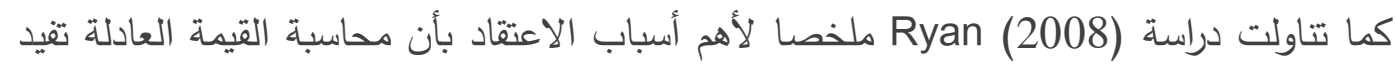

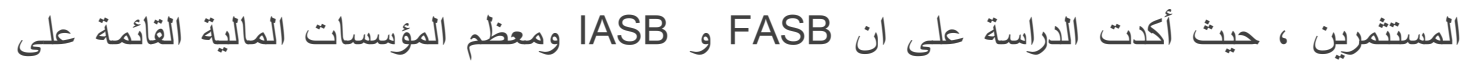

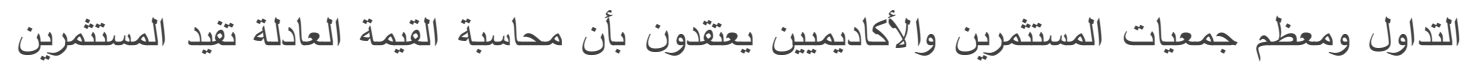

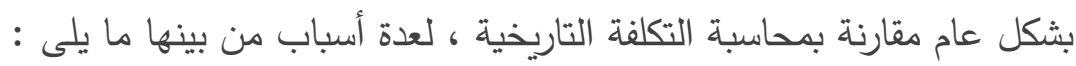

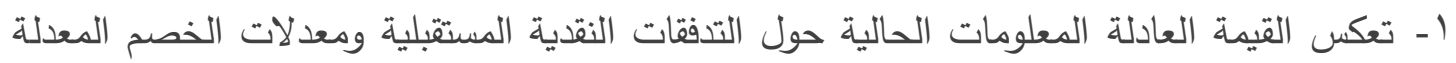

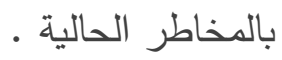


ז- إن محاسبة القيمة العادلة لا تسمح للشركات بإدارة دخلها من خلال تداول المكاسب ، بسبب أن

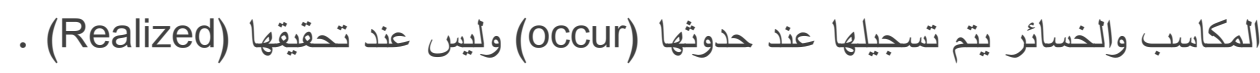
r- عندما تكون توزيعات (Distributions) التدفقات النقدية المستقبلية مختلفة أو غير متماثلة فإنها تعد أكثر دلالة بالنسبة للمستثرين لكى يعتمدوا على المعدل المتوسط بطريقة

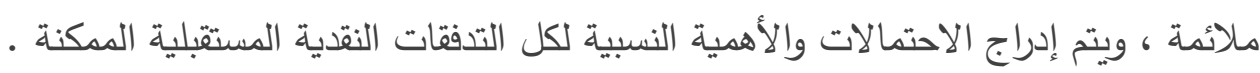
ولقد عرضت الدراسة أيضا أسباب اعتقاد البعض بأن محاسبة القيمة العادلة تضر المستثمرين ، وفند الباحث هذه الأسباب ومن بينها أنه فى حالة غياب سوق نشطة فإن القيمة العادلة يتم تحديدها بناءً

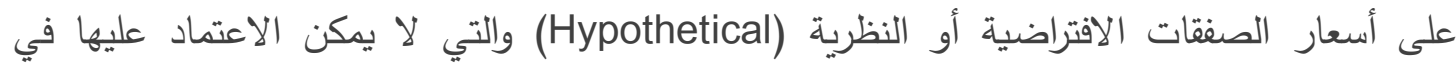
القياس • إلا أن الباحث يرى أن هذا الأمر لا يعتبر فى الواقع نقدا لمحاسبة القيمة العادلة في حد ذاتها

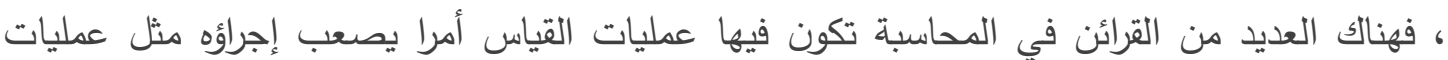

المقايضات غير النقدية والأصول غير الملموسة. (Ryan, 2008)

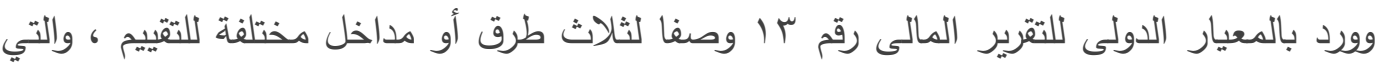

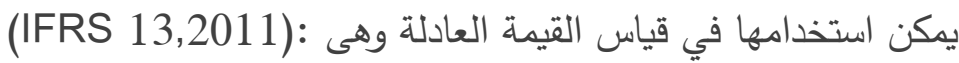
ا - مدخل السوق : ويستخدم الأسعار والمعلومات المناسبة الأخرى في السوق ، وتثمل عمليات مماثلة أو أصول أو التزامات مماثلة الوسعار ولمعات (Identical) ץ- مدخل الاخل : ويتضمن هذا المدخل تحويل المبالغ المستقبلية (مثل التدفقات النقدية أو الدخل أو

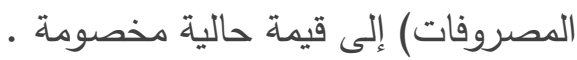
r- مدخل التكلفة : ويعكس هذا المدخل المبلغ المطلوب في الوقت الحالي لاستبدال الخدمات المحققة من الأصل (وكثيرا ما يشار إليها بالتكلفة الاستبدالية الجارية والتي تختلف عن التكلفة المستهدفة)

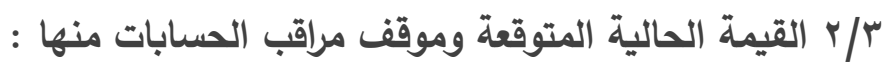
أكدت دراسة (2008).Truong, et al على أن نموذج القيمة الحالية يعد من أكثر وأهم الأساليب المستخدمة في تقييم أصول منشآت الأعمال ـ وأكد فريق العمل لمجلس مراقبة شركات المحاسبة العامة (PCAOB, 2004) وجود سوق نشطة أو أصول مماثلة ، والعناصر التالية تؤثر في تحديد القيمة الحالية : ا - تقدير التدفقات النقدية المستقبلية . r- التغيرات المحتملة في قيمة أو توقيت التدفقات النقدية . r- سعر أو قيمة تحمل عدم التأكد الكافية أو المتأصلة في الأصل. ع - القيمة الزمنية للنقود ، ممثلة في سعر الفائدة الخالي من المخاطر • 
○ـ عوامل أخرى لحالات خاصة (other case - specific factors) مثل عدم السيولة وعدم اكتمال أو نقصان السوق (Market imperfections) -

ولقد حددت قائمة مفاهيم المحاسبة المالية رقم V طريقتان للقيمة الحالية لقياس القيمة العادلة

للأصل هما : (SFAC No.7,2000)

ا - طريقة القيمة الحالية المتوقعة (Expected - Present - Value) : ففي سيناريوهات التدفق النقدى المضاعف أو المركب (Multiple) تعكس هذه الطريقة نطاق أو مدى النتائج المدكنة ومعدل الخطر المطلق (Risk - free rate) المستخدم في تقدير القيمة العادلة .

r- طريقة القيمة الحالية التقليدية (Traditional - Present - Value) : وتتضمن وضع تقدير وحيد للتدفقات النقدية ومعدل فائدة وحيد (معدل مطابق للخطر) لاستخدامه في تقدير القيمة العادلة

ولقد أكد معيار المحاسبة المصرى رقم اب أن المنهج التقليدى قد لا يكون مناسبا فى معالجة بعض

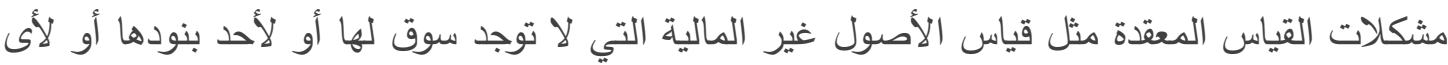

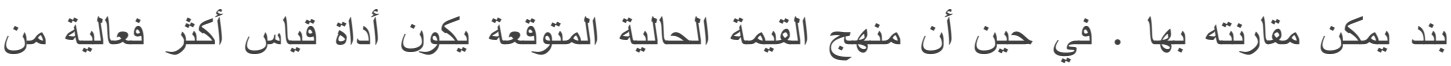
المنهج التقليدى ، ويستخدم جميع التوقعات بشأن التدفقات النقدية الممكنة بدلا من تدفق نقدين التهى واحد يكون أكثر احتمالا • ومن ثم يختلف منهج القيمة المتوقعة عن المنهج التقليدى بالتركيز على التحليل

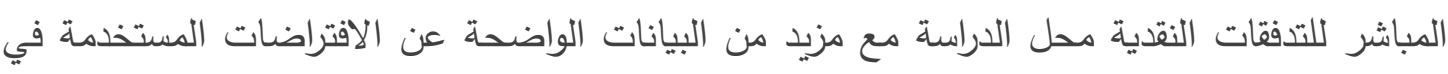

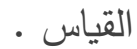
هذا ويخضع تطبيق نموذج القيمة الحالية لقيد تتاسب التكلفة مع العائد ، حيث تحتاج إدارة المنشأة إلى مواءمة تكلفة الحصول على معلومات إضافية مقابل درجة الموثوقية الإضافية التى تضفيها هذه

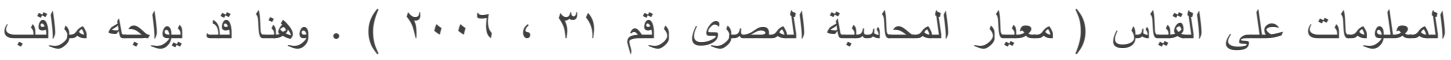
الحسابات بمخاطر تنشأ عن إمكانية تحيز الإدارة فى عملية القياس عند تحديدها لمقدار وتوقيت التدفقات النقدية المتوقعة ومعدلات الخصم ، حيث يجب أن تكون هذه التدفقات ومعدلات الخصم خالية من أية عوامل ليس لها صلة بالأصل محل القياس مثل التدفقات النقدية المرتبطة بإعادة هيكلة مستقبلية

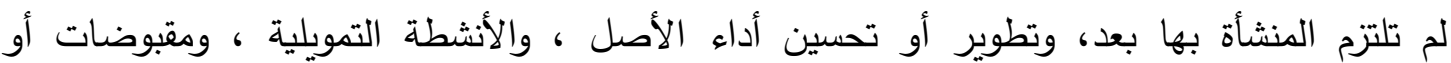
مدفوعات ضريبة الاخل حيث يحدد معدل الخصم قبل الضريبة .

وبالرغم من أهمية منهج القيمة الحالية المتوقعة ، إلا أن أغلب القياسات المبنية على تقديرات بما فى

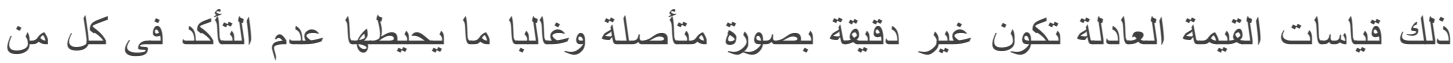

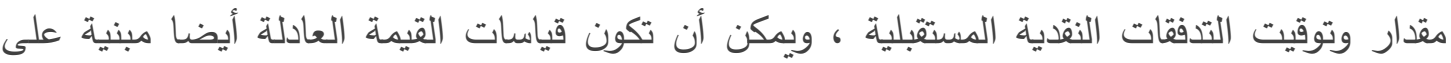
أساس افتراضات عن الظروف المستقبلية والمعاملات أو الأحداث التى تكون نتأنسائجها غير مؤكدة ، وبذلك تكون عرضة إلى التغيير بمرور الوقت ـ وتبنى دراسات مراقب الحسابات لمثل هذه الافتراضات

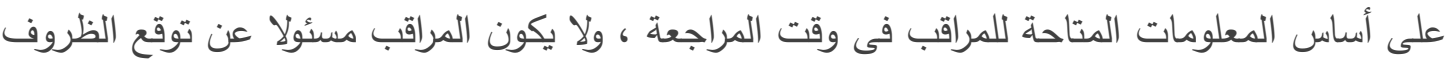

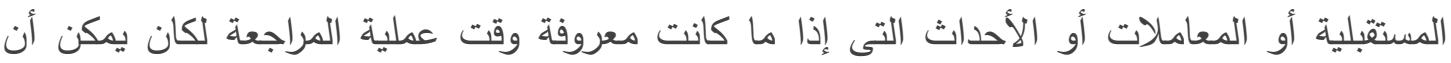


يكون لها تأثير جوهرى على إجراءات الإدارة أو افتراضاتها التى تثكل أساس قياسات القيمة العادلة (

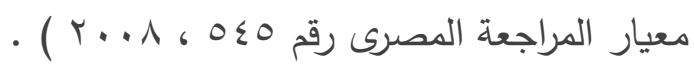

وعلى الرغم من احتمال وجود أدلة تؤيد الافتراضات التى بنيت عليها المعلومات المالية المستقبلية ، إلا

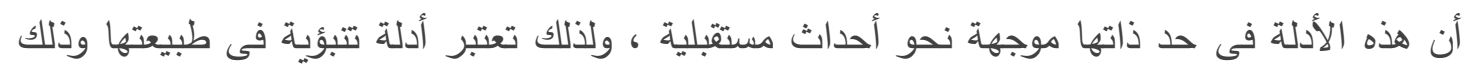

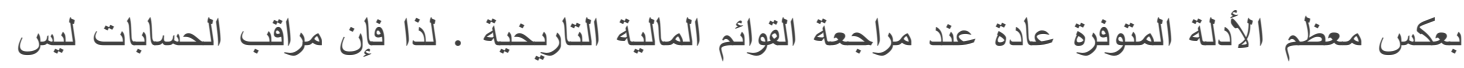

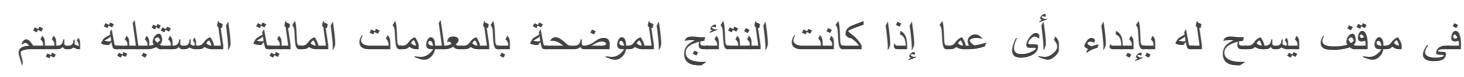

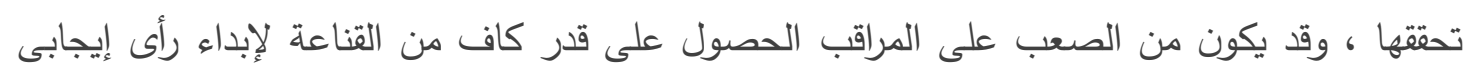
بأن تلك الافتراضات خالية من التحريف الهام والمؤثر • وعليه فعند إبداء الرأى على مدى معقولية

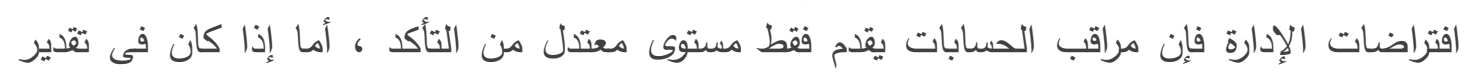

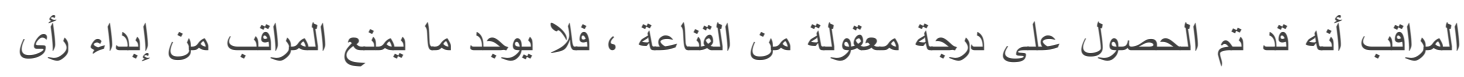

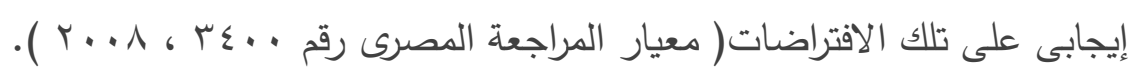

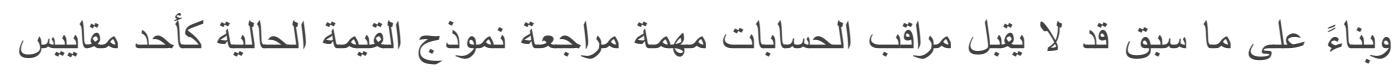
القيمة العادلة أو قد ينسحب من المهمة أو قد يبدى رأيا عكسيا أو رأيا متحفظا فى تقريره عن نتائج

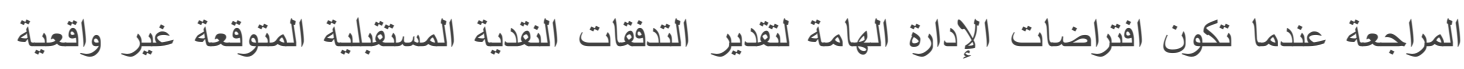
بدرجة واضحة أو غير ملائمة للغرض الذى أعدت من أجله أو فى حالة قصور المعلومات المستقبلية

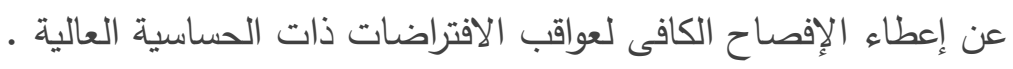

ولقد تتاول معيار المحاسبة المصرى رقم اب أسس تقدير التدفقات النقدية المستقبلية والعناصر

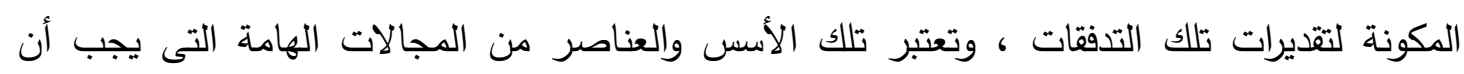

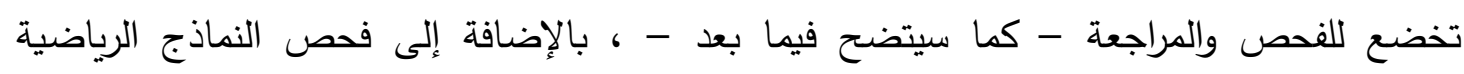

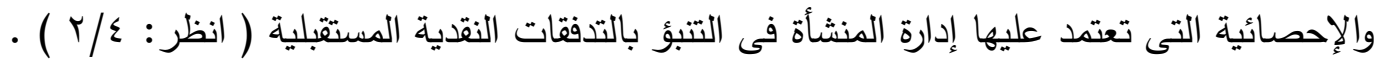

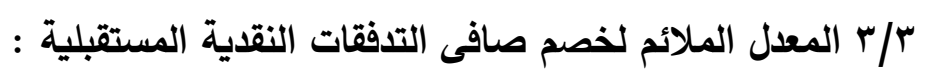

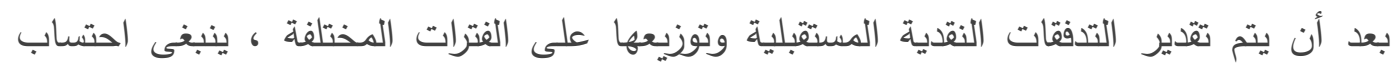
القيمة الحالية لهذه التدفقات النقدية عن طريق خصمها ، ومعدل أو سعر الخصم هو السعر قبل

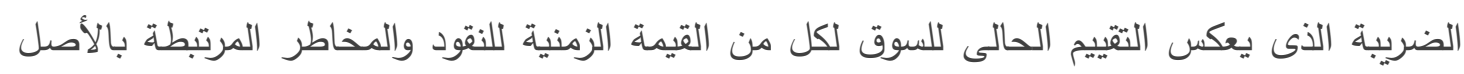

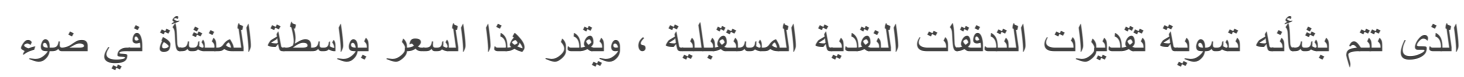

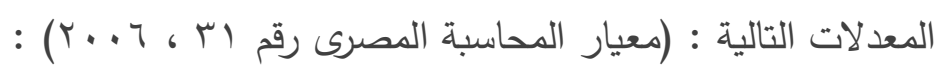

ا - متوسط التكلفة المرجحة لرأس المال (Weighted Average Cost of Capital-WACC) للمنشأة والمحددة باستخدام بعض الأساليب مثل نموذج تسعير الأصل الرأسمالى . Asset Pricing Model - CAPM) r- سعر الاقتراض المتزايد للمنشأة . 


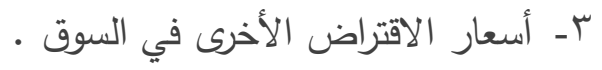

والطريقة المناسبة لاحتساب متوسط التكلفة المرجحة لرأس المال (WACC) موضوع فنى للغاية وتوجد حوله أدبيات أكاديمية كثيرة ، حيث أكدت دراسة (2004) .McLaney, et al على وجود تباين واسع فى تحديد WACC بين الشركات المدرجة فى البورصات بالمملكة المتحدة ، وفى الأغلب الأعم

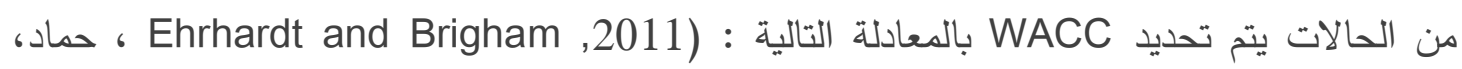

WACC $_{a}=(1-T c) \times R D \times \frac{g}{(1+g)}+R \square \times\left[1-\frac{g}{(1+g)}\right]$

: : متوسط التكلفة المرجحة لرأس المال بعد خصم الضريبة : هامث : Rـ

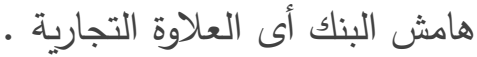

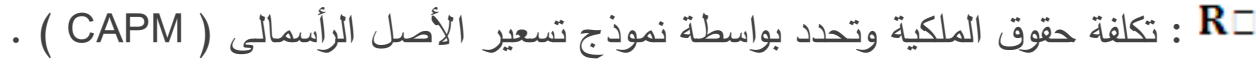

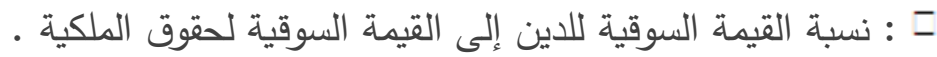

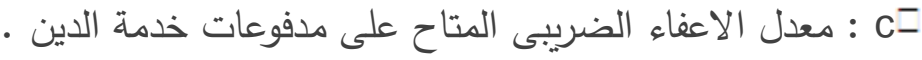

ونظرا لأن معيار المحاسبة الدولى رقم جس والمصرى رقم اب قد حددا معدل أو سعر الخصم بالسعر قبل الضريبة الذى يعكس التقييم الحالى للسوق للقيمة الزمنية للنقود والمخاطر المرتبطة بالأصل

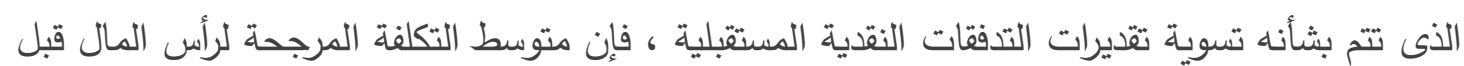
خصم الضريبة تحدد بالمعادلة التالية:

$\mathrm{WACC}_{\mathrm{b}}=\mathrm{WACC}_{\mathrm{a}} \times[1 \div(1-\mathrm{T})]$

WAC $\square_{b}$ (7) : معدل الضريبة المستحقة. وتعد تكلفة حقوق الملكية أصعب مكون فى WACC من حيث إمكانية التحديد، ويستخدم نموذج

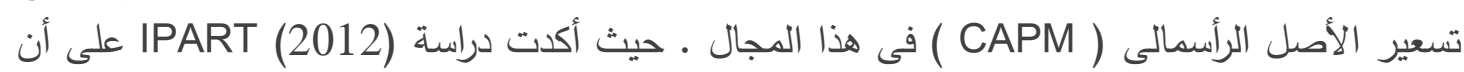

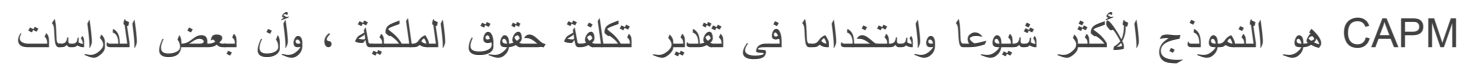

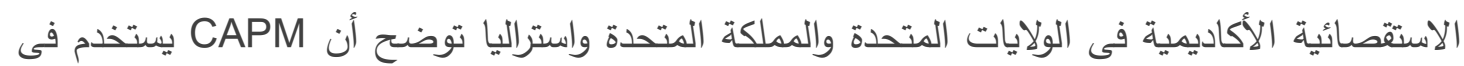

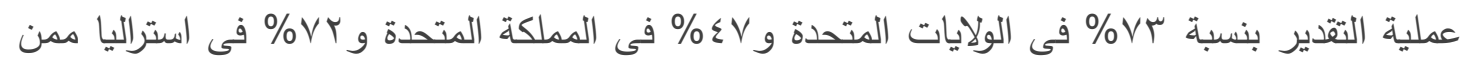
شملهم الاستطلاع من التنفيذيين بالشركات فى هذه الدول. والنظرية التي يقوم عليها CAPM هى أن تكلفة حقوق الملكية مساوية لمعدل العائد الخالى من فن النين المخاطر (عائد أذون الخزانة) ويضاف إليه معامل بيتا لعلاوة المخاطر السوقية والتي يطلبها 


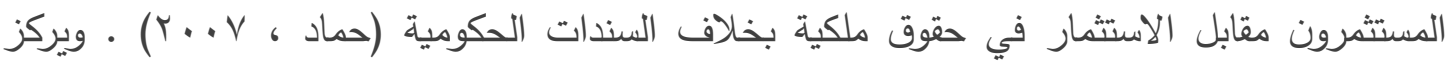

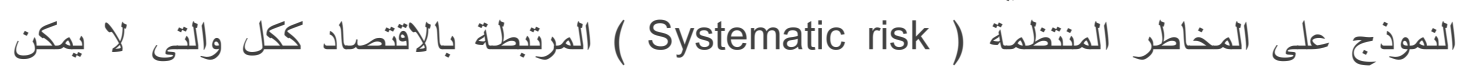

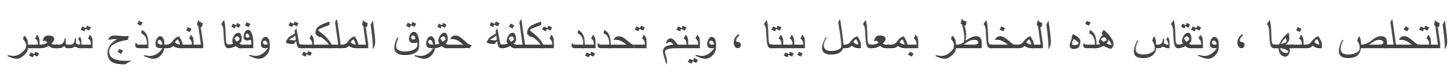
الأصل الرأسمالى (CAPM) بالمعادلة التالية:(Fama and French,2004,IPART,2012) $\mathbf{E}\left(\mathbf{R}_{\mathfrak{j}}\right)=\mathbf{R}_{\mathrm{F}}+\left(\mathbf{R}_{\mathrm{M}}-\mathbf{R}_{\mathrm{F}}\right) \boldsymbol{\beta}_{\mathbf{l}}$

$$
\begin{aligned}
& \text { حيث إن } \\
& \text { E( } \\
& \text { : معدل العائد الخالى من المخاطر = عائد أذون الخزانة. } \\
& \text { : متوسط عائد السوق المتوقع للأصل. } \\
& \text { 䧑 }
\end{aligned}
$$

ويرى الباحث أن تحديد عائد السوق المتوقع للأصل يجب أن يتم فى ظل الاحتمالات القائمة

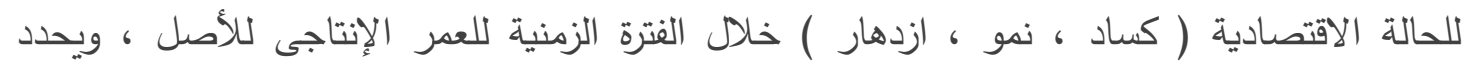
متوسط عائد السوق المتوقع للأصل بادية (كباد ، المدادلة التالية :

$$
\begin{aligned}
& \overline{\mathrm{R}}_{\mathrm{M}}=\left[\left(\mathrm{P}_{\mathrm{S} 1} \widetilde{\mathrm{R}}_{\mathrm{M} 1}+\mathrm{P}_{\mathrm{S} 2} \widetilde{\mathrm{R}}_{\mathrm{M} 2}+\mathrm{P}_{\mathrm{S} 3} \widetilde{\mathrm{R}}_{\mathrm{M} 3}\right)^{1}+\left(\mathrm{P}_{\mathrm{S} 1} \widetilde{\mathrm{R}}_{\mathrm{M} 1}+\mathrm{P}_{\mathrm{S} 2} \widetilde{\mathrm{R}}_{\mathrm{M} 2}+\mathrm{P}_{\mathrm{S} 3} \widetilde{\mathrm{R}}_{\mathrm{M} 3}\right)^{2}+\cdots+\left(\mathrm{P}_{\mathrm{S} 1} \widetilde{\mathrm{R}}_{\mathrm{M} 1}+\mathrm{P}_{\mathrm{S} 2} \widetilde{\mathrm{R}}_{\mathrm{M} 2}\right.\right. \\
& \text { حيث إن : }
\end{aligned}
$$

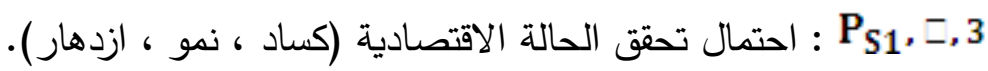

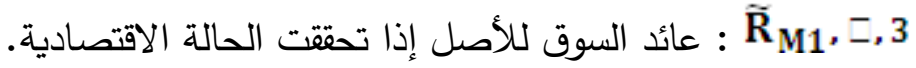

$$
\begin{aligned}
& \text { प }
\end{aligned}
$$

(Fama and French,2004): أما معامل بيتا للأصل فيتم تحديده بالمعادلة التالية : التئة

$\beta_{\mathbf{j}}=\left[\operatorname{Cov}\left(\mathbf{R}_{\mathbf{j}}, \mathbf{R}_{\mathbf{M}}\right)\right] \div \square^{2}(R M)$

$$
\begin{aligned}
& \text { حيث إن : } \\
& \text { : } \operatorname{Cov}\left(\mathbf{R}_{\mathbf{j}}, \square_{M}\right) \\
& \text { 告 } \sigma^{2}(R M)
\end{aligned}
$$

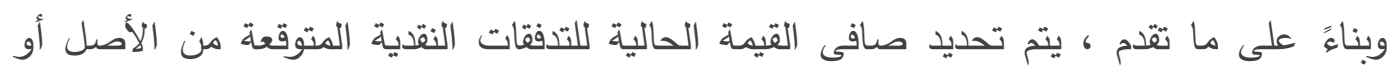

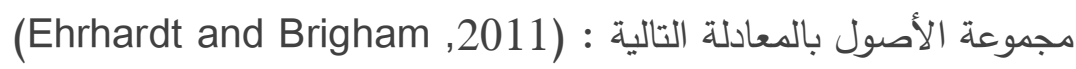

$N P V=\left[\frac{F_{1}}{(1+K)^{1}}+\frac{F_{2}}{(1+K)^{2}}+\cdots+\frac{F_{n}}{(1+K)^{n}}\right]$ 
NIV

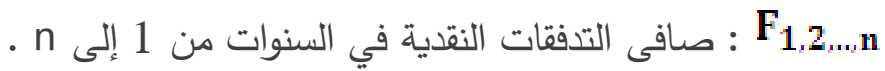

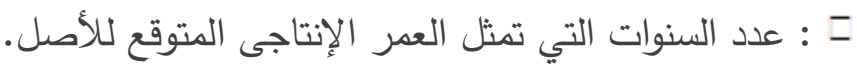
: : معدل الخصم = متوسط التكلفة المرجحة لرأس المال قبل الضريبة.

ومن نافلة القول أن صافى التدفقات النقدية السنوية ( F

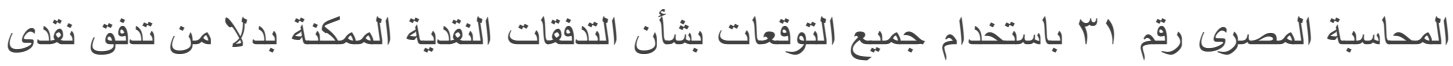

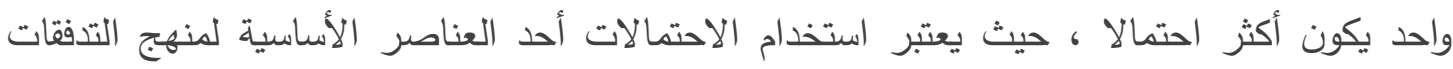

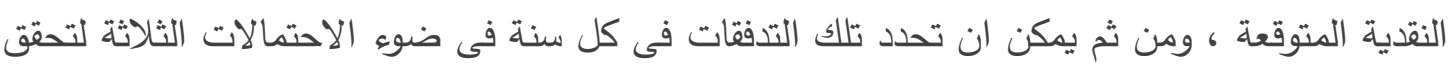

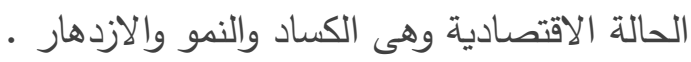
وتجدر الإثارة إلى أن معدل العائد الخالى من المخاطر - يتحدد في الأغلب الأعم من الحالات -

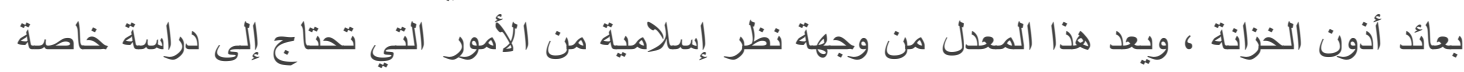
من جانب المهتمين بهذا الموضوع ( رجال الشريعة ورجال الاقتصاد والمال ) ، وكمحاولة مبدئية يقترح

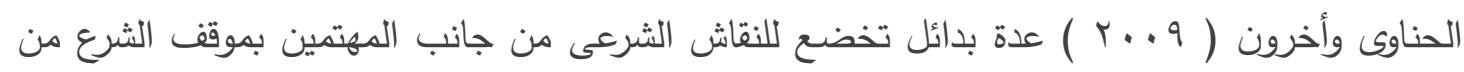

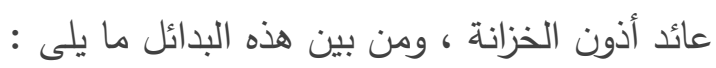

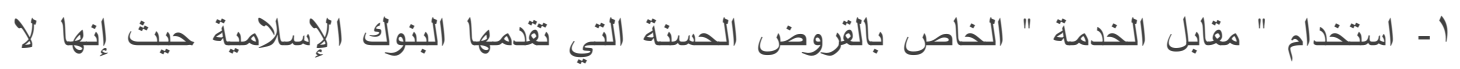

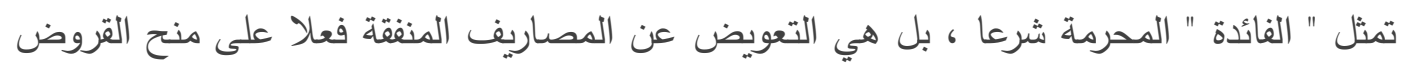

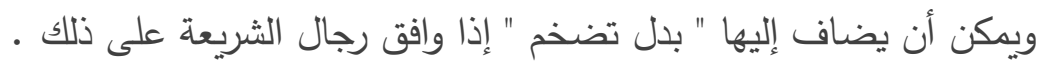

r- استخدام " نسبة الزكاة على الأموال " وهى في حدود ر, r \% ، ويؤخذ على هذه النسبة أنها

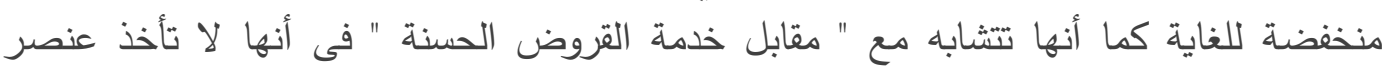

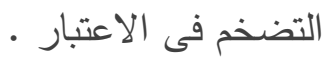

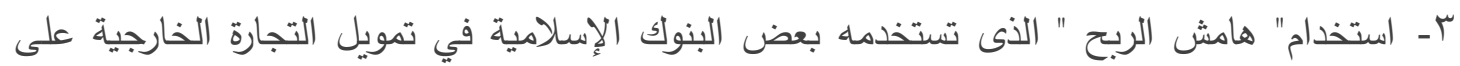
أساس عمليات المرابحة الإسلامية وذلك في حالة حصول هذه البنوك على ضمانى ضدانات مصرفية

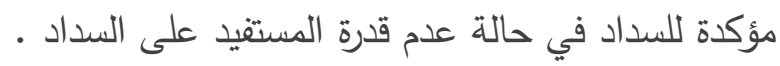

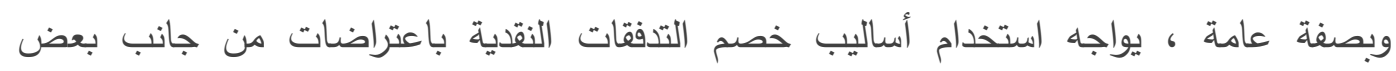
المهتمين بشئون الاقتصاد الإسلامى والمعاملات المالية الإسلامية لارتباط مفهوم الخصم عادة بالفائدة

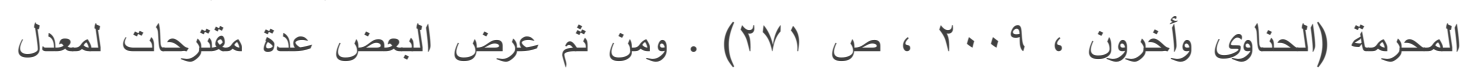

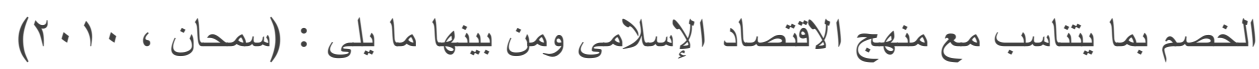
1 - استخدام المتوسط المرجح لمعدل عوائد الاستثمارات المثيلة ( التي لا تتعارض مع الإن أحكام الثريعة )

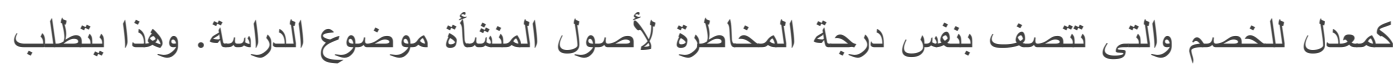


حصر البيانات والمعلومات التفصيلية على شكل سلاسل زمنية عن الاستثمارات المثيلة ، وحساب الأوزان الترجيحية لتكرار حدوث العائد.

r- استخدام نسبة العائد التشغيلى القطاعى كمعدل للخصم بحيث يتم تقسيم الأنشطة الاستثارية إلى إلى

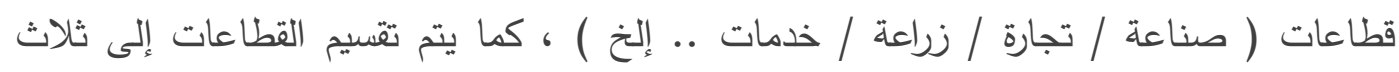

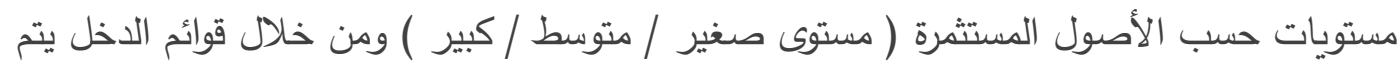

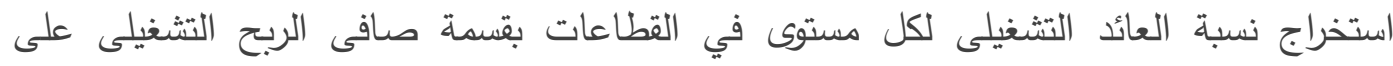

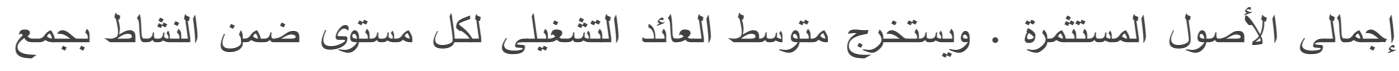
النسب المستخرجة وقستها على عدد الثركات ( الناجحة فقط ) فى كل مستوى . ل

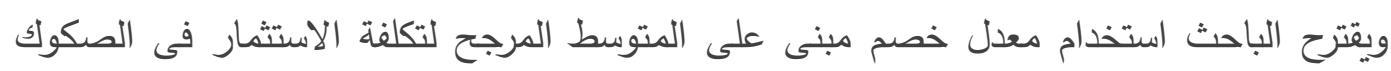

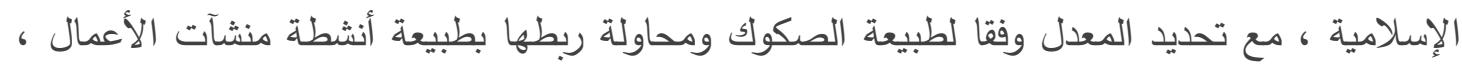

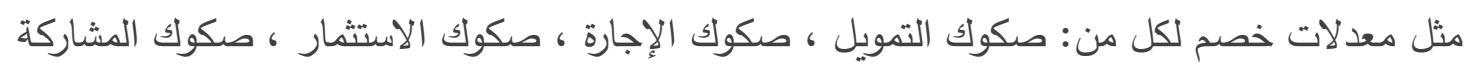

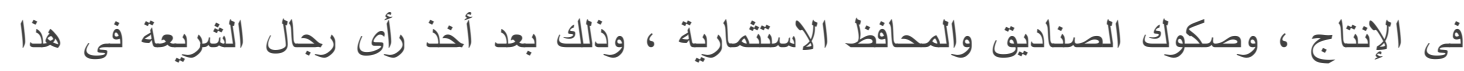
المقترح الإنتاج

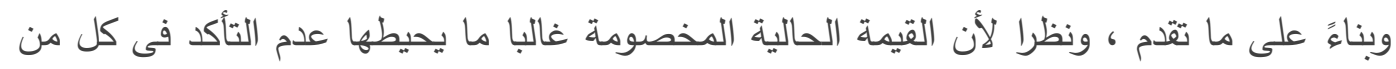

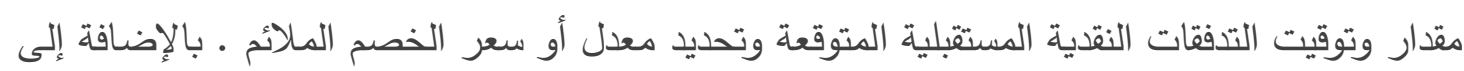
ما ورد بمعيارى المراجعة الدولى والمصرى رقم

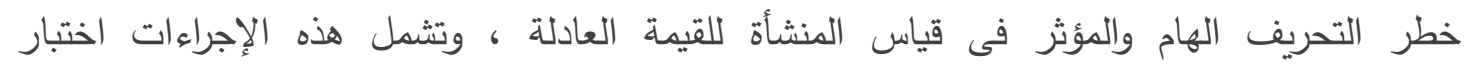

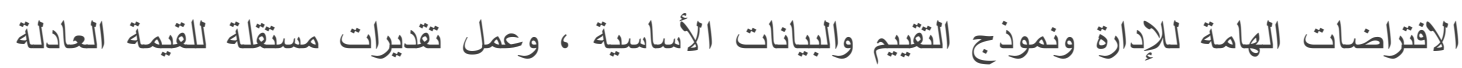

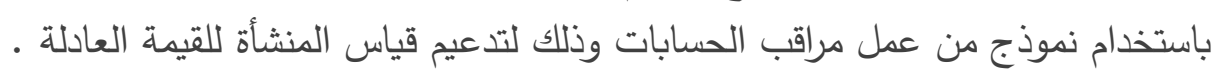

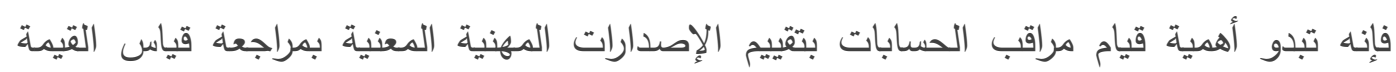

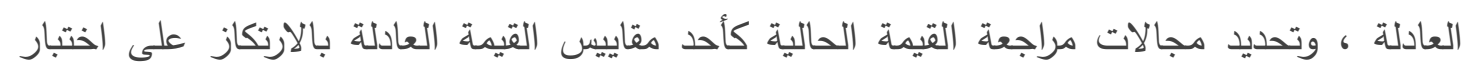

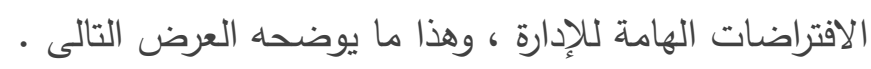

\section{رابعا : الإطار الفكرى لمراجعة القيمة الحالية كمدخل لقياس القيمة العادلة}

ذكر (2009) أن استخدام عمل الخبراء فى عملية قياس القيمة العادلة يعتبر

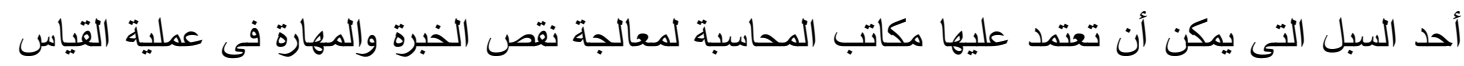

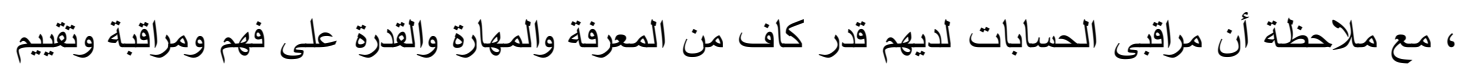

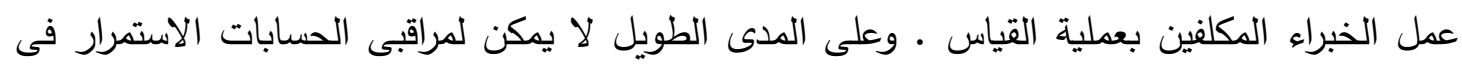

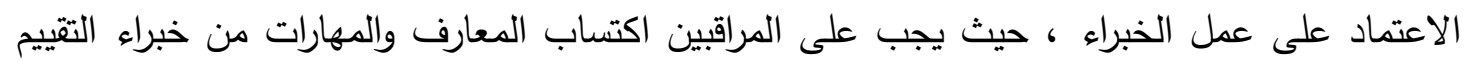

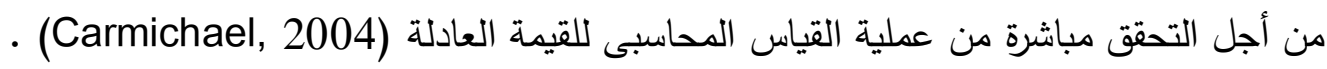




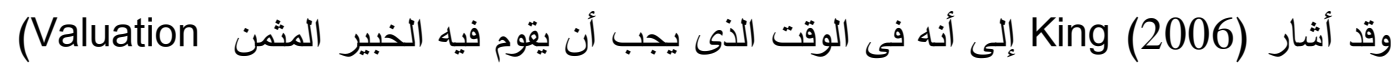

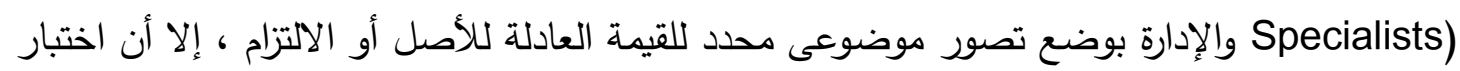

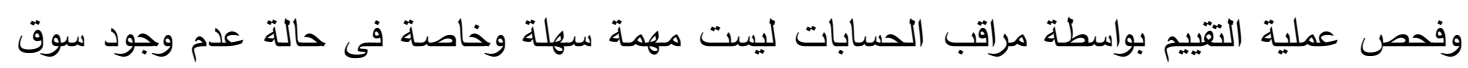

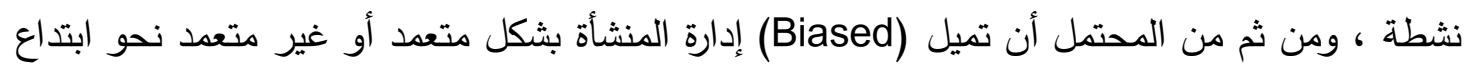

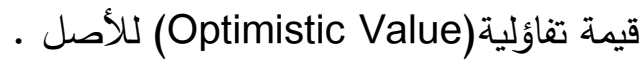
والعرض الآتى بعد يوضح دور المنظمات المهنية فى توجيه وإرشاد مراقبى الحسابات نحو مراجعة

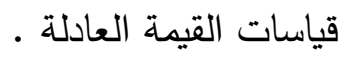

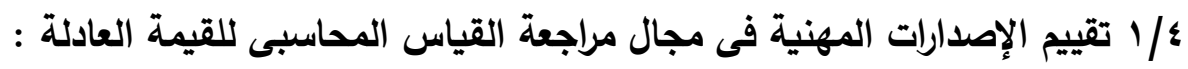

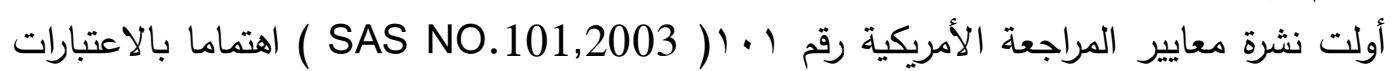

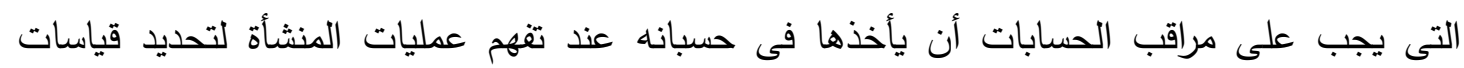

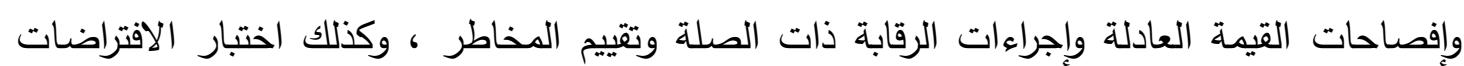

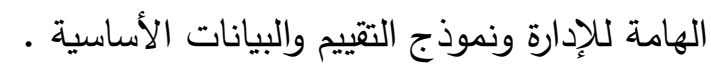

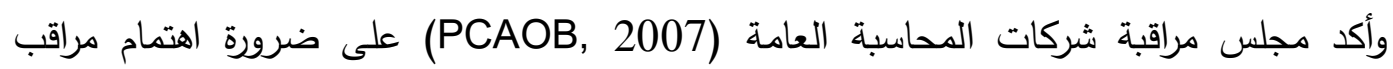

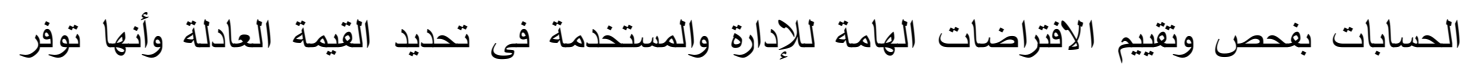

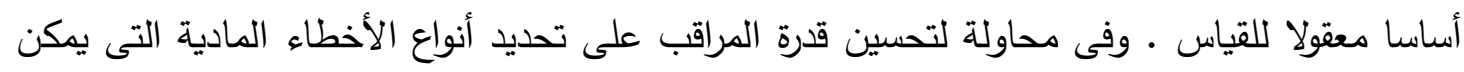

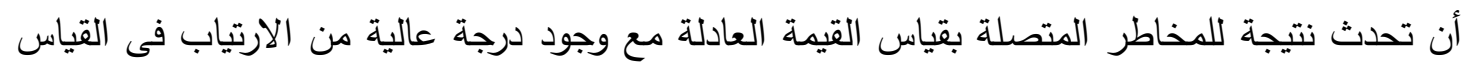

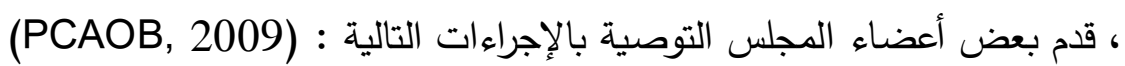
اـ - تقييم مدى خبرة الإدارة فى القيام بوضع تقديرات دقيقة للقيمة العادلة . r- تتييم ما إذا كان يتم استخدام نموذج معين وتحديد مدى قبول النموذج عموما . r- البحث عن افتراضات بديلة عن افتراضات الإدارة واستخدامها فى تقييم قدرة الإدارة على وضع

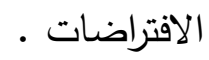
ع - التحقق من صحة المعومات من طرف ثالث .

وقد تناول معيارى المراجعة الدولى والمصرى رقم

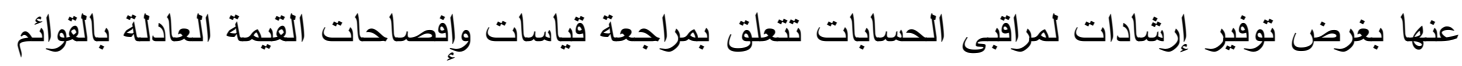

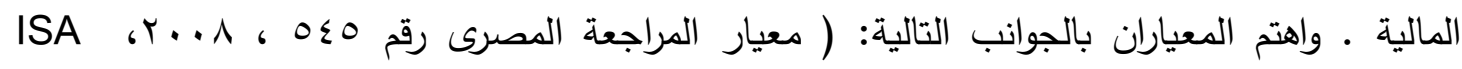
( No.545, 2004 تفهم إجراءات المنثأة فى تحديد قياسات وإفصاحات القيمة العادلة وأنثطة الرقابة ذات الصلة

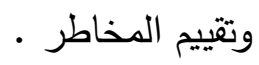
تقييم مدى ملاءمة قياسات وإفصاحات القيمة العادلة . 
إجراءات المراجعة التى تتعامل مع خطر التحريف الهام والمؤثر فى قياسات وإفصاحات المنشأة للقيمة العادلة .

وتناول مجلس المعايير الدولية للمراجعة والتأكيد (IAASB, 2008) تحديات مراجعة التقييم المحاسبى

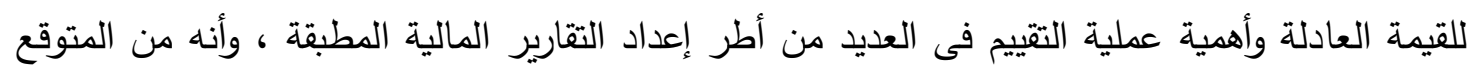

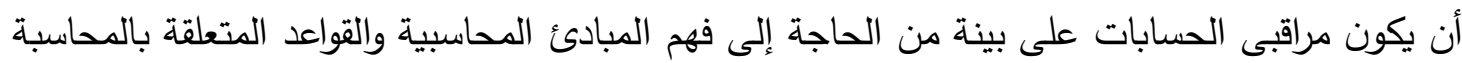

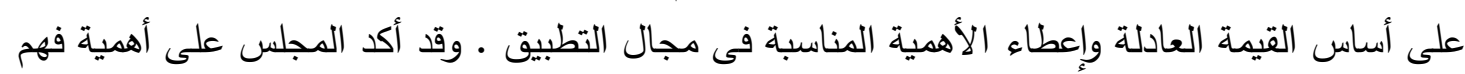

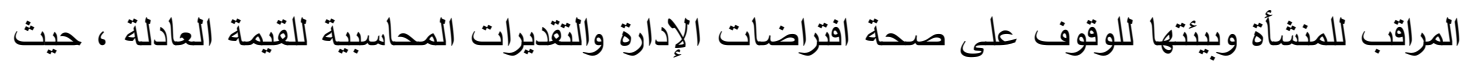
أن درجة عدم التأكد من التقديرات يزيد ويؤثر بدوره على مخاطر الأخطاء الجوهرية .

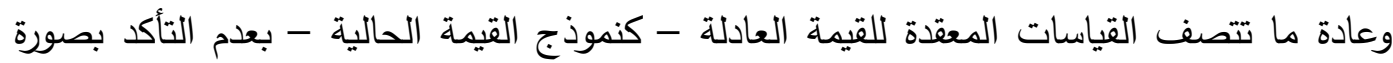
كبيرة فيما يخص مصداقية عملية القياس ، ويمكن أن يكون عدم التأكد بدرجة أكبر نتيجة لكل من :

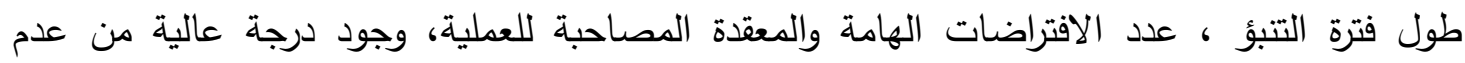

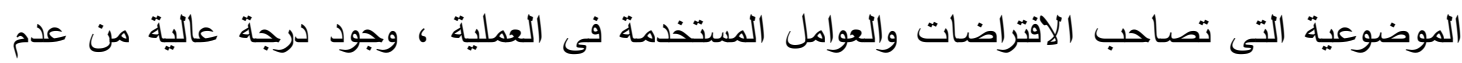

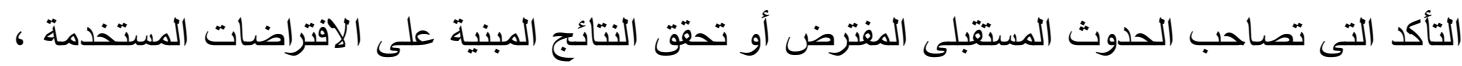

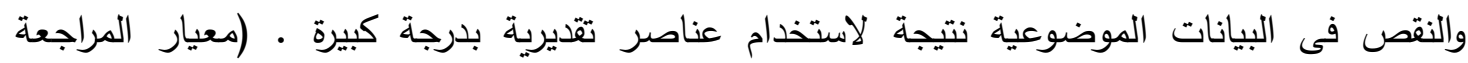

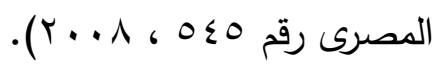

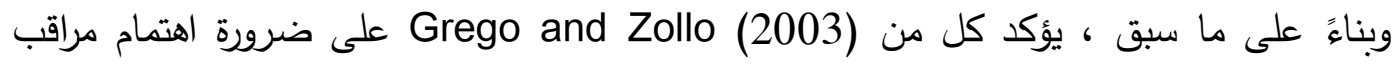

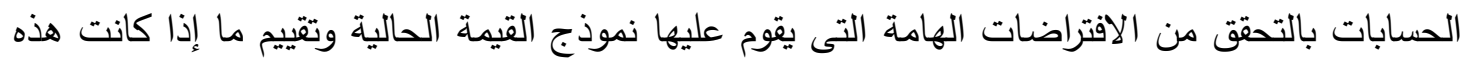

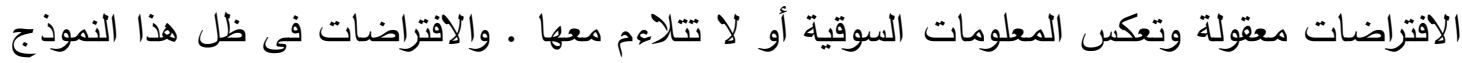

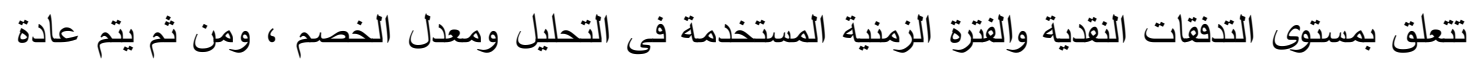

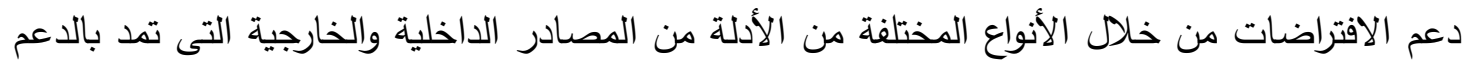

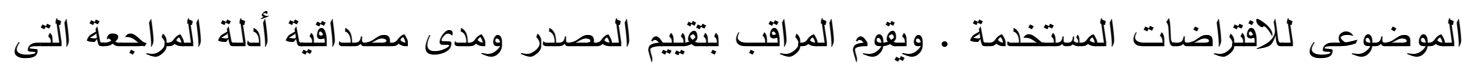
تؤيد افتراضات الإدارة بما فى ذلك دراسة الافتراضات فى ضوه المعلومات التاريخية وتقييم ما إذا كانت

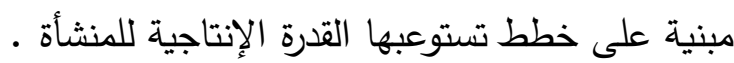

ولقد تم تعديل معيار المراجعة الدولى رقم • ؟0 عام 9 . . ب والمرتبط بمراجعة التقديرات المحاسبية

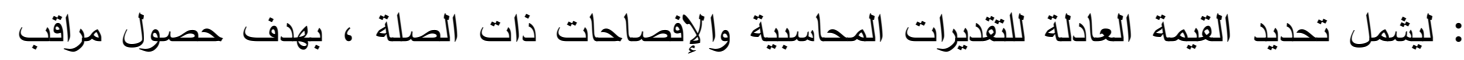
الحسابات على أدلة المراجعة الملائمة والكافية حول معقولية تلك التقديرات وكفاية الإفصاحات ذات

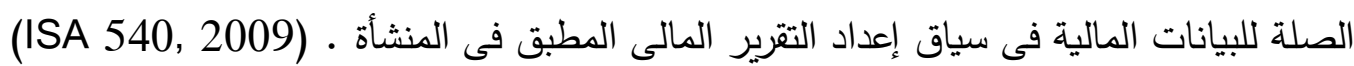

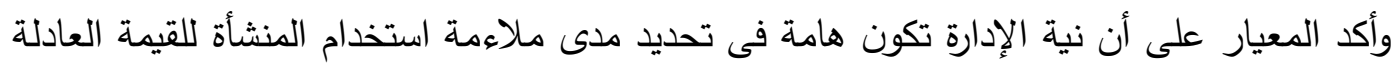
، وحيث أن مدى أدلة المراجعة التى يجب الحصول عليها عن نية الإدارة تعتبر أمر يرجع للحكم المهنى

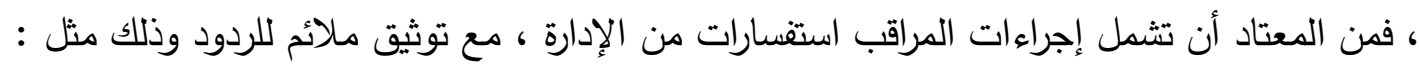

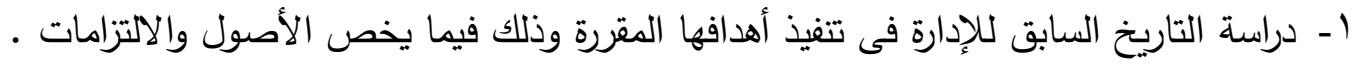




$$
\begin{aligned}
& \text { r- فحص الخطط الدكتوبة والمستتدات الأخرى كالموازنات ومحاضر الاجتماعات . } \\
& \text { r- دراسة أسباب الإدارة المعلنة لاختيار أسلوب معين • }
\end{aligned}
$$

ـ - دراسة قدرة الإدارة على تتفيذ أسلوب عمل معين، فى ظل الظروف الاقتصادية للمنشأة، بما فى ذلك

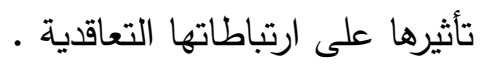

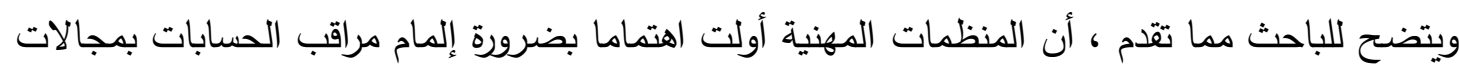

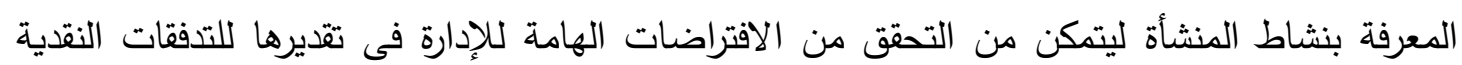

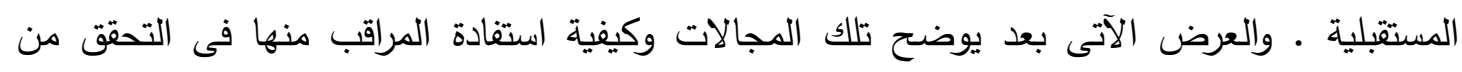

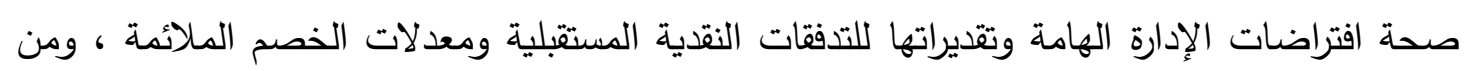

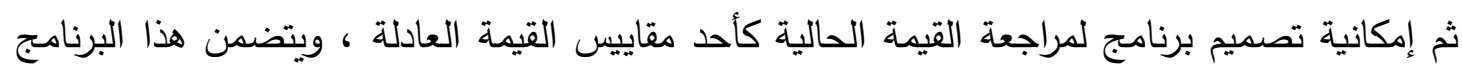
أهم الجوانب التى تخضع للفحص والتحقق بواسطة مراقب الحسابات.

\section{؟ ץ برنامج مراجعة الافتراضات الهامة لتدديد القيمة الحالية لصافى التدفقات النقدية :}

ينبغى على مراقب الحسابات أن يحصل على مستوى كاف من المعرفة عن نثاط المنشأة ، ليكون

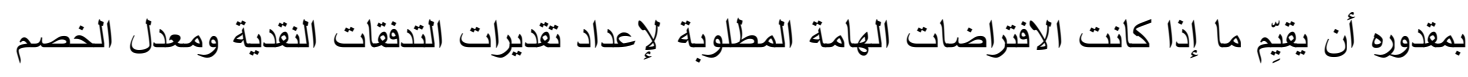

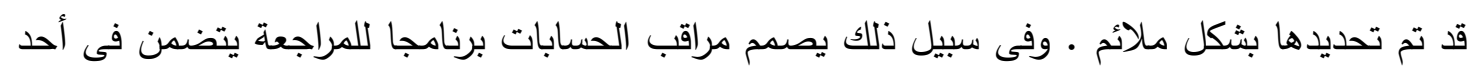

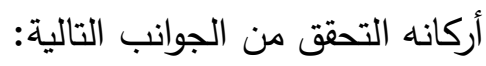

\section{ب/ أنثطة الرقابة ذات الصلة على نظام إعداد تقديرات التدفقات النقدية :}

وتتضمن هذه الأنشطة السياسات والإجراءات المرتبطة بتقويم الأداء ومعالجة المعلومات وعناصر

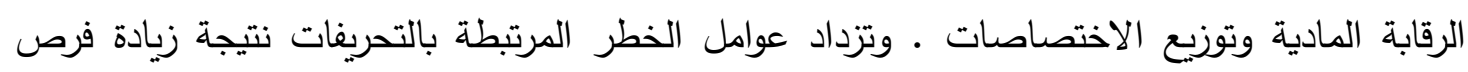

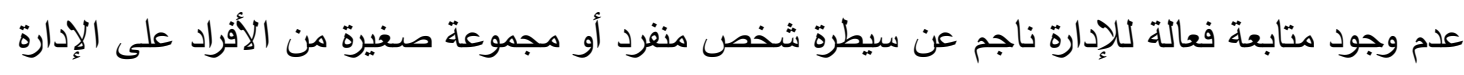

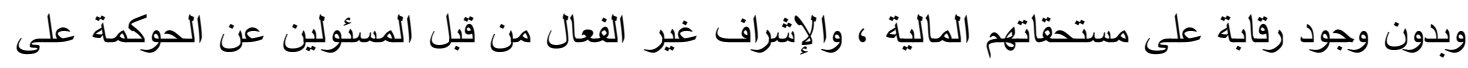

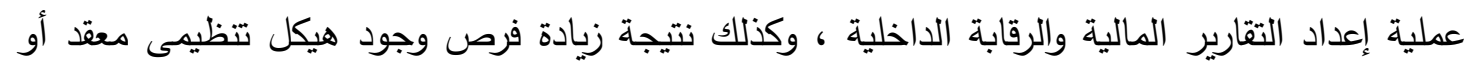

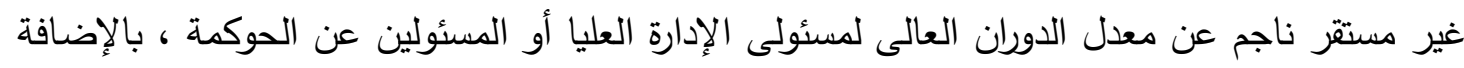

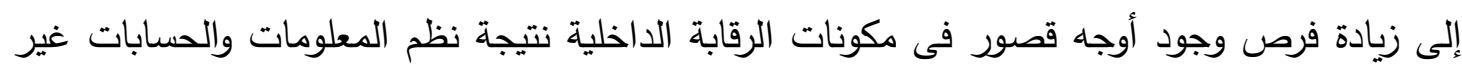

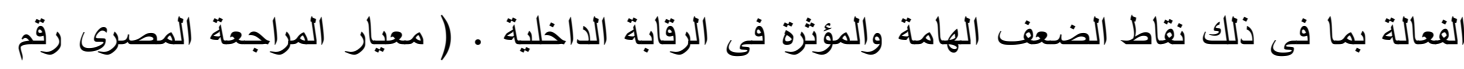


ويقع على عاتق مراقب الحسابات - درءا للمسئولية والمساءلة - عبء تتظيم جلسات مناقثة فعالة بين أعضاء فريق المراجعة فيما يتعلق بمخاطر الغش مع ممارسته لارجة ملائمة من الثك المهنى

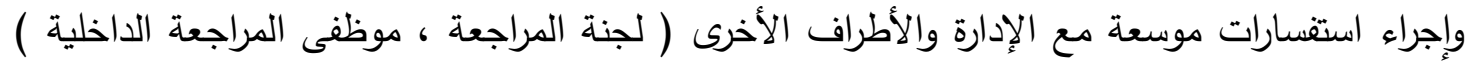

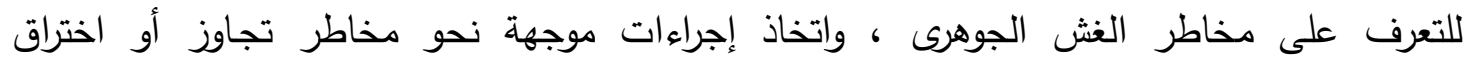
(Override) صحة ما يلى :

1 - إن الافتراضات معقولة ومؤيدة وتمثل أفضل تقديرات الإدارة للظروف والأوضاع الاقتصادية للأصل

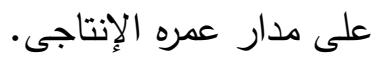

r- إن التدفقات النقدية المستقبلية الداخلة والخارجة معدة إعدادا جيدا على أساس تلك الافتراضات. r- إن التدفقات النقدية المستقبلية تم إعدادها على أساس متسق مع القوائم المالية التاريخية وباستخدام مبادئ محاسبية مناسبة. ع - تقييم المصادر الداخلية والخارجية المؤيدة لافتراضات الإدارة الهامة , بما فيها تقييم الافتراضات في ظل المعلومات المالية التاريخية.

0ـ - تقييم ما إذا كانت الافتراضات مبنية على خطط يمكن للشركة تحقيقها من خلال قدراتها المتوفرة . 7- ان تقدير التدفقات النقدية المستقبلية قد تم على ضوء آخر الموازنات والتوقعات التى اعتمدتها الإدارة

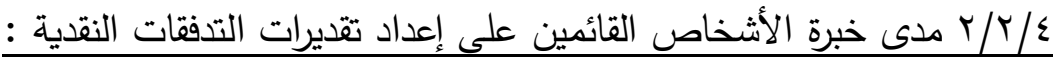

يتعرف مراقب الحسابات على عنصر الخبرة من خلال فحص ودراسة سياسات الموارد البشرية والتى ترتبط بوجود معايير لاختيار أفضل الأفراد المؤهلين مع التركيز على الخلفية التعليمية والخبرة

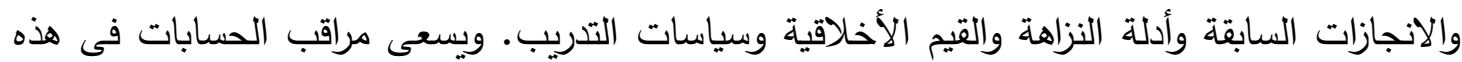

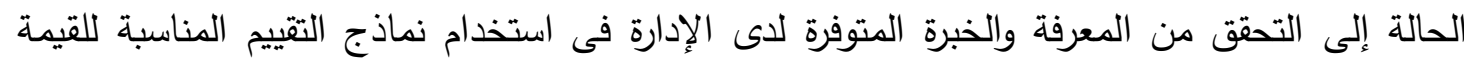

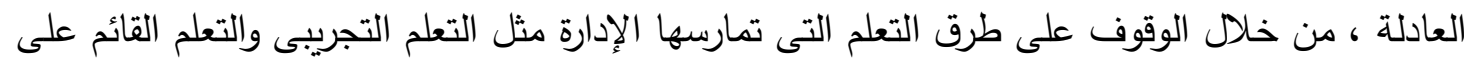

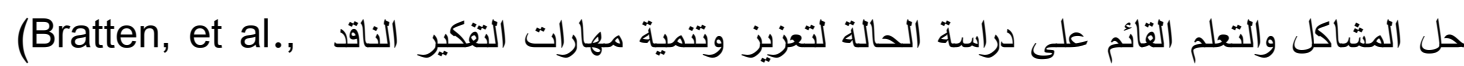

بالإضـافة إلى تحقق مراقب الحسابات من قدرة المنشأة على الاستمرار من خلال ما تقوم به الإدارة

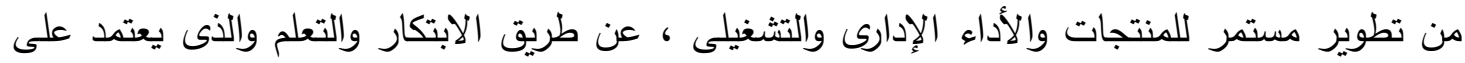


ثلاثة قواعد أساسية وهى ؛ تحسين قدرات العاملين ، رفع كفاءة نظم المعلومات ، والدافعية أو التحفيز وتفويض السلطة والإجراءات التنظيمية (Motivation) إلى التحقق من قدرة الإدارة على تحديد العناصر الدكونة لتقديرات التدفقات النقدية المستقبلية التالية: (

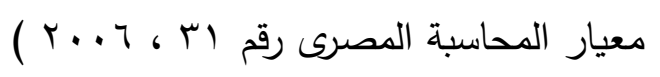
ا ـ أن تعكس تقديرات التدفقات النقدية المستقبلية ومعدل الخصم الافتراضات الثابتة بثأن زيادة الأسعار التي ترجع إلى التضخم.

r- يتم استخدام معدل خصم مناسب للتدفقات النقدية الدستقبلية بالعملة الأجنبية ، وتترجم القيمة الحالية باستخدام سعر الصرف الفورى في تاريخ حساب القيمة العادلة.

r- ان تقديرات التدفقات النقدية المستقبلية لا تثمل كل من : التدفقات النقدية الداخلة أو الخارجة التي بلتي

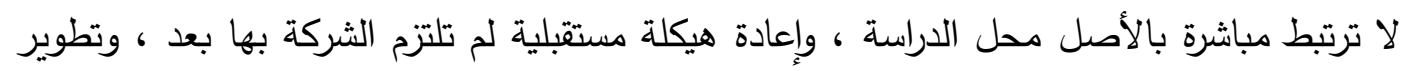

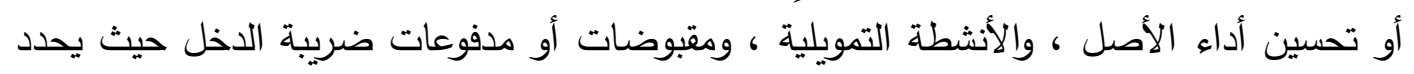
معدل الخصم قبل الضريبة.

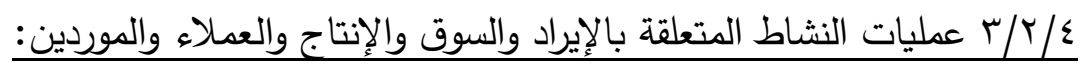

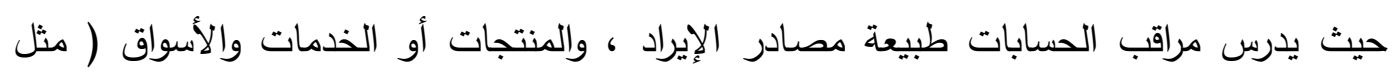

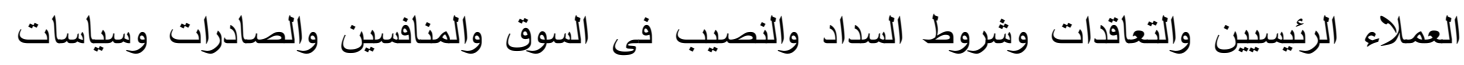

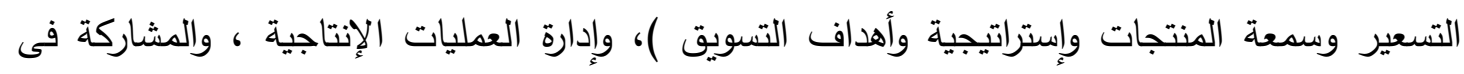

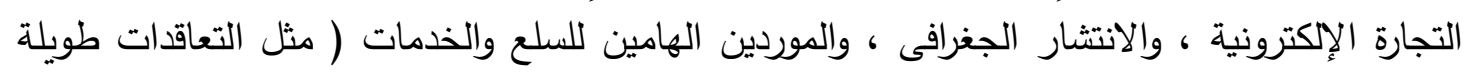

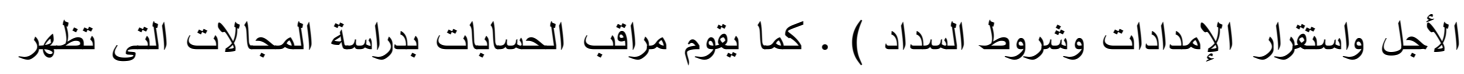

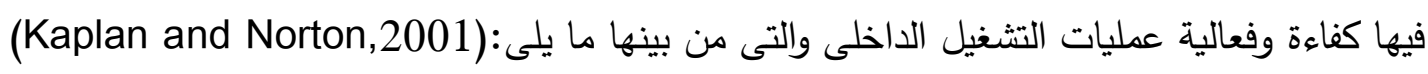

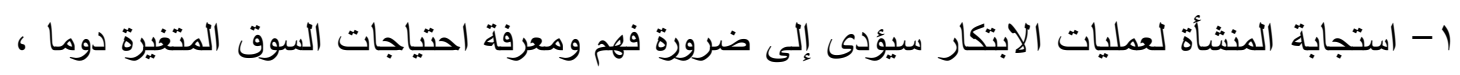

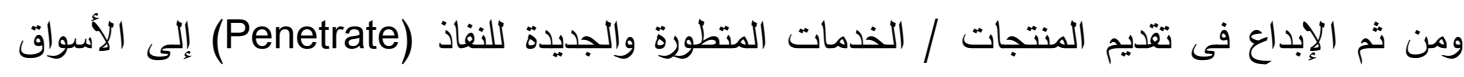

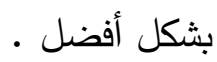

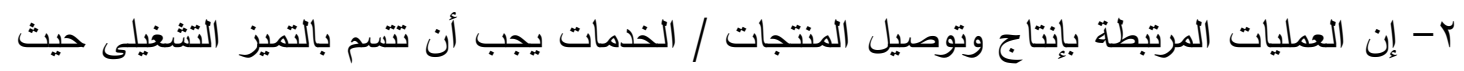

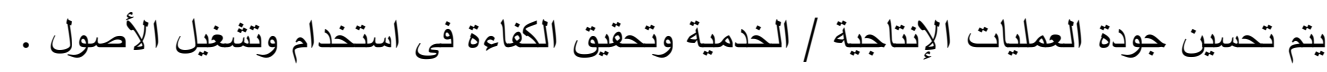

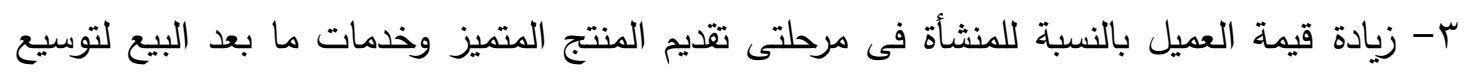

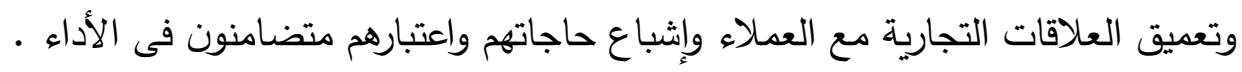

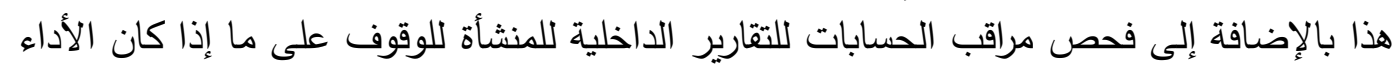

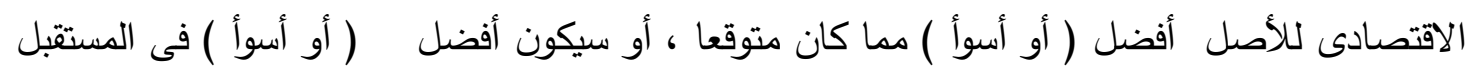

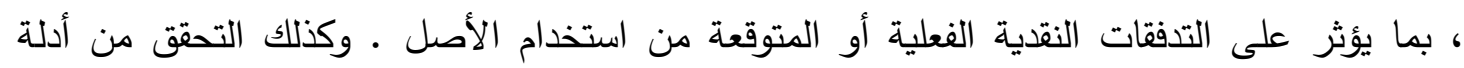

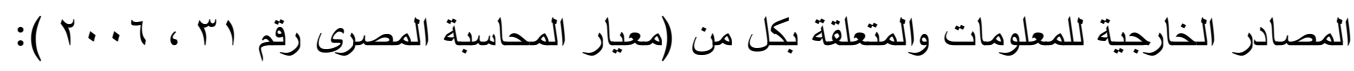


1- الانخفاض الجوهرى ( أو الزيادة ) فى القيمة السوقية للأصل خلال الفترة .

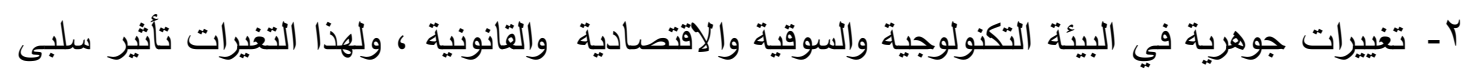

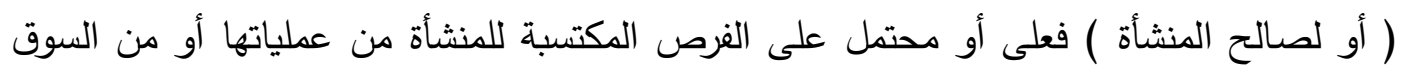

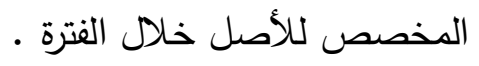

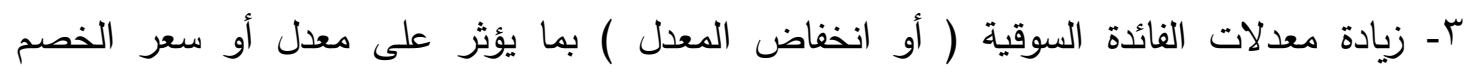

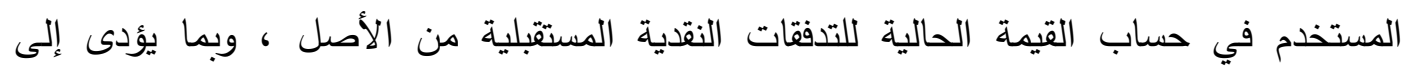

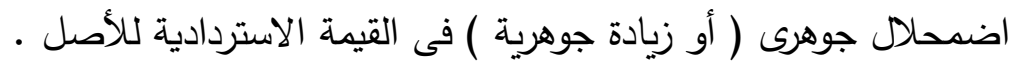
ع - انخفاض القيمة السوقية لرأس المال عن صافى القيمة الدفترية للأصول .

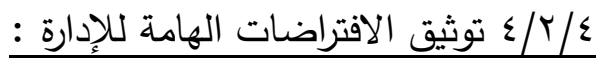

ينبغى على مراقب الحسابات الحصول على أدلة عن نوايا الإدارة فيما يتعلق بالاقتراضات الهامة

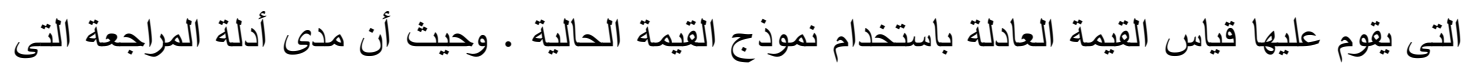

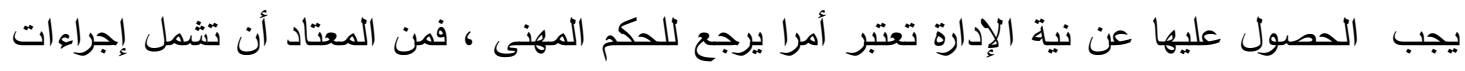

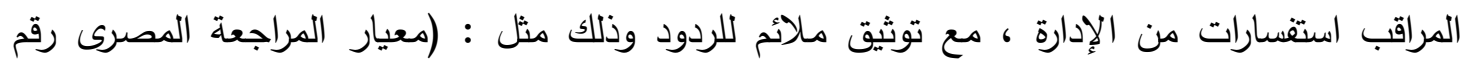
(r... ، ، 0 0 0

1- دراسة التاريخ السابق للإدارة فى تتفيذ أهدافها المقرة وذلك فيما يخص الأصول والالتزامات . ז- فحص الخطط المكتوبة والمستتدات الأخرى كالموازنات ومحاضر الاجتماعات . r- دراسة أسباب الإدارة المعلنة لاختيار أسلوب عمل معين •

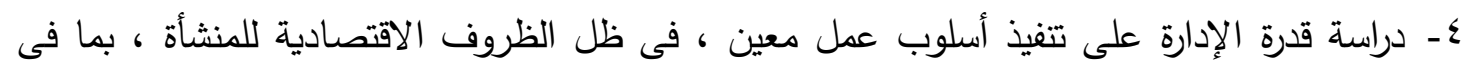
ذلك تأثيرها على ارتباطاتها التعاقدية .

هـ الحصول على إقرارات مكتوبة من الإدارة تتعلق بملاءمة أساليب القياس والافتراضات الهامة للإدارة

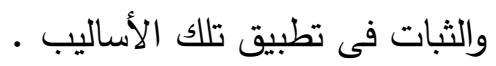

ج- تقييم مصادر الأدلة ( الداخلية والخارجية ) المؤيدة للافتراضات الهامة للإدارة وإلى أى حد يمكن الاعتماد عليها . - الإن.

ك/ إ الأساليب المستخدمة لتطبيق وتطوير افتراضات الإدارة ومتابعة التغييرات فى هذه الافتراضات : 
نظرا لأن بعض قياسات القيمة العادلة تكون أكثر تعقيدا عن غيرها بشكل متأصل وترتبط بعدم

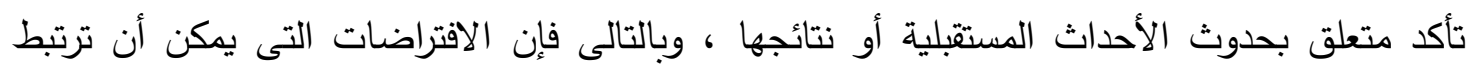
باستخدام الحكم الثخصى يجب أن تتم كجزء من عملية القياس ـ ـوتفهم مراقب الحسابات لعملية القياس بما فى ذلك درجة تعقيده ، تساعده فى تحديد مخاطر التحريف الهام والمؤثر وتقييمها ، وذلك من أجل وند

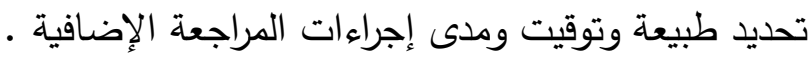

ففى مجال التتبؤ بالقيم المتوقعة للطلب خلال العمر الإنتاجى المتبقى للأصل اعتمادا على البيانات

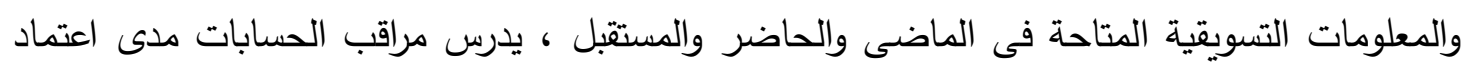

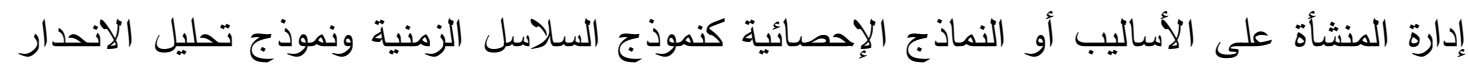

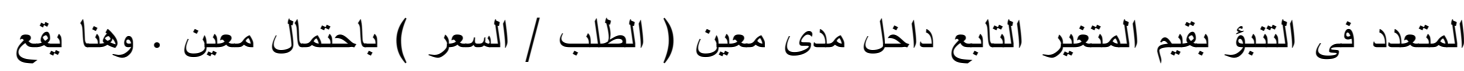

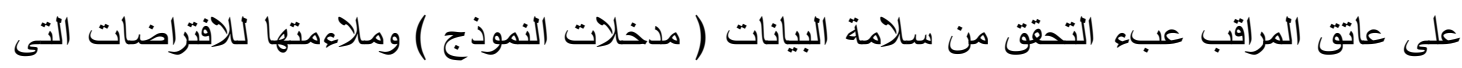
يقوم عليها النموذج المستخدم العربك علبه

وفى مجال تحديد معدل خصم صافى التدفقات النقدية المستقبلية يدرس مراقب الحسابات مدى ملاءمة

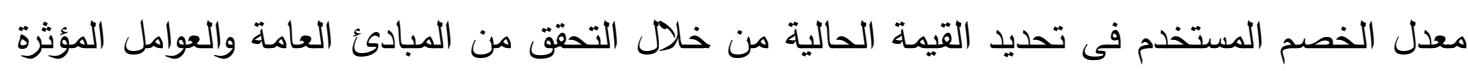

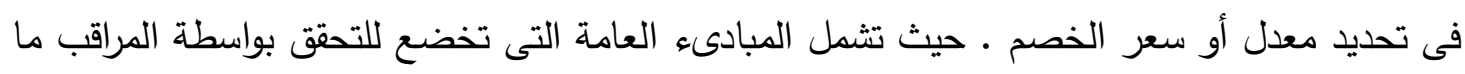
يلى ا - أن تظهر أسعار الفائدة المستخدمة لتخصيم التدفقات النقدية والافتراضات المتفقة مع الافتراضات المتأصلة في التدفقات النقدية المقدرة. r- أن تكون أسعار الخصم خالية من أية عوامل ليس لها صلة بالأصل محل التقييم. ץ- أن تعكس أسعار الخصم مجموعة من النتائج المكنة وليس فقط قيمة الحد الأدنى والحد الأقصى. ع- أن تستخدم أسعار خصم مستقلة لفترات مستقبلية مختلفة تكون فيها القيمة العادلة حساسة لأى اختلاف في المخاطر عن الفترات المختلفة أو تكون حساسة لتوقيت وشروط سعر الفائدة.

0ـ أن يكون سعر الخصم قبل الضرائب وعندما يكون الأساس المستخدم لتقدير سعر الخصم بعد الضرائب يتم تعديل هذا الأساس ليظهر السعر قبل الضرائب ، التزاما بمعايير المحاسبة المصرية. كما تشمل العوامل المؤثرة فى تحديد معدل أو سعر الخصم والتى تخضع للتحقق بواسطة مراقب الحسابات ما يلى : العمانى ا - القيمة الزمنية للنقود للفترات حتى نهاية العدر الإنتاجى للأصل. r- التوقعات بشأن الاختلافات الممكنة في قيمة أو توقيت التدفقات النقدية. 
r- مقابل تحمل درجة عدم التأكد المتأصلة في الأصل.

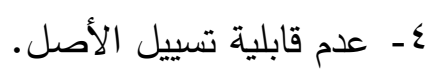

وتتعدد معدلات الخصم التى تستخدم فى تحديد القيمة الحالية للتدفقات النقدية المستقبلية ، ويقوم

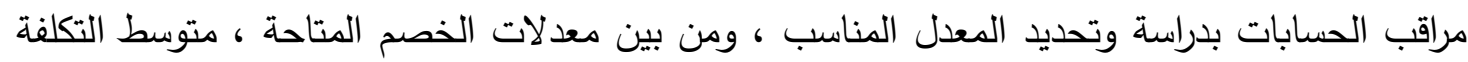

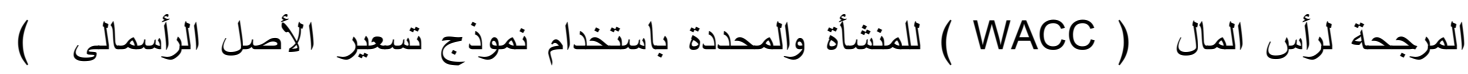

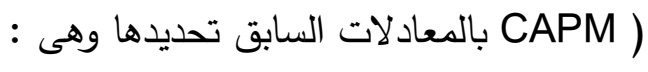

$$
\begin{gathered}
\mathbf{E} \llbracket\left(\mathbf{R}_{\beth_{j}}\right)=\mathbf{R}_{\mathrm{F}}+\left(\bar{R}_{\mathrm{M}}-\square_{\mathrm{F}}\right) \beta_{\mathrm{j}} \\
\text { WACC }_{\mathrm{a}}=(1-\mathrm{Tc}) \times \mathbf{R D} \times \frac{\mathrm{g}}{(1+\mathrm{g})}+\mathbf{R} \square \times\left[1-\frac{\mathrm{g}}{(1+\mathrm{g})}\right] \\
\text { WACC }_{\mathrm{b}}=\text { WACC }_{\mathrm{a}} \times[1 \div(1-\mathrm{T})]
\end{gathered}
$$

:

فبالنسبة لظروف الصناعة يقوم مراقب الحسابات بدراسة السوق والمنافسة والطلب والقدرة الإنتاجية

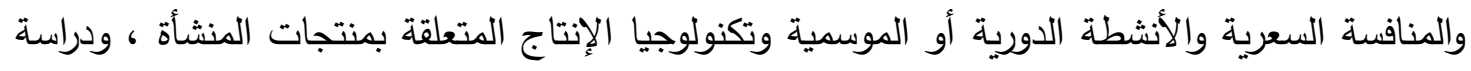

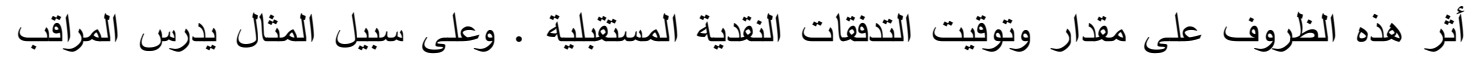

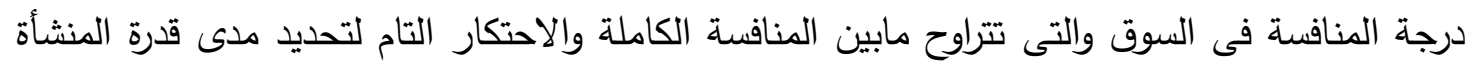

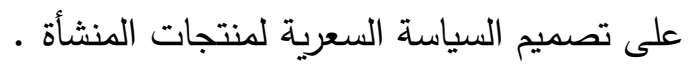

أما البيئة التنظيمية فيدرس المراقب التشريعات واللوائح التى تؤثر بثدة على العمليات الإنتاجية

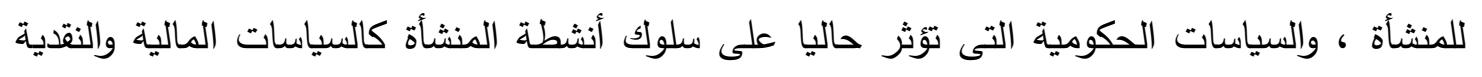

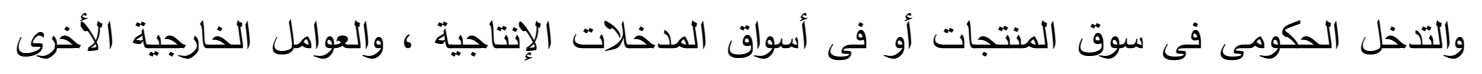

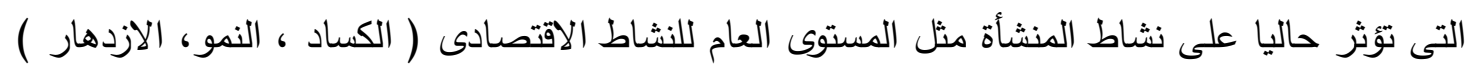

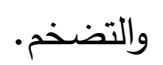

فالظروف الاقتصادية المتقلبة قد تؤدى إلى زيادة الضغوط على الإدارة لتحقيق بعض النتائج المالية

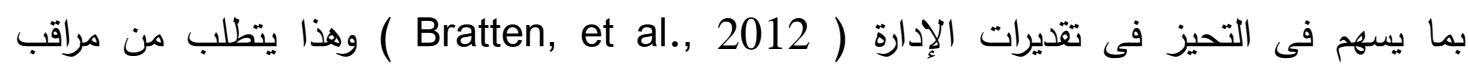

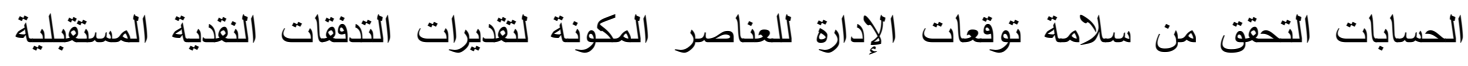

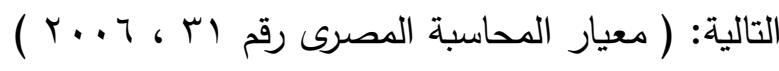


1- التذفقات النقدية الداخلة من الاستخدام المتواصل للأصل أو مجموعة الأصول . r- التدفقات النقدية للخارج التى تتكبدها المنشأة بالضرورة لإحداث التدفقات الداخلة . r- صافى التدفقات النقدية المتوقع تحصيلها أو سدادها لبيع الأصل أو التصرف فيه فى نهاية عمره الإنتاجى ( القيمة المتبقية للأصل ).

\section{الاستعانة بعمل الخبراء فى تحديد تقديرات التدفقات النقدية : الن}

فى حالة استعانة إدارة المنثأة بعمل الخبير فى تحديد الافتراضات الهامة لتقدير التدفقات النقدية ،

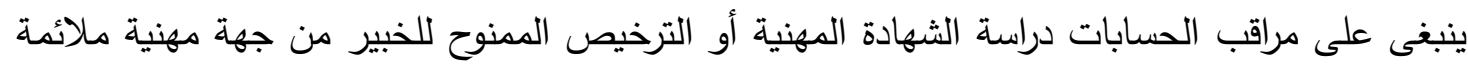

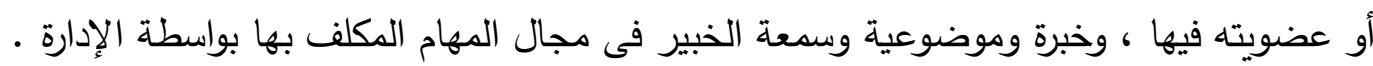

كما يقوم مراقب الحسابات بعمل استفسارات بخصوص أية إجراءات يقوم بها الخبير ليتأكد عما إذا

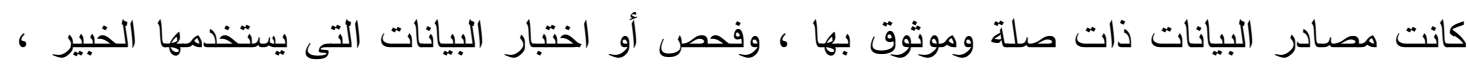

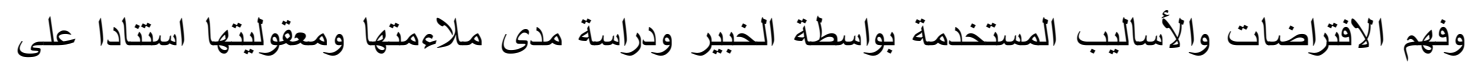

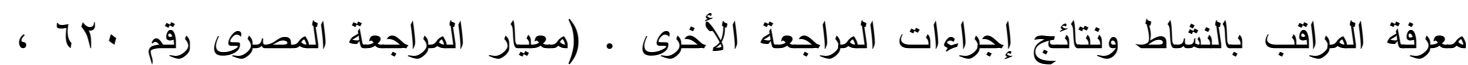
(r...

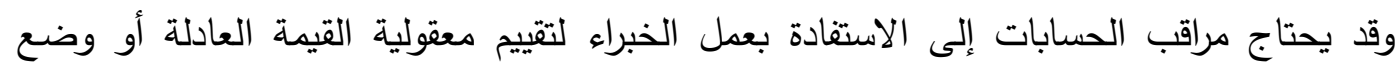
تقديرات مستقلة عن القيمة العادلة ، وفى كلتا الحالتين ، تطلب المعايير المهنية من المراقب تقيييم عمل العل

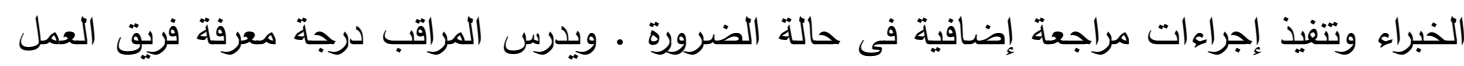

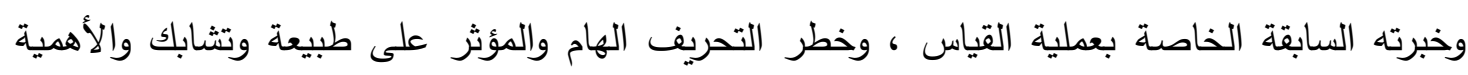

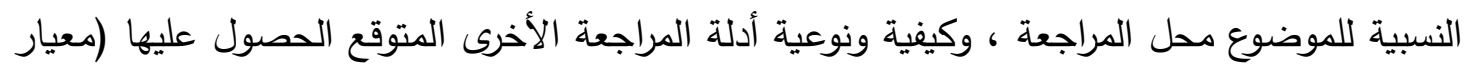

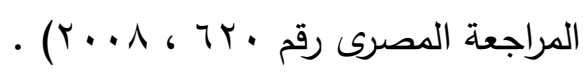

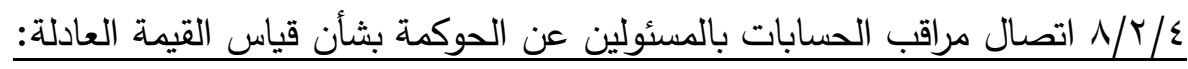

بسبب حالة عدم التأكد الذى يرتبط غالبا ببعض قياسات القيمة العادلة ، فإن التأثير الدحتمل لأى الثى

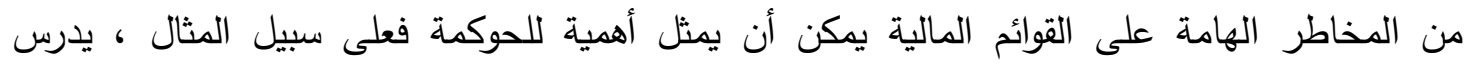

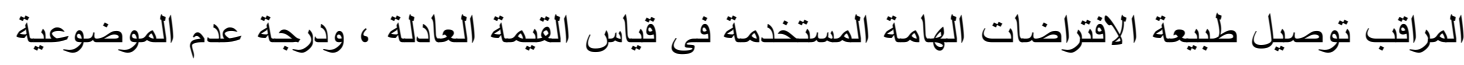

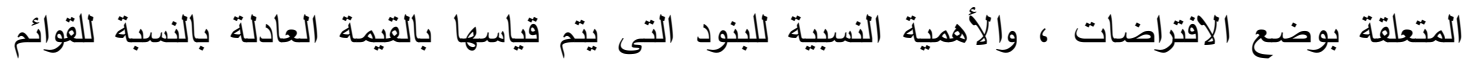

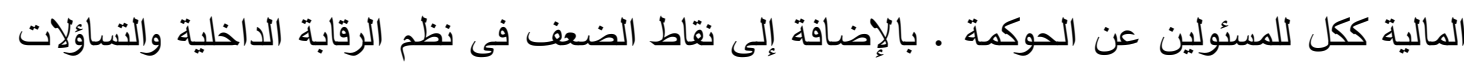

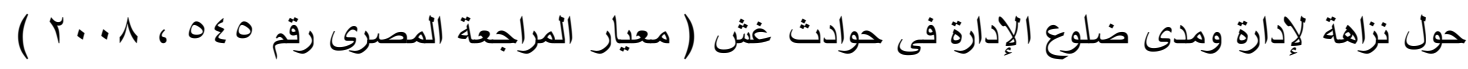


هذا بالإضافة إلى دراسة مراقب الحسابات للمعلومات المتاحة حول الموقف المالى للمديرين أو

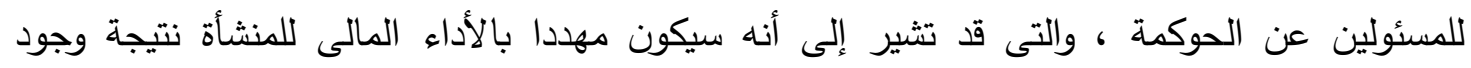

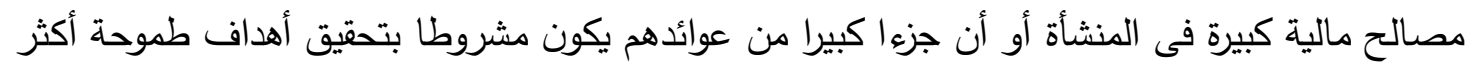

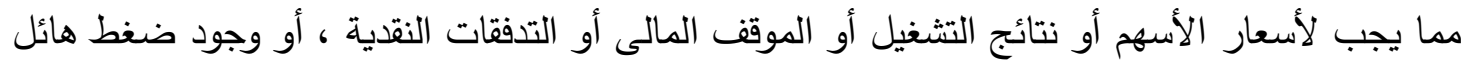

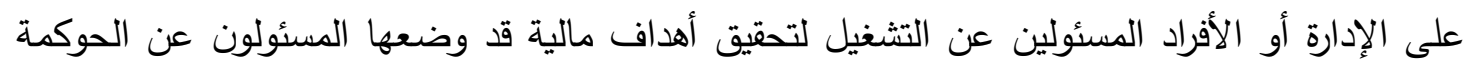

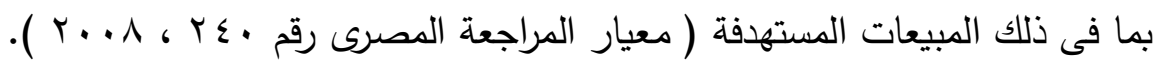

\section{و/ ا اتساق تقديرات التدفقات النقدية المستقبلية المتوقعة مع تقديرات النترات السابقة :}

يحصل مراقب الحسابات على درجة من المعرفة عن المعلومات المالية التاريخية لتتيييم ما إذا كانت

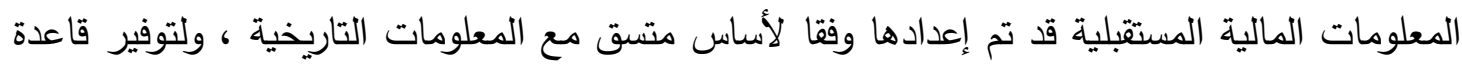

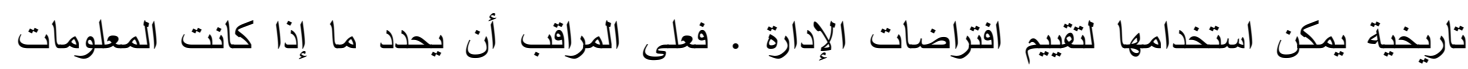

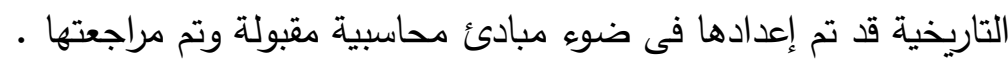

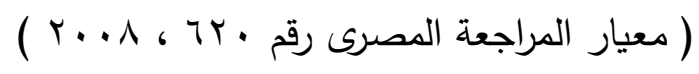

كما يدرس مراقب الحسابات تاريخ المنشأة من الجوانب التالية: ( معيار المراجعة المصرى رقم • ع؟ ،

( r... 1- الدعاوى ضد المنشأة أو إدارتها أو المسئولين عن الحوكمة ، بالغش والتدليس ومخالفة القوانين • واللوائح r- الفثل المستمر للإدارة فى تصحيح نقاط الضعف الهامة والمؤثرة فى نظام الرقابة الداخلية فى الوقت المناسب ، ذات الأثر على التدفقات النقدية المتوقعة.

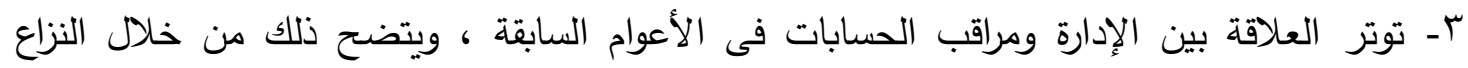

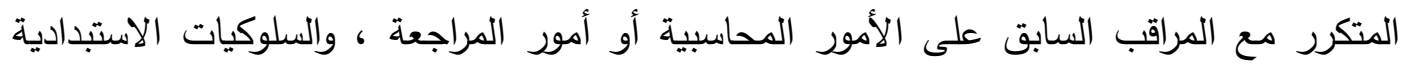

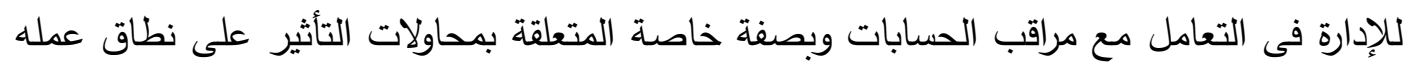

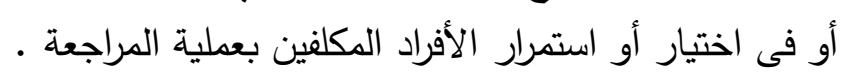

ـ- اعتياد الإدارة على تقديم وعود للمحللين أو الدائنين أو غيرهم من الأطراف الأخرى بتحقيق نتائج

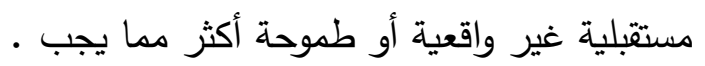

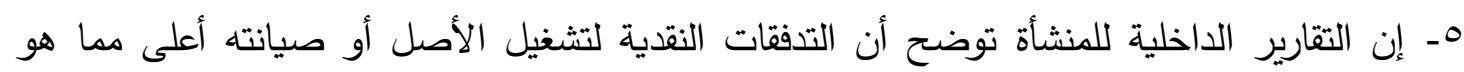

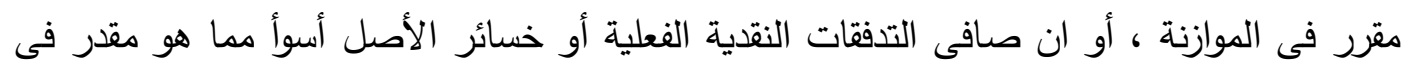


إن النزاهة والقيم الأخلاقية هى عناصر أساسية لبيئة الرقابة التى تؤثر فى مدى فعالية التصميم

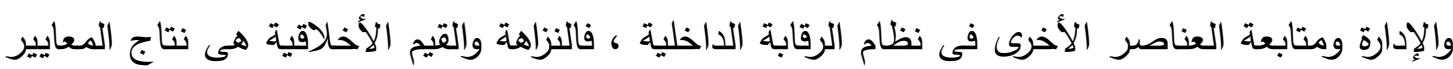

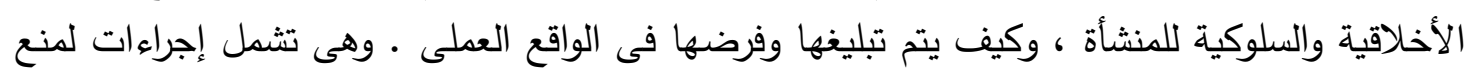

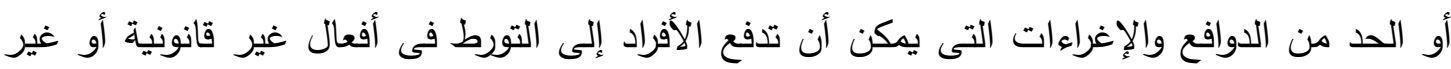

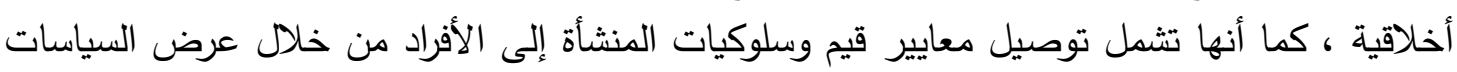

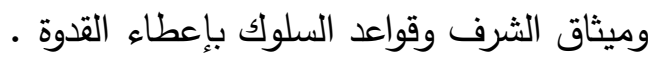

ويبرز دور مراقب الحسابات فى التحقق من خطط الإدارة الموثقة للإثراف على برامج القيم والمبادئ ومدى الالتزام بها ، وبرامج تدريب العاملين على كيفية تطبيق المعايير والإجراءات المرتبطة

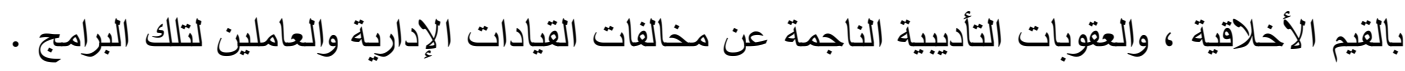
هذا بالإضافة إلى تحقق مراقب الحسابات من الإجراءات الرقابية الواجب توافرها لتحقيق معايير القيادة الأخلاقية وتثمل؛ قواعد نجاح البرامج الأخلاقية وعوامل المناخ الأخلاقى، تحقيق مواطنة

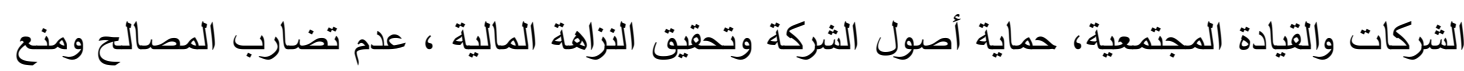

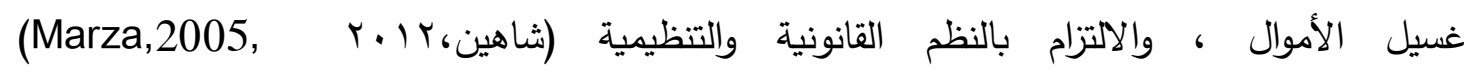
. Reamer,2007, Carmichael et al.,2011, : 11/ / فحص الأداء المالى وغير المالى للمنشأة :

وتشمل الأمثلة على الموضوعات التى يمكن لمراقب الحسابات دراستها : النسب المالية وغير المالية الهامة ، ومؤشرات الأداء الهامة ومقاييس أداء العاملين ، وتحليل الاتجاهات واستخدام تقارير

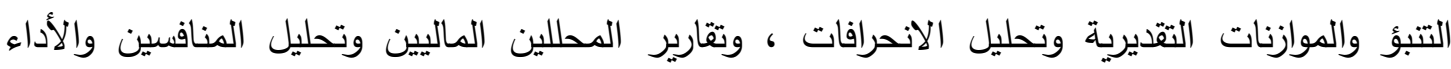

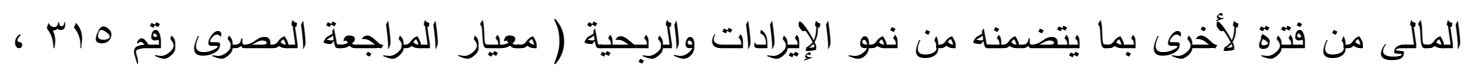

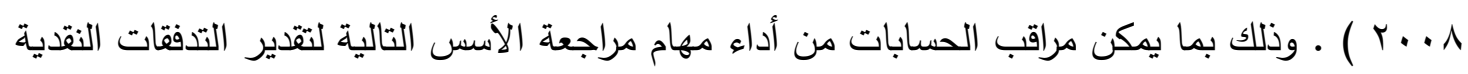

1 - اختبار أسباب الفروق بين التنبؤات الماضية للتدفقات النقدية والتدفقات النقدية الفعلية ، للحكم على مدى معقولية الافتراضات التي قامت عليها تلك التنبؤات.

r- إن تقدير التدفقات النقدية حتى نهاية العمر الإنتاجى للأصل قد تم باستخدام معدل نمو ثابت أو

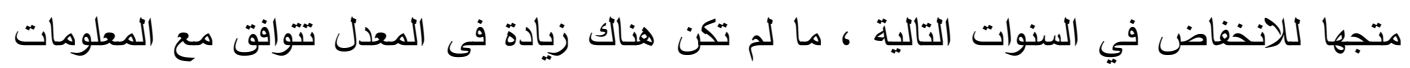

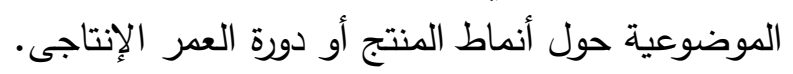


r- عدم تجاوز معدل النمو في التدفقات النقدية المستقبلية متوسط معدل النمو على المدى الطويل بالنسبة للمنتجات أو الصناعات أو السوق الذى يستخدم فيها الأصل.

ع - متابعة الدراسات الخاصة بإمكانية دخول المنافسين للسوق وتقييد النمو ، للوقوف على صعوبات تجاوز معدلات النمو التاريخية على المدى البعيد.

وبناءً على ما تقدم ، تبدو أهمية إجراء دراسة ميدانية ، للوقوف على مدى ملاعمة الإطار الفكرى

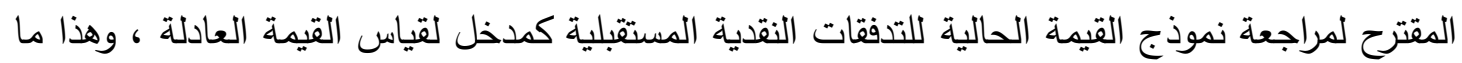

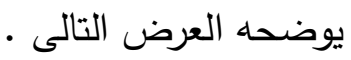

خامسا: دراسة ميدانية عن عناصر التحقق من نموذج القيمة الحالية تهدف الدراسة الميدانية إلى استقراء فكر مراقبى الحسابات والقيادات الإدارية بمنشآت الأعمال المصرية دادية ، للوقوف على مدى ملاعمة الإطار الفكرى المقترح بشأن استخدام القيمة الحالية كأحد مقاييس القيمة العادلة للأصول طويلة الأجل. وذلك من خلاء تحديد مجالات المعرفة بنشاط الشركة للتحقق من صحة

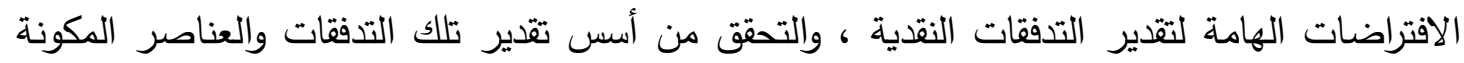
لها ، وكذلك التحقق من المبادئ والعوامل المؤثرة فى تحديد معدل الخصم ، بالإضافة إلى التحقى من من التصني

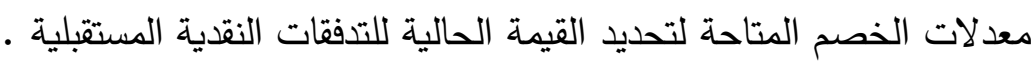

ولتحقيق الهدف من الدراسة الميدانية يتتاول الباحث طبيعة تلك الدراسة وتحليل النتائج واختبار

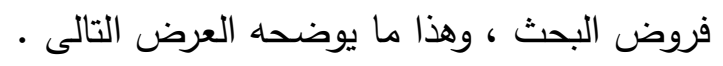

1/0 طبيعة الدراسة الميدانية واختبار الاعتمادية لمتغيرات الدراسة : يتضمن هذا الجزء مجتمع وعينة الدراسة ، وطريقة تجميع البيانات ، والأساليب الإحصائية المستخدمة فى تحليل البيانات ، واختبار الاعتمادية لمتغيرات الدراسة. 1/1/0 مجتمع وعينة الدراسة وطريقة تجميع البيانات:

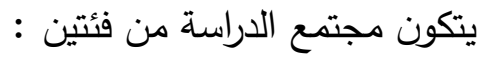

الأولى : وتضم مراقبى الحسابات بمؤسسات المراجعة الكبرى والتى تتبع مؤسسات مراجعة دولية (مثل من

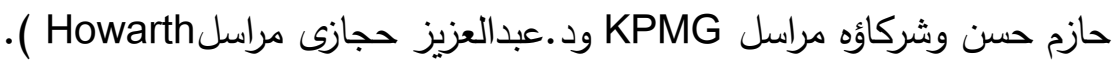


الثانية : وتضم القيادات الإدارية بشركات المساهمة المصرية المقيدة أسهها فى سوق الأوراق المالية المصرية ، وتتبع قطاعات متتوعة كالبنوك والاتصالات والأدوية والعقارات. وقد تم تحديد حجم عينة الدراسة من المجموعة الأولى (عينة مراقبى الحسابات) بعدد مائة مفردة تم اختيارها بطريقة حكمية من تلك المؤسسات ، بينما تم تحديد حجم عينة الدراسة من المجموعة الثانية (عينة القيادات الإدارية) بعدد مائة مفردة تم اختيارها من قطاعات متنوعة كالبنوك والاتصالات والأدوية

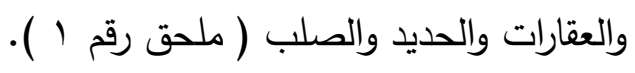

وتم تجميع البيانات اللازمة لاختبار فروض البحث وتحقيق الهدف من الدراسة الميدانية عن طريق قائمة استقصاء والتى اعتمد عليها الباحث كوسيلة رئيسة لجمع البيانات الأولية بغية استقراء فكر مراقبى لإنى الحسابات والقيادات الإدارية بثأن إجراءات التحقق من تحديد القيمة الحالية للتدفقات النقدية المستقبلية كمخل لقياس القيمة العادلة . وقد تم استخدام عدد إحدى وسبعين استمارة من قوائم الاستقصاء

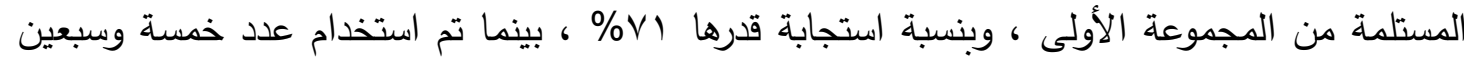

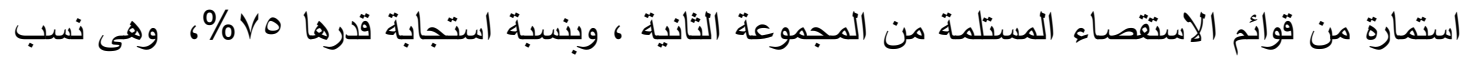

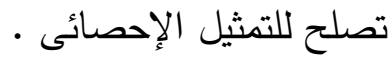

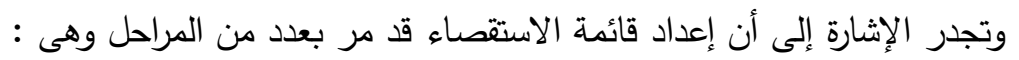
1- استقراء الكتابات السابقة وما صدر عن المنظمات المهنية المتخصصة والهيئات المعنية بمعايير المحاسبة والمراجعة ، بغية حصر كافة الجوانب التى يمكن أن تتضمنها قائمة الاستقصاء ، ومن ثم تم إعداد قائمة استقصاء مبدئية . بائ. r- تم عرض القائمة المبدئية على عدد محدود من مراقبى الحسابات والقيادات الإدارية ، بغية التأكد من مدى ملى كفاية وملاءمة الأسئلة الواردة بالقائمة . .

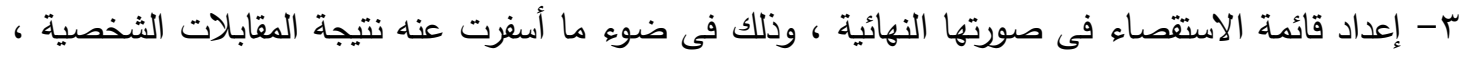

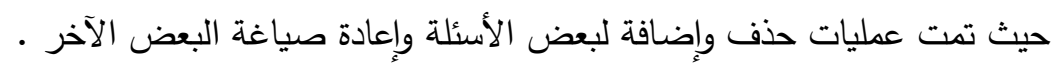

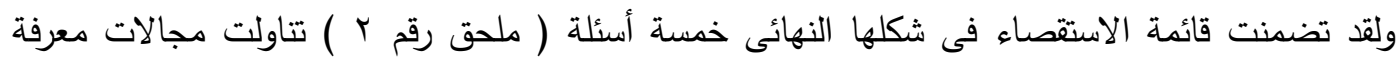

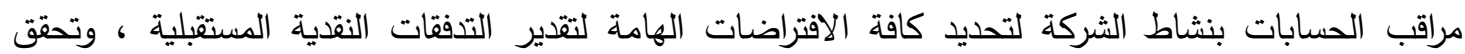
المراقب من: أسس تقدير تلك التدفقات ، والعناصر المكونة لتقديرات التدفقات النقدية ، والمبادئ والعوامل المؤثرة

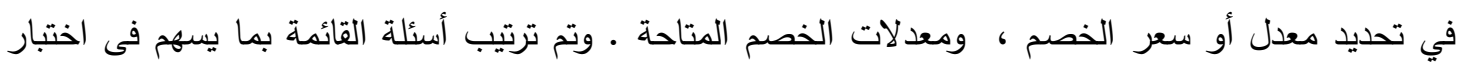

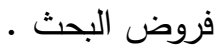

ب/l/ الأساليب الإحصائية المستخدمة فى تحليل البيانات:

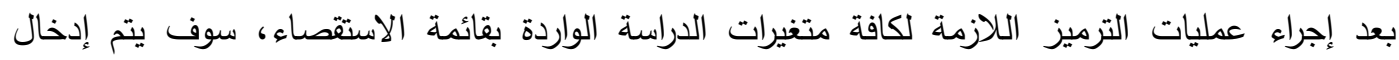

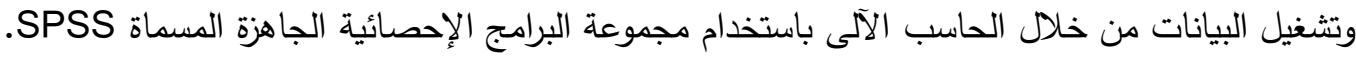

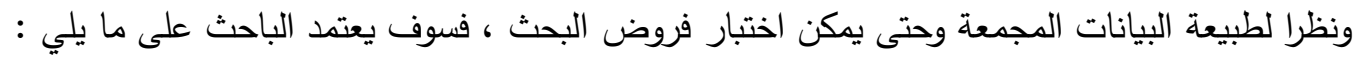
: Mann - Whitney U اختبار 
ويستخدم لمعرفة ما إذا كانت توجد اختلافات ذات دلالة إحصائية بين آراء مراقبي الحسابات والقيادات الإدارية فيما يتعلق بدرجة الأهمية النسبية لإجراءات تحقق مراقب الحسابات من تحديد القيمة الحالية للتدفقات

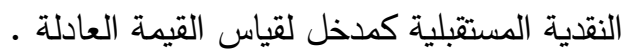
r- اختبار تحليل التمايز ( Discriminant Analysis ): ويعتبر من أساليب تحليل المتغيرات المتعددة لاستكثاف أسباب الاختلافات المشاهدة عند صعوبة فهم العلاقات السببية بدرجة كافية ( جونسون ووشرن ، 1991 ). ويستخدم هذا الاختبار للتوصل إلى تحديد مجموعة

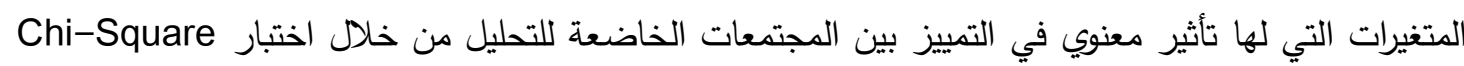

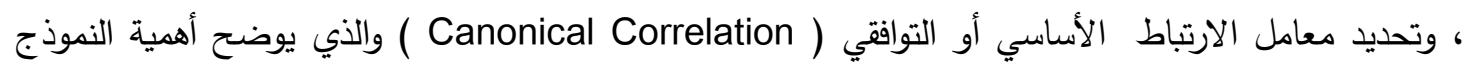

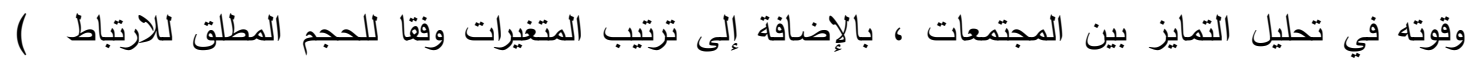
ضمن دالة التمييز ، وكذلك تحديد قيمة معامل Absolute size of correlation ) يحدد مدى قدرة النموذج على التمييز بين عينات الدراسة. ب- اختبار Cronbach's Alpha:

ويستخدم باعتباره أكثر أساليب تحليل الاعتمادية (Reliability) دلالة في تقييم درجة التتاسق الداخلى بين

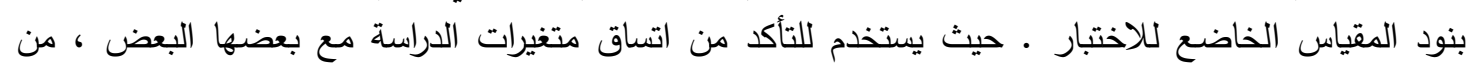

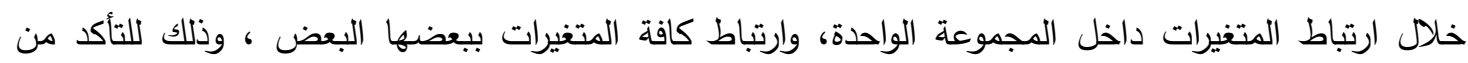

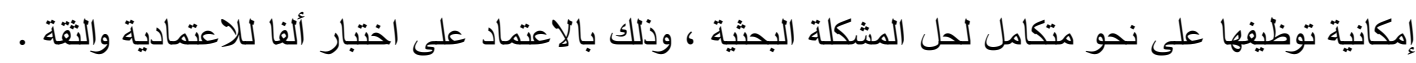

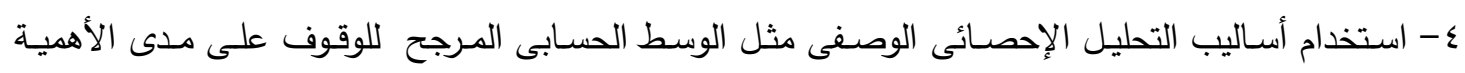

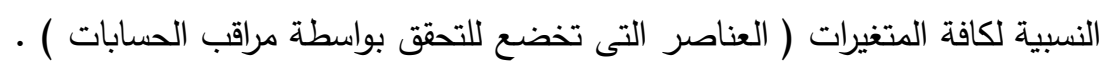

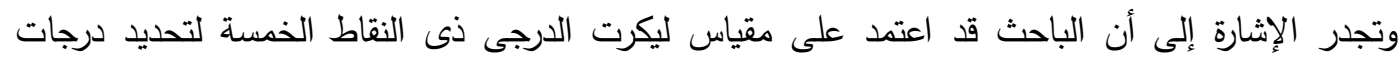

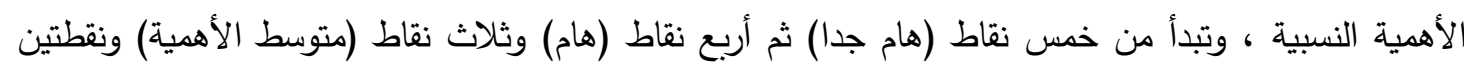

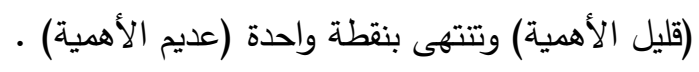

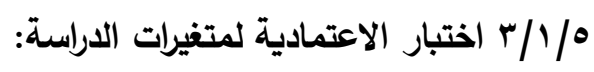

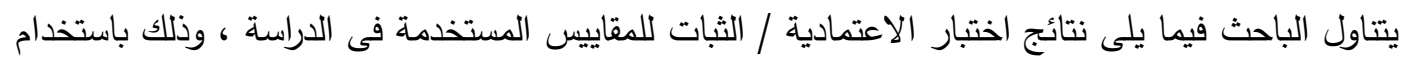

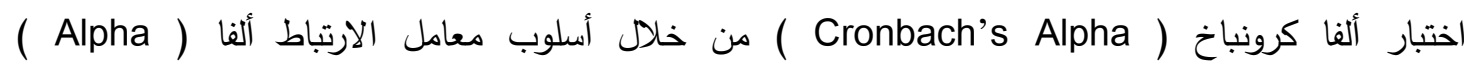
. Correlation Coefficient ومن المتعارف عليه إحصائياً أن إحصائية الاختبار يجب ألا تقل عن آ,، (Ellison, et al.,2009)

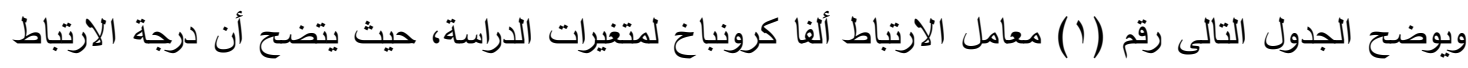

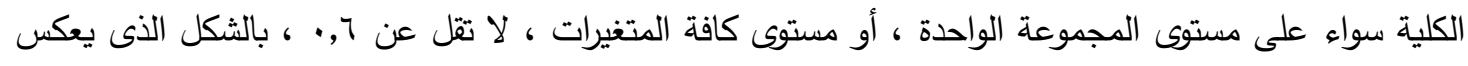

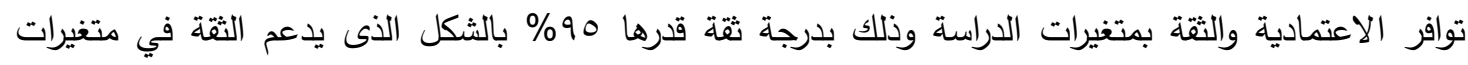
الدراسة ويؤكد صلاحيتها لمراحل التحليل التالية .

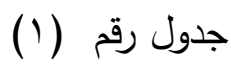

قيمة معاملات Cronbach'sAlpha لمتغيرات الدراسة

\begin{tabular}{|c|c|c|c|c|}
\hline \multicolumn{3}{|c|}{$\begin{array}{c}\text { معامل ارتباط } \\
\text { Cronbach's Alpha }\end{array}$} & \multirow{2}{*}{ المتغير } & \multirow{2}{*}{ المتغيـر } \\
\hline مراقبيى الحسابات & القيادات الإدارية & مراقبى الحسابات & & \\
\hline
\end{tabular}

$-r \varepsilon \Lambda-$ 


\begin{tabular}{|c|c|c|c|c|}
\hline \multicolumn{3}{|c|}{$\begin{array}{c}\text { معامل ارتباط } \\
\text { Cronbach's Alpha }\end{array}$} & المتغير & المتغيـر \\
\hline$\cdot, 9 \leq \vee V$ & . , १४^. & $\cdot, 90 . \varepsilon$ & & - المقياس الكلى. \\
\hline$\cdot, \wedge \wedge \vee \varepsilon$ & $\cdot, \Lambda \leqslant \wedge r$ & . , q1 9 & $\mathbf{A}$ & - مجالات معرفة المراقب بنشاط الثركة. \\
\hline$\cdot, \wedge \vee r \vee$ & • & $\cdot, \wedge \vee \wedge \wedge$ & $\mathbf{B}$ & - أسس تقدير التدفقات النقدية. \\
\hline$\cdot, \vee \wedge \cdot r$ & $\cdot, V \leq r V$ & . , $\vee Q \bullet r$ & C & - العناصر المكونة لتقديرات التدفقات. \\
\hline$\cdot, \wedge \wedge r r$ & $\cdot, \wedge \vee \wedge r$ & $\cdot, \wedge \vee \wedge \varepsilon$ & D & - مبادئ وعوامل تحديد معدل الخصم . \\
\hline$\cdot, \wedge \vee \diamond 々$ & • & $\cdot, \wedge \leqslant \wedge \leqslant$ & $\mathbf{E}$ & - معدلات الخصم المتاحة. \\
\hline
\end{tabular}

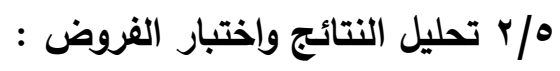

يتتاول الباحث فى هذا الجزء عرض أهم ما أظهرته نتائج التحليل الإحصائى لبيانات الدراسة الميدانية المرتبطة بتحقق مراقب الحسابات من القيمة الحالية كأحد مقاييس القيمة العادلة ، وذلك فيكاتك

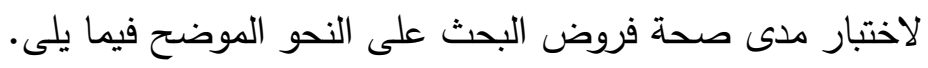

1/\%/ أهمية مجالات المعرفة بنشاط الثركة للتحقق من صحة الافتراضات الهامة:

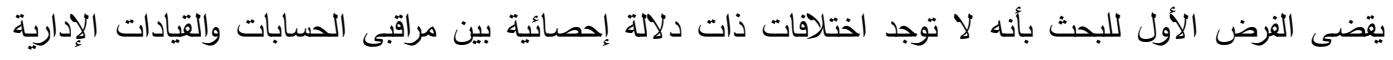

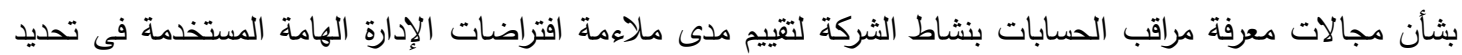
القيمة العادلة .

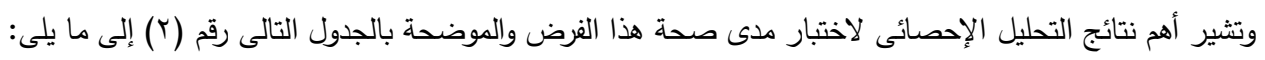

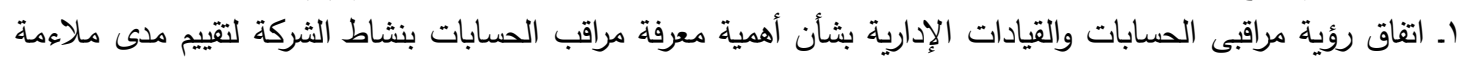

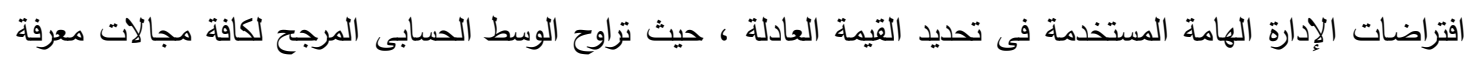

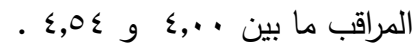

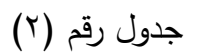

أهمية معرفة مراقب الحسابات بنشاط الثركة للتحقق من الافتراضات الهامة للإدارة

\begin{tabular}{|c|c|c|c|c|}
\hline $\begin{array}{l}\text { اختبار } \\
\text { Discrimin } \\
\text { ant }\end{array}$ & $\begin{array}{l}\text { اختبار } \\
\text { Mann- } \\
\text { Whitne } \\
\text { v }\end{array}$ & \multicolumn{2}{|c|}{ الوسط الحسابى } & \multirow{2}{*}{ من الافتراضات المعرفة بنشاط الثركة لتحادقارة لتقدير التدفقاتب التقات } \\
\hline التجميعية * الارتباط & $\begin{array}{c}\mathrm{P}- \\
\text { value }\end{array}$ & القيادات & الحسابا & \\
\hline
\end{tabular}




\begin{tabular}{|c|c|c|c|c|}
\hline$\cdot, \leqslant \wedge \leqslant(Y)$ & $\cdot, \cdots \wedge$ & $\varepsilon, r \wedge$ & $\{, 0 \leqslant$ & 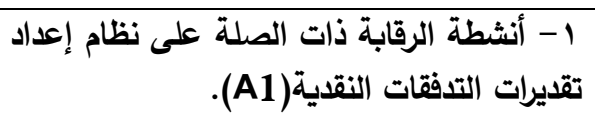 \\
\hline$\cdot, 700(1)$ & $\bullet, \ldots 1$ & $\varepsilon, .0$ & $\{, \leqslant 1$ & 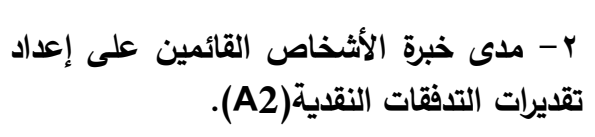 \\
\hline$\cdot, r \cdots(v)$ &.,+71 & $\varepsilon, r$. & $\varepsilon, r V$ & 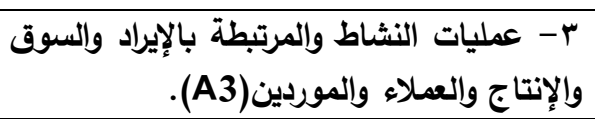 \\
\hline$\cdot, \cdot 0 \cdot(1 \cdot)$ & $\cdot, \varepsilon r$ & $\varepsilon, Y_{0}$ & $\varepsilon, \Upsilon_{\wedge}$ & ـ - توثيق الافتراضات الهامة للإدارة(A4). \\
\hline$\cdot, 1 \cdot 7(\wedge)$ & $\cdot, 000$ & $\varepsilon, 10$ & $\left\{, Y_{1}\right.$ & 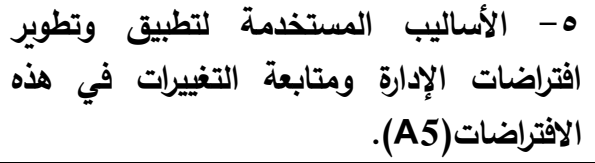 \\
\hline$\cdot, \cdots(11)$ & $\cdot, 9 \vee 7$ & $\varepsilon, \ldots$ & $\varepsilon, \ldots$ & 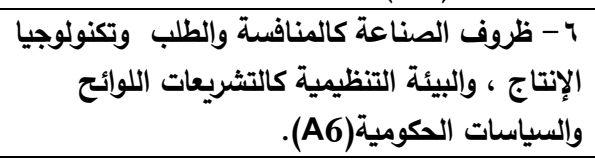 \\
\hline$\cdot, r \cdot r(\Psi)$ &., $1 \leq 7$ & $\varepsilon, 19$ & $\varepsilon, r V$ & 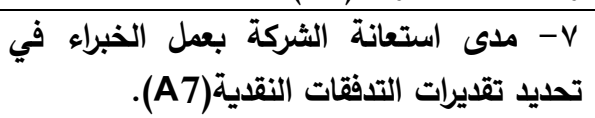 \\
\hline$\cdot, \cdot \wedge \uparrow(9)$ & $\cdot, \leqslant \wedge r$ & $\{, 10$ & $\varepsilon, r$. & 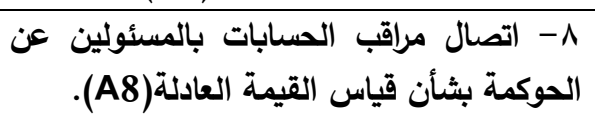 \\
\hline$\cdot, \leqslant \leqslant 9(r)$ & $\cdot, \cdot$, & $\varepsilon, .9$ & \&, o & 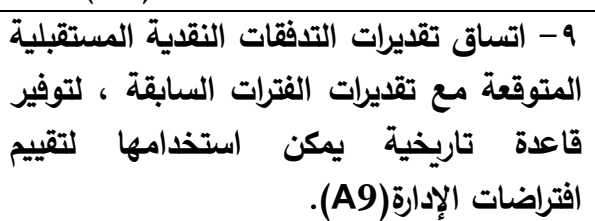 \\
\hline$\cdot, r \vee \vee(0)$ & $\cdot,+\leqslant 0$ & $\varepsilon, 1 V$ & $\varepsilon, r q$ & 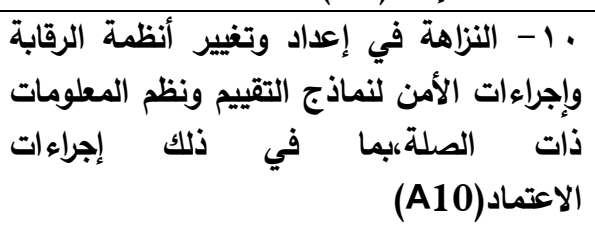 \\
\hline$\cdot, \varepsilon \cdot \wedge(\varepsilon)$ & $\cdot, 117$ & $\varepsilon, r_{0}$ & $\{, £ \wedge$ & 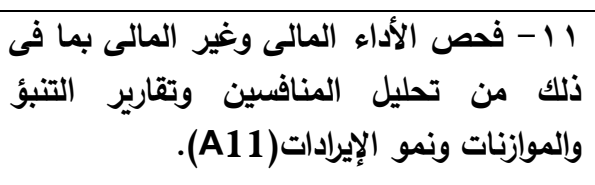 \\
\hline
\end{tabular}

قدرة على التمييز (الاختلاف) بين عينتى الدراسة وفقا للحجم المطلق للارتباط ضمن دالة التمييز. Whitney U

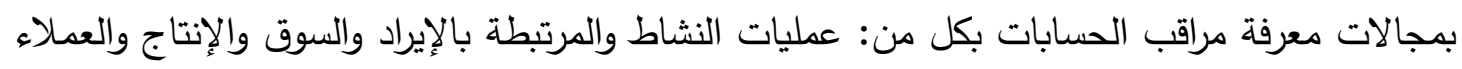

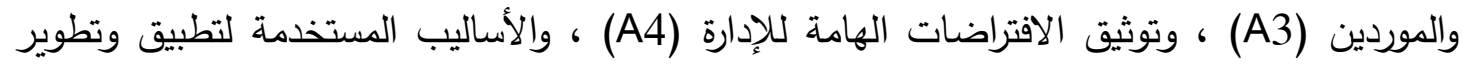
افتراضات الإدارة (A5) ، وظروف الصناعة والبيئة التنظيمية كالمنافسة والطلب وتكنولوجيا الإنتاج

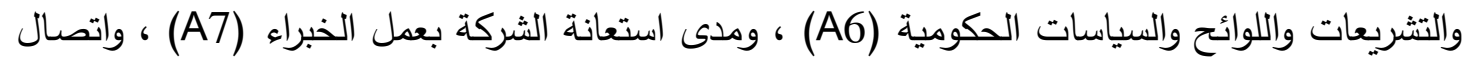

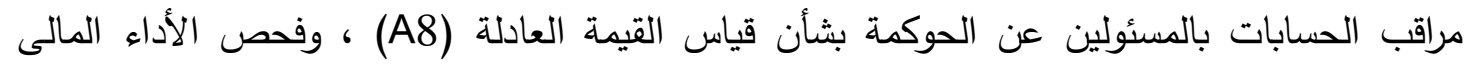


وغير المالى بما فى ذلك من تحليل المنافسين وتقارير التتبؤ والموازنات ونمو الإيرادات (A11) ، حيث

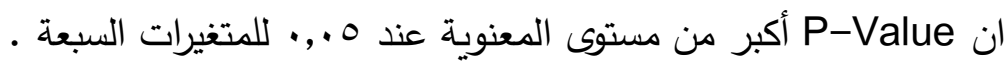

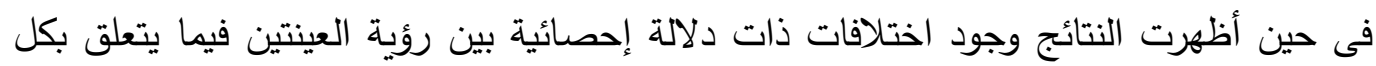

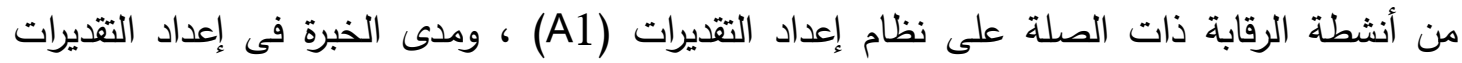

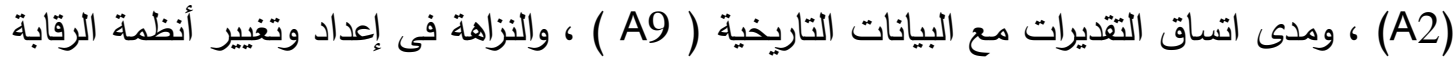

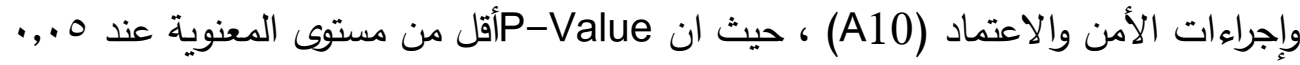

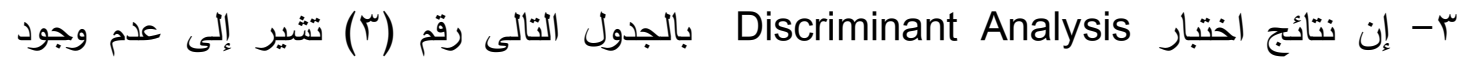
اختلاف متمايز ذات دلالة إحصائية بين عينتى الدراسة بثأن مجالات معرفة مراقب الحسابات بنشاط

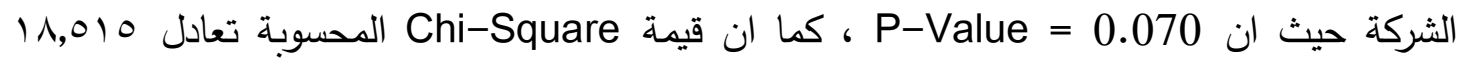

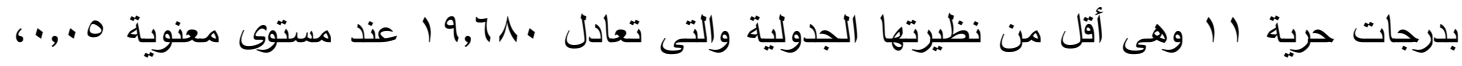

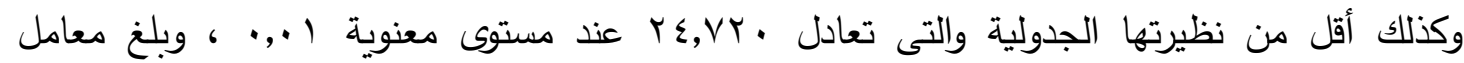

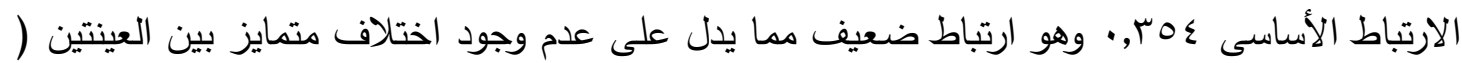

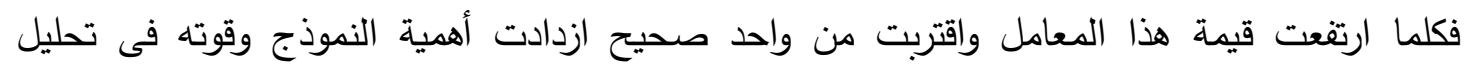

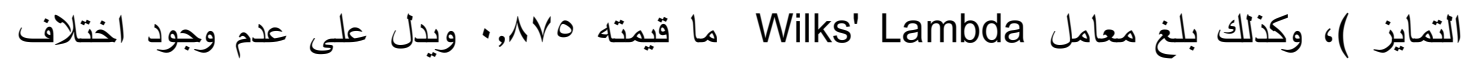

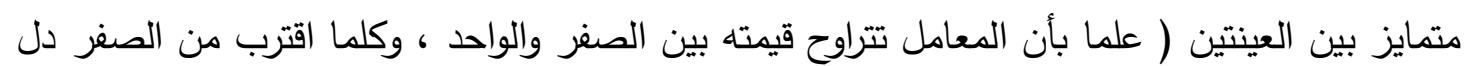

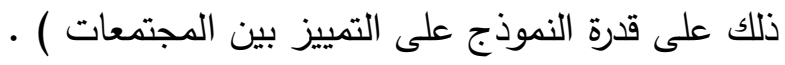

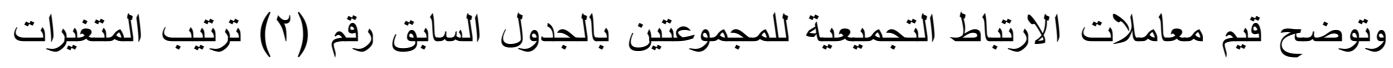

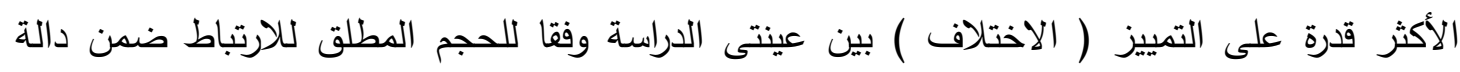

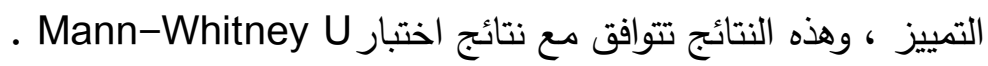

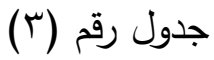

نتائج اختبار تحليل التمايز ( Discriminant Analysis )

\begin{tabular}{|c|c|c|c|c|c|}
\hline $\begin{array}{c}\text { معامل الارتباط الأسساسى (Canonical Correlation } \\
\text { () }\end{array}$ & P-value & DF & Chi-square & $\begin{array}{c}\text { Wilks' معامل } \\
\text { Lambda }\end{array}$ & المتغيرات \\
\hline \& & $\cdot, \cdot \vee$. & 11 & 11,010 & •, A & $\begin{array}{c}\text { A1 - A11 } \\
\text { مجالات معرفة مراقب الحسابات بنشاط الشركة }\end{array}$ \\
\hline r., ror & $\cdot,, . \leqslant 9$ & 1. & $\mid \Lambda, r \Psi V$ & 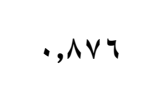 & $\begin{array}{c}\text { B12 - B21 } \\
\text { أسس تقدير التدفقات النقاية }\end{array}$ \\
\hline . & , , & v & $r \cdot, \uparrow \wedge 0$ & ז4 \,. & $\begin{array}{c}\text { C22 - C28 } \\
\text { العناصر الدكونة لتقديرات التدفقات النقدية }\end{array}$ \\
\hline שיז,. & D & 9 & $19, \pi \circ 1$ & .,Av. & $\begin{array}{c}\text { D29 - D37 } \\
\text { مبادئ وعوامل تحيد معدل الخصم }\end{array}$ \\
\hline ו וT, &.,.,$Y r$ & 7 & $17, r \vee A$ &.,$\wedge 9$. & $E 38-E 43$ \\
\hline
\end{tabular}

- Y०1 - 


\begin{tabular}{|c|c|c|c|c|c|}
\hline $\begin{array}{c}\text { معامل الارتباط الأساسىى (Canonical Correlation } \\
\text { ( ) }\end{array}$ & $\mathrm{P}$-value & DF & Chi-square & معامل 'Wambda & المتغيرات \\
\hline & & & & & معدلات الخصم المتاحة \\
\hline
\end{tabular}

وبناءً على ما تقدم ، يتم قبول الفرض الأول للبحث والذى يقضى بأنه لا توجد اختلافات ذات دلالة

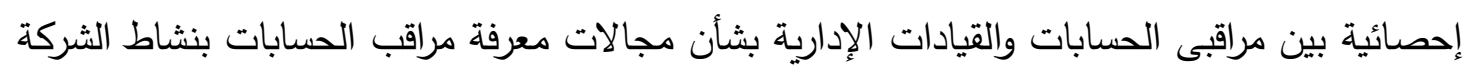

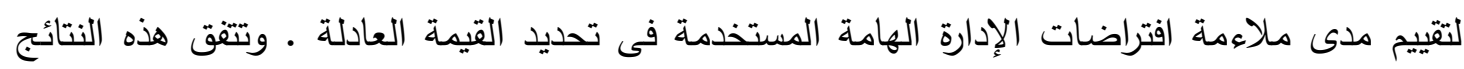
أيضا مع ما أكدته المجالس والمنظمات المهنية والباحثين على أهمية معرفة مراقب الحسابات بنشاط الشركة كأساس للوقوف على مدى صحة الافتراضات الهامة للإدارة فى مجال تقدير التدفقات النقدية المستتبلية .

\section{} يقضى الفرض الثانى للبحث بأنه لا توجد اختلافات ذات دلالة إحصائية بين مراقبى الحسابات والقيادات

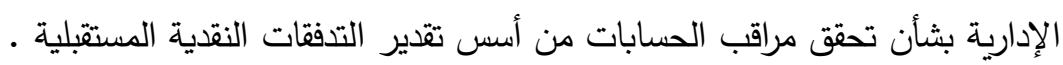

وتثير أهم نتائج التحليل الإحصائى لاختبار مدى صحة هذا الفرض والموضحة بالجدول التالى رقم (ع) إلى ما يلى:

$$
\text { جدول رقم (乏) }
$$

أهمية تحقق مراقب الحسابات من أسس تقدير التدفقات النقدية المستثبلية

\begin{tabular}{|c|c|c|c|c|}
\hline اختبار Discriminant & $\begin{array}{r}\text { اختبار } \\
\text { Mann- }\end{array}$ & \multicolumn{2}{|c|}{ الوسط الحسابى المرجح } & \multirow{2}{*}{$\begin{array}{c}\text { أسس تقدير التدفقات النقدية المستقبلية التى تخضع للتحقق بواسطة مراقب الحسابات }\end{array}$} \\
\hline معاملات الارتباط & P-value & القيادات & مراقبى & \\
\hline$\cdot, 79 \vee(r)$ & $\cdot, \ldots r$ & $\varepsilon, r$. & $\leq, 0 \leqslant$ & 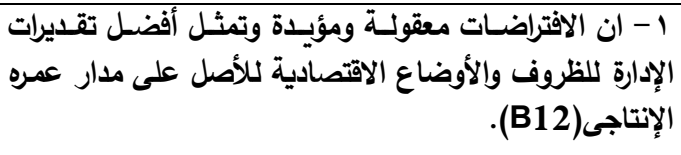 \\
\hline , $V Y \backslash(1)$ & $\cdot, \ldots 1$ & $\varepsilon, Y_{O}$ & $\{, \diamond 9$ & 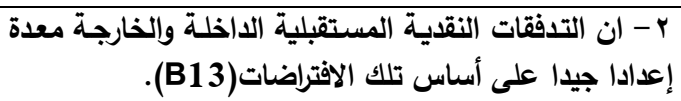 \\
\hline$\cdot, r q \curlyvee(\vee)$ & $\cdot, \cdot \wedge r$ & $\{, \mu$ & $\leq, \leq 4$ & 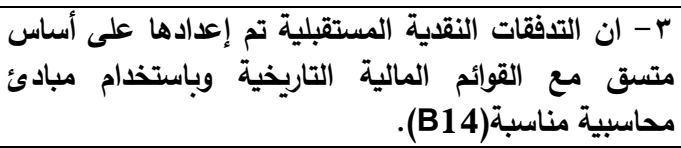 \\
\hline , $r$ rq (q) & $\cdot, r q \leq$ & $\leq, r \leq$ & \&,rv & 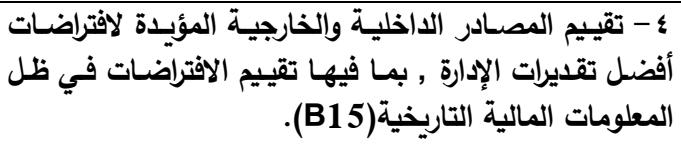 \\
\hline ., $\{01(\xi)$ & $\cdot, 1 \cdot v$ & צ & $\varepsilon, r r$ & 0- تقيـيم مـا إذا كانت الافتراضـات مبنية على خطط يمكن \\
\hline
\end{tabular}




\begin{tabular}{|c|c|c|c|c|}
\hline & & & & للشركة تحقيقها من خلال قراتها المتوفرة(B16). \\
\hline , rav $(0)$ & , , & $\{10$ & $\varepsilon, \Gamma q$ & 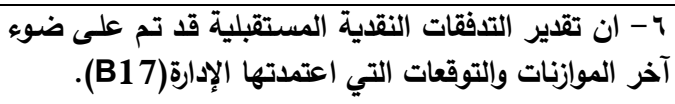 \\
\hline., $01 Y(r)$ & דו +, & $\{, .0$ & $\varepsilon, \Gamma_{0}$ & 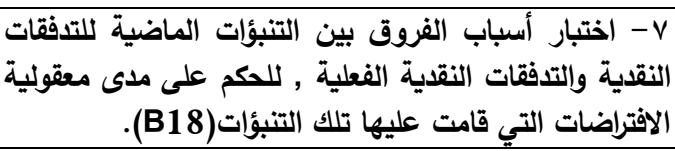 \\
\hline . &., 104 & $\{, \cdot$ & $\varepsilon, r$. & 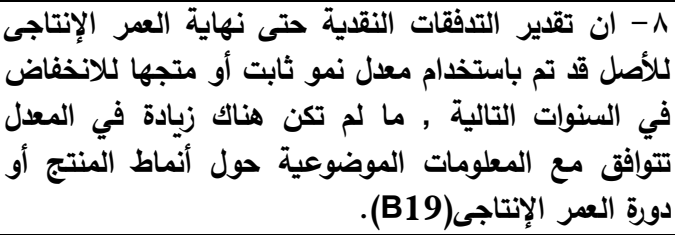 \\
\hline$\cdot, \cdot v \leqslant(1 \cdot)$ & , q4० & \&, & $\{, .4$ & 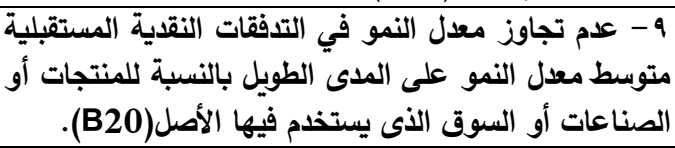 \\
\hline$\cdot, r \circ \Delta(\wedge)$ & $\cdot$ & $\{, \cdot \wedge$ & \& & 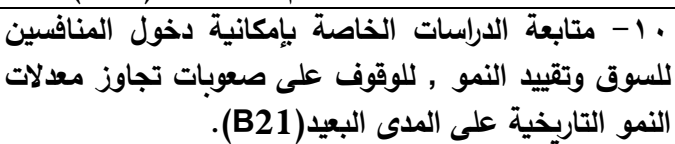 \\
\hline
\end{tabular}

1- اتفاق رؤية عينتى الدراسة بشأن أهمية تحقق مراقب الحسابات من أسس تقدير التدفقات النقدية المستقبلية ،

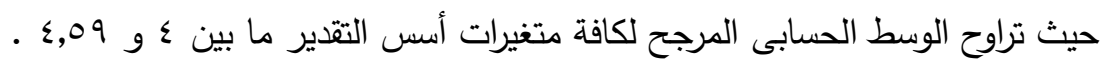
r- إن نتائج اختبارU Mann-Whitney تثير إلى عدم وجود اختلافات ذات دلالمة إحصائية بين رؤية العينتين

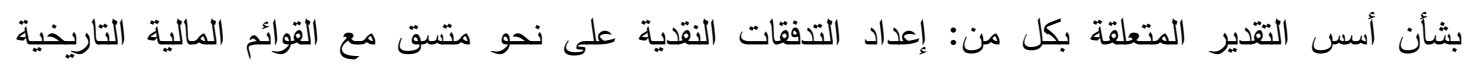
وباستخدام مبادئ محاسبية مناسبة (B14) ، وتتييم المصادر الداخلية والخارجية المؤيدة لافتراضات الإدارة 
(B15) ، وتقييم ما إذا كانت الافتراضات مبنية على خطط مسبقة (B16) ، وأن تقدير التدفقات قد تم باستخدام

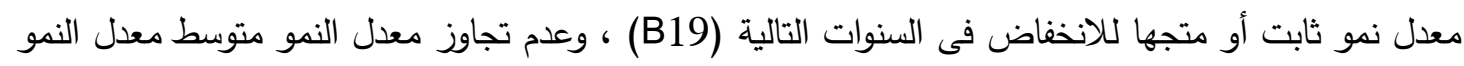
للمنتجات أو الصناعات أو السوق الذى يستخدم فيها الأصل (B20) ، ومتابت متابعة الدراسات الخاصة بإمكانية

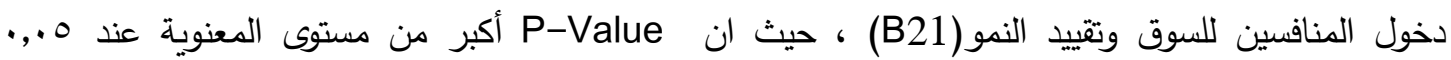
للمتغيرات الستة .

فى حين أظهرت النتائج وجود اختلافات ذات دلالة إحصائية بين رؤية العينتين للمتغيرات

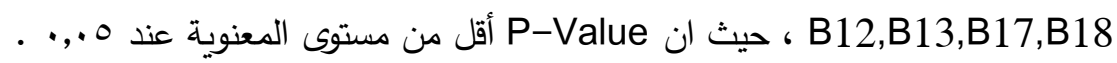
r- إن نتائج اختبار Discriminant Analysis بجدول رقم (ץ) تثير إلى عدم وجود اختلاف متمايز ذات

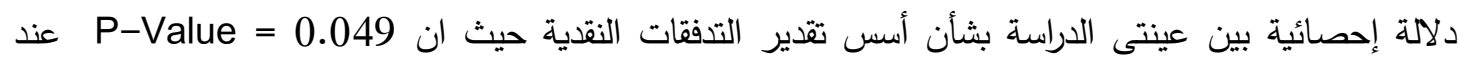

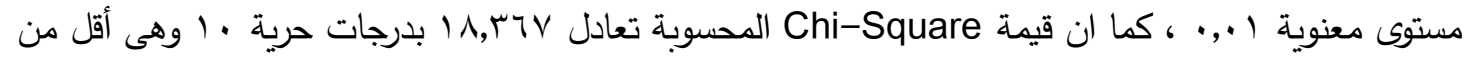

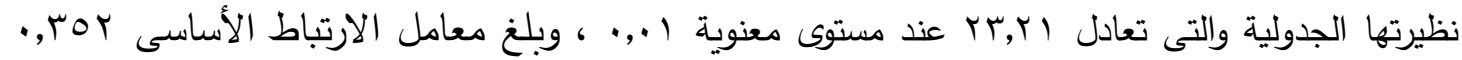

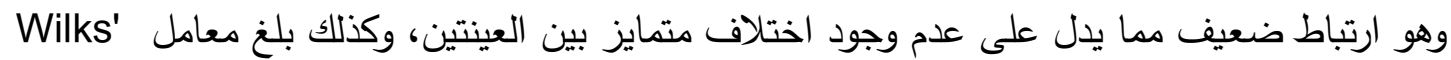
Lambda وتوضح قيم معاملات الارتباط التجميعية للمجموعات بالجدول السابق رقم (ع) ترتيب المتغيرات الأكثر قدرة على التمييز ( الاختلاف ) بين عينات الدراسة وفقا للحجم المطلق للارتباط ضمن دالة

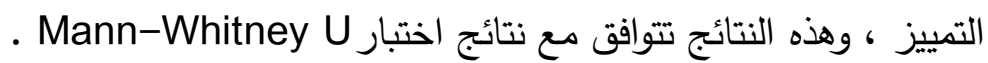
وبناءً على ما تقدم ، يتم قبول الفرض الثانى للبحث والذى يقضى بأنه لا توجد اختلافات ذات دلالة إحصائية بين مراقبى الحسابات والقيادات الإدارية بشأن تحقق مراقب الحسابات من أسس تقدير التدفقات النقدية

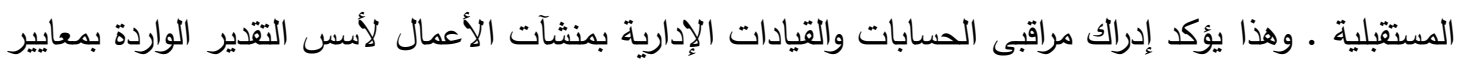

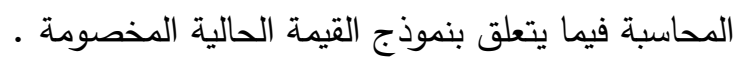

/ r/ أهمية تحقق مراقب الحسابات من سلامة العناصر المكونة لتقديرات التدفقات النقدية المستقبلية: يقضى الفرض الثالث للبحث بأنه لا توجد اختلافات ذات دلالة إحصائية بين مراقبى الحسابات والقيادات الإدارية بشأن تحقق مراقب الحسابات من العناصر المكونة لتقديرات التدفقات النقدية المستقبلية .

وتثير أهم نتائج التحليل الإحصائى لاختبار مدى صحة هذا الفرض والموضحة بالجدول التالى رقم (0) إلى ما يلى: اـ اتفاق رؤية عينتى الدراسة بشأن أهمية تحقق مراقب الحسابات من العناصر المكونة لتقديرات التدفقات النقدية المستقبلية ، حيث تراوح الوسط الحسابى المرجح لكافة متغيرات العناصر المكونة لتقديرات التدفقات ما بين ^V, و و عـ,ـ . r- إن نتائج اختبار Uann-Whitney U تشير إلى عدم وجود اختلافات ذات دلالة إحصائية بين رؤية العينتين على أن منهج القيمة الحالية المتوقعة والمبنى على استخدام الاحتمالات يعد أداة قياس أكثر 
فعالية من منهج القيمة الحالية التقليدية والمبنى على وضع تقدير وحيد لكل من التدفقات النقدية ومعدل أو سعر الخصم (C22) ، وأن صافى التدفقات النقدية المتوقع تحصيلها لبيع الأصل فى نهاية وحئ عمره

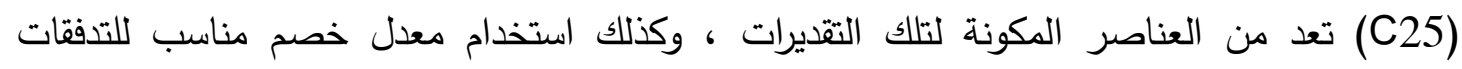

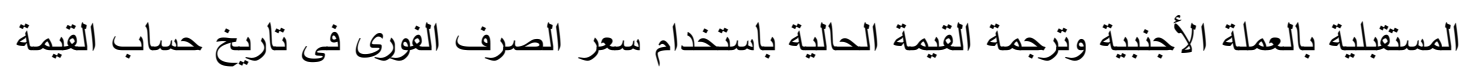

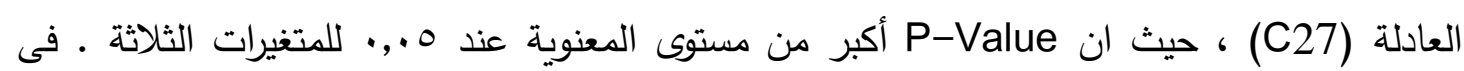

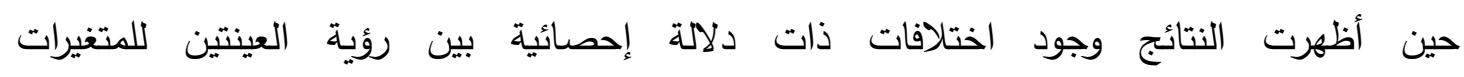

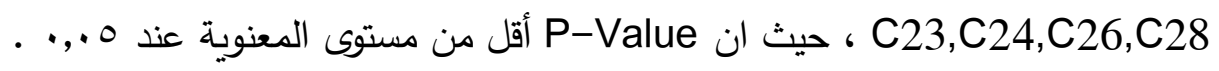

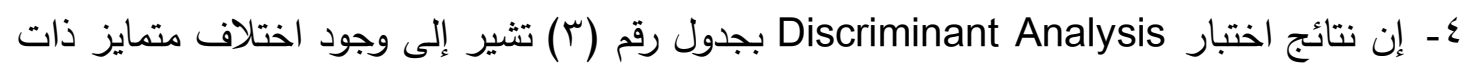

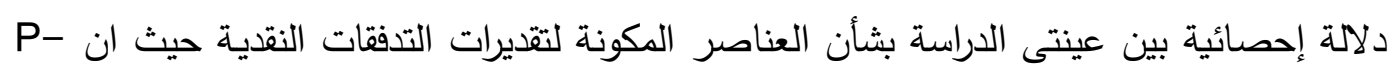
V Value = 0.004

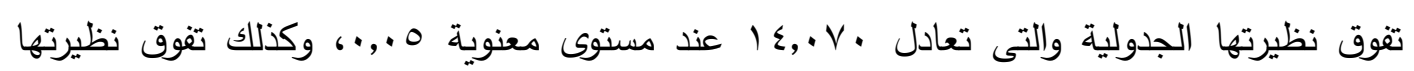

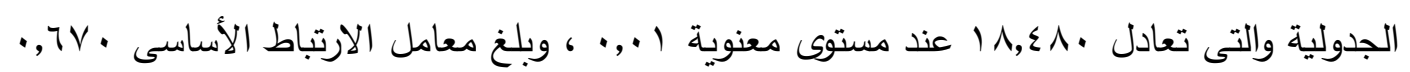

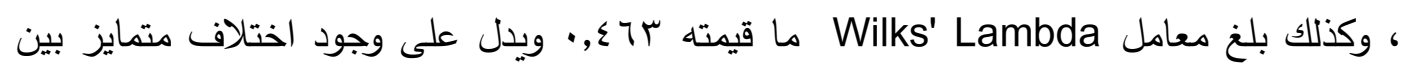

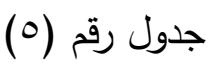

\begin{tabular}{|c|c|c|c|c|}
\hline $\begin{array}{l}\text { اختبار } \\
\text { Discriminant } \\
\text { Analysis }\end{array}$ & $\begin{array}{l}\text { اختبار } \\
\text { Mann- } \\
\text { Whitney }\end{array}$ & \multicolumn{2}{|c|}{ الوسط الحسابى } & العناصر المكمنة لتقديرات التدفقات النقدية المستقلية \\
\hline معاملات الارتباط & P-value & 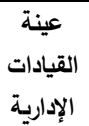 & ع عراقبيى & التى تخضع للتحقق بواسطة مراقب الحسابات \\
\hline$[, r v(v)$ & ,919 & $\{, 10$ & $\{, \mid V$ & 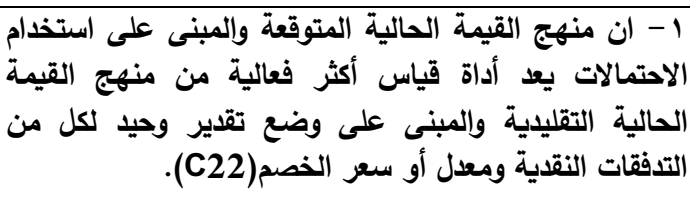 \\
\hline . &,$\ldots$ & $\varepsilon, Y$. & $\{, \S \wedge$ & 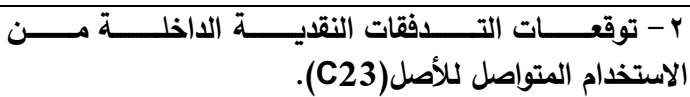 \\
\hline (י), &,,$\cdots$ & $\{, 1 T$ & $\{, 0 \leqslant$ & 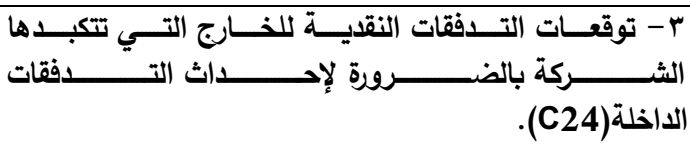 \\
\hline , & .,.94 & \&, & $\varepsilon, r Y$ & 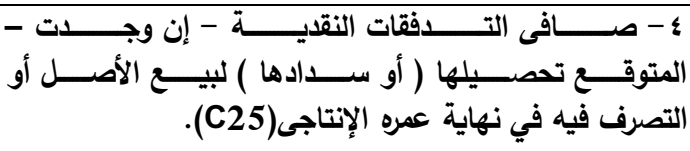 \\
\hline
\end{tabular}




\begin{tabular}{|c|c|c|c|c|}
\hline (צ) צד \&,. & , & $\{, \ldots$ & \&,YV & 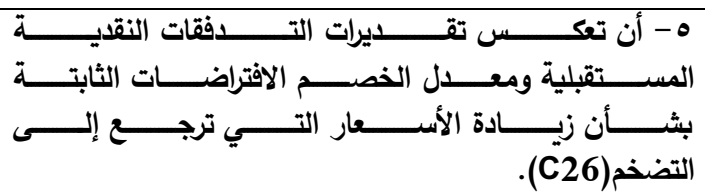 \\
\hline (ע) & . FYY & $\{, .9$ & $\{, Y$ & 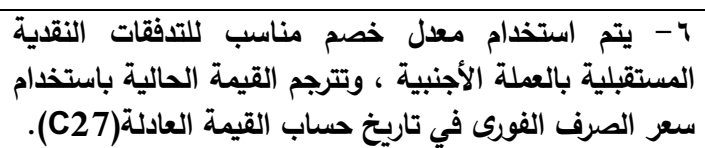 \\
\hline ,OVA(T) & ז.,., & $r, \wedge v$ & \&, & 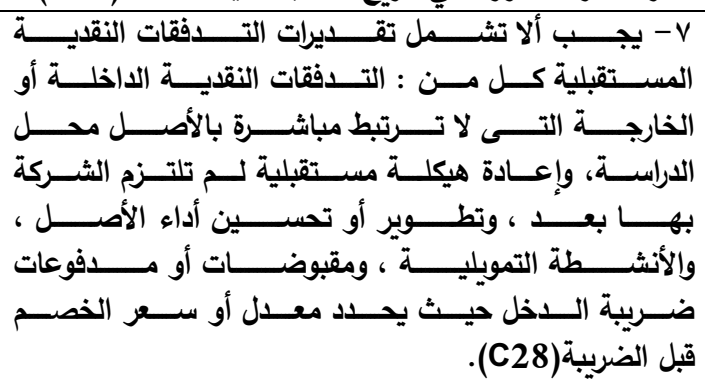 \\
\hline
\end{tabular}

أهمية تحقق مراقب الحسابات من سلامة العناصر المكونة لتقديرات التدفقات النقدية المستقبلية وتوضح قيم معاملات الارتباط التجميعية للمجموعات بالجدول السابق رقم (0) ترتيب المتغيرات الأكثر قدرة على التمييز ( الاختلاف ) بين عينتى الدراسة وفقا للحجم المطلق للارتباط ضمن دالة التمييز ،

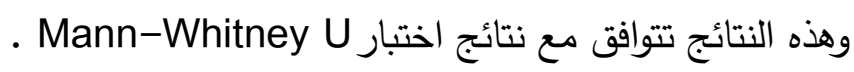
وبناءً على ما تقدم ، يتم رفض الفرض الثالث للبحث ( فرض العدم ) وقبول الفرض البديل والذى يقضى بوجود اختلافات ذات دلالة إحصائية بين مراقبى الحسابات والقيادات الإدارية بشأن تحقق مراقب الحسابات من العناصر المكونة لتقديرات التدفقات النقدية المستقبلية ـ ومع ذلك يمكن قبول فرض العدم حيث لا توجد اختلافات ذات دلالة إحصائية بين المراقبين والقيادات الإدارية فى ضوء نتـائج اختبار . C22,C25,C27 لثلاث متغيرات مأخوذة بصورة منفردة وهى Mann-Whitney U 
ويتضح للباحث مما تقدم ، أنه على الرغم من الأهمية النسبية للمتغيرات C23,C24,C26,C28

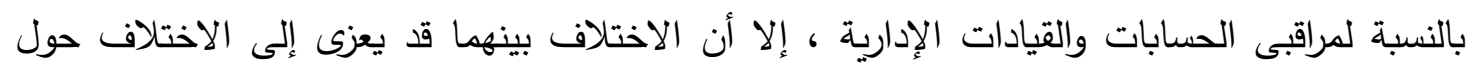

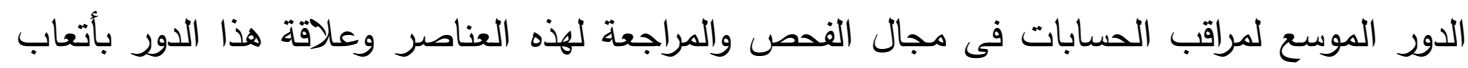

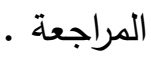

/ أه/ / أهية تحقق مراقب الحسابات من المبادئ والعوامل المؤثرة فى تحديد معدل خصم التدفقات

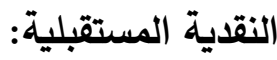
يقضى الفرض الرابع للبحث بأنه لا توجد اختلافات ذات دلالة إحصائية بين مراقبى الحسابات

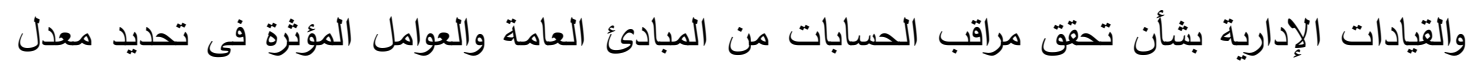
خصم التدفقات النقدية المستقبلية . وتثير أهم نتائج التحليل الإحصائى لاختبار مدى صحة هذا الفرض والموضحة بالجدول التالى

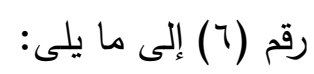

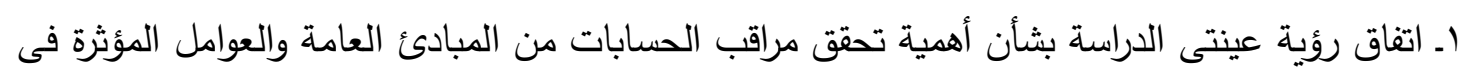

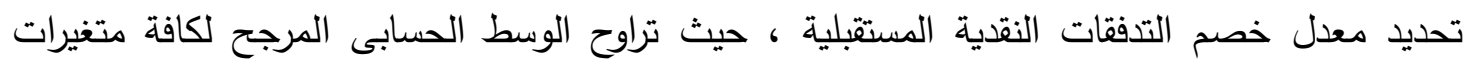

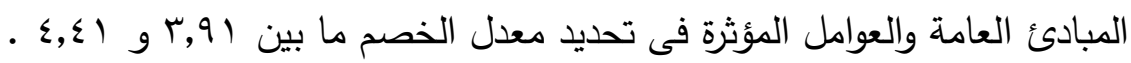

جدول رقم (T)

أهمية تحقق مراقب الحسابات من المبادئ والعوامل المؤثرة فى تحديد معدل خصم التدفقات

\begin{tabular}{|c|c|c|c|c|}
\hline $\begin{array}{l}\text { اختبار } \\
\text { Discriminant } \\
\text { Analysis }\end{array}$ & $\begin{array}{l}\text { اختبار } \\
\text { Mann- } \\
\text { Whitney }\end{array}$ & \multicolumn{2}{|c|}{ الوسط الحسابى } & التبفقات النق العامة والعوامل المؤثرة فى تحديد معدل خصم \\
\hline معاملات الارتباط & P-value & القائادات & مراقبى & مرادب الحسمب \\
\hline (0) & $\cdot, r \circ r$ & \&,17 & צ & 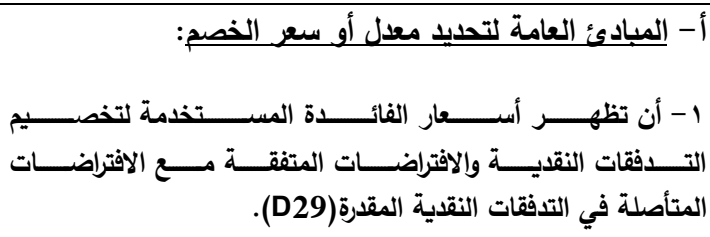 \\
\hline , $\leqslant \Psi \vee(Y)$ & .,. rq & $£, \cdot V$ & T & 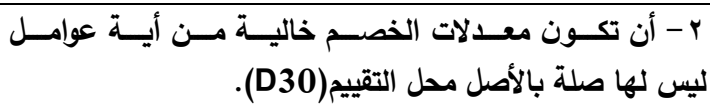 \\
\hline,,$r \mid \odot(\xi)$ & r & $\varepsilon, . r$ & $\varepsilon, 10$ & 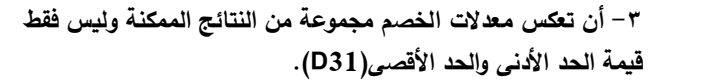 \\
\hline
\end{tabular}




\begin{tabular}{|c|c|c|c|c|}
\hline$\cdot, 0 \cdot r(1)$ &,., 11 & $£, . \wedge$ & \&, « & 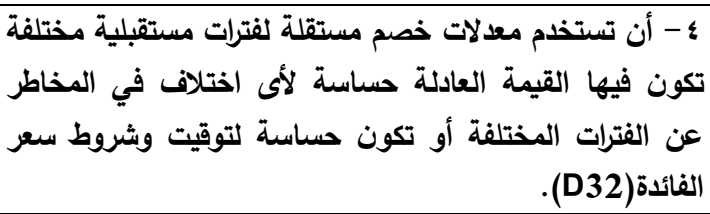 \\
\hline$\cdot, r Y r(r)$ & . YY. & $\varepsilon, .9$ & \&, & 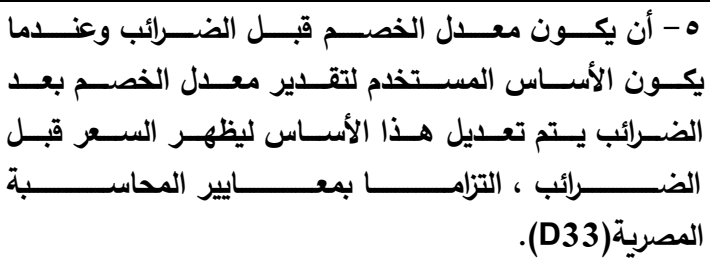 \\
\hline$, r, r \leq \neg(\xi)$ &., $.0 \mathrm{~V}$ & $\{, 19$ & $\{, r v$ & ب- بل العوامل المؤثثة في تقدير معدل الخصد: الزمنية للنقود للفترات حتى نهاية العمر الإنتاجى \\
\hline$\cdot, V Y \bullet(r)$ & $\cdot, \ldots 1$ & $r, q 4$ & ؟ & 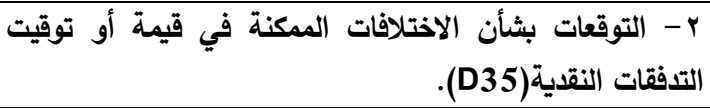 \\
\hline$\cdot, \vee \wedge \cdot(1)$ & , , . & r,q & \&,rq & r- مقابل تحمل درجة عدم التأكد المتأصلة فى الأصل(D36). \\
\hline$\cdot, 0 v \cdot(r)$ &.,$\ldots 7$ & $r, q 1$ & $\varepsilon, Y V$ & ـ - عدم قابلية تسييل الأصل(D37). \\
\hline
\end{tabular}

r- إن نتائج اختبار Mann-Whitney Uثير إلى عدم وجود اختلافات ذات دلالة إحصائية بين رؤية العينتين فيما يتعلق ببعض المبادئ العامة لتحديد معدل الخصم وهى: أن تظهر أسعار الفائدة المستخدمة لتخصيم التدفقات النقدية والافتراضات المتفقة مع الافتراضات المتأصلة في التدفقات النقدية 
(D29) ، و أن تعكس معدلات الخصم مجموعة من النتائج الممكنة وليس فقط قيمة الحد الأدنى والحد الأقصى (D31) ، و أن يكون معدل الخصم قبل الضرائب وعندما يكون الأساس المستخدم لتقدير معدل الخصم بعد الضرائب يتم تعديل هذا الأساس ليظهر المعدل قبل الضرائب التزاما بمعايير المحاسبة المصرية (D33) ، حيث ان P-Value) أكبر من مستوى المعنوية عند ه.,. • للمتغيرات الثلاثة ـ

كما أظهرت النتائج عدم وجود اختلافات ذات دلالة إحصائية بشأن أحد العوامل المؤثرة فى تحديد

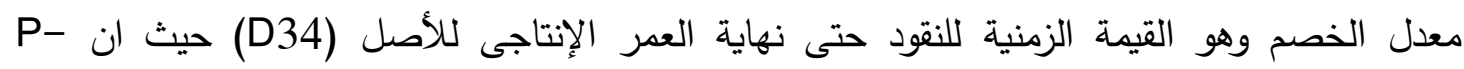
. Value $=0.057$

فى حين أظهرت النتائج وجود اختلافات ذات دلالة إحصائية بين رؤية العينتين للمتغيرات

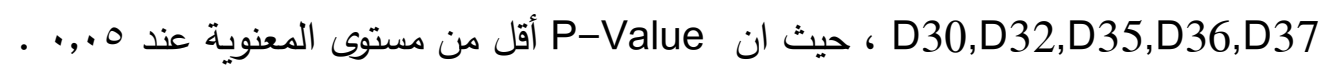
r- إن نتائج اختبار Discriminant Analysis بجدول رقم (r) تشير إلى عدم وجود اختلاف متمايز ذات دلالة إحصائية بين عينتى الدراسة بشأن المبادئ العامة والعوامل المؤثرة فى تحديد معدل خصم

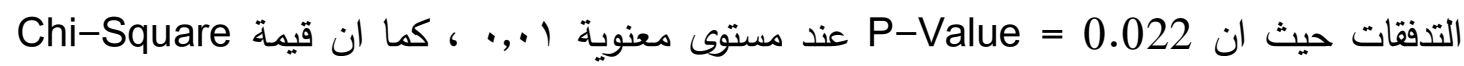

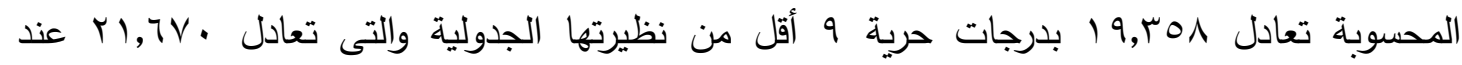

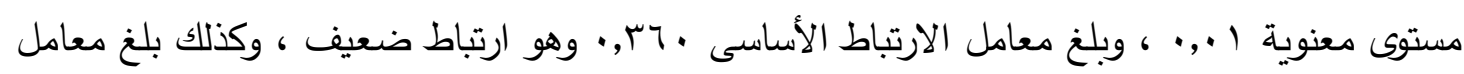
ما قيمته • WVilks' Lambda وتوضح قيم معاملات الارتباط التجميعية للمجموعات بالجدول السابق رقم (؟) ترتيب المتغيرات

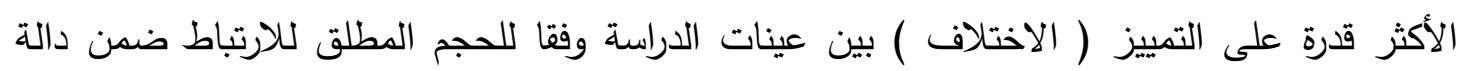

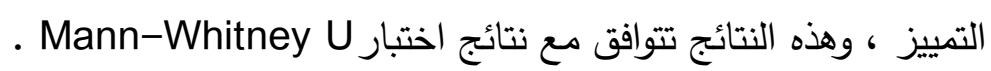

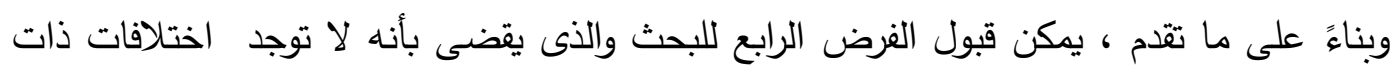

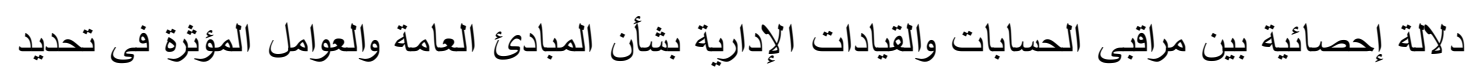
معدل خصم التدفقات النقدية المستقبلية .

إ/ / / أهمية تحقق مراقب الحسابات من صحة وسلامة المعدل المستخدم فى خصم التدفقات النقدية المستقبلية: يقضى الفرض الخامس للبحث بأنه لا توجد اختلافات ذات دلالة إحصائية بين مراقبى الحسابات والقيادات الإدارية بشأن تحقق مراقب الحسابات من معدل الخصم المستخدم فى تحديد القيمة الحالية للتدفقات النقدية المستقبلية . 
وتثير أهم نتائج التحليل الإحصائى لاختبار مدى صحة هذا الفرض والموضحة بالجدول التالى

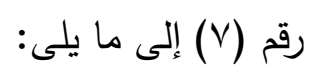

اــ اتفاق رؤية عينتى الدراسة بشأن أهمية تحقق مراقب الحسابات من صحة وسلامة المعدل المستخدم

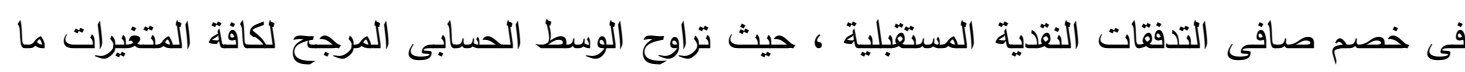

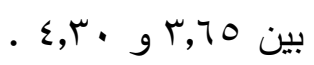

r- إن نتائج اختبار Uann-Whitney U تثير إلى عدم وجود اختلافات ذات دلالة إحصائية بين رؤية العينتين فيما يتعلق ببعض بدائل اختيار معدل أو سعر خصم صافى التدفقات النقدية وهى: أ- متوسط التكلفة المرجحة لرأس المال للشركة والمحددة باستخدام نموذج تسعير الأصل الرأسمالى دمعلى

$$
\text { . P-Value = } 0.109 \text { (E38) }
$$

ب - معدل خصم إسلامى للتدفقات النقدية مبنى على المتوسط المرجح لتكلفة الاستثار في الصكوك

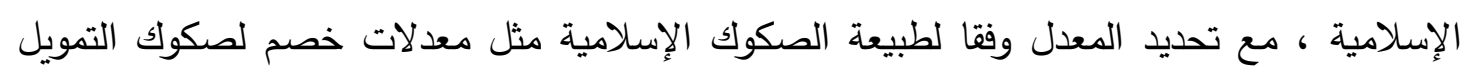

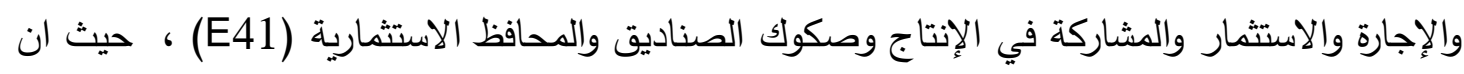

$$
\text { .P-Value = } 0.139
$$

ج - معدل خصم إسلامى للتدفقات النقدية مبنى على المتوسط المرجح لمعدل عوائد الاستثمارات المثيلة

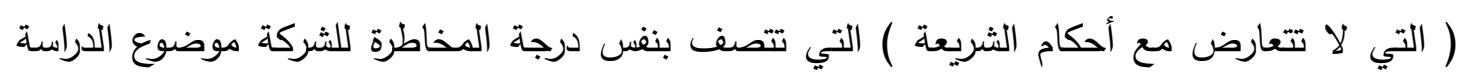

$$
\text { . P-Value = حيث ان (E42) }
$$

بينما أظهرت النتائج وجود اختلافات ذات دلاتلة إحصائية بين رؤية العينتين للمتغيرات

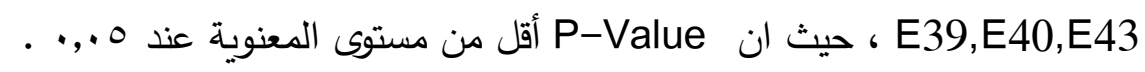

جدول رقم (v)

أهية تحقق مراقب الحسابات من صحة وسلامة المعدل المستخدم فى خصم صافى التدفقات النقدية

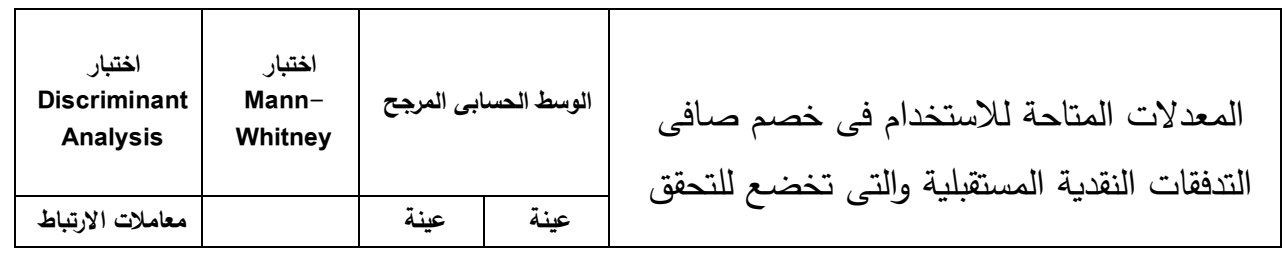




\begin{tabular}{|c|c|c|c|c|}
\hline التجميعية & P-value & الإلاريادية & الحسابات & بواسطة مراقب الحسابات \\
\hline ., $\leqslant \leqslant \backslash(\xi)$ &., 1.9 & $r, \wedge 0$ & $\{, 1$. & 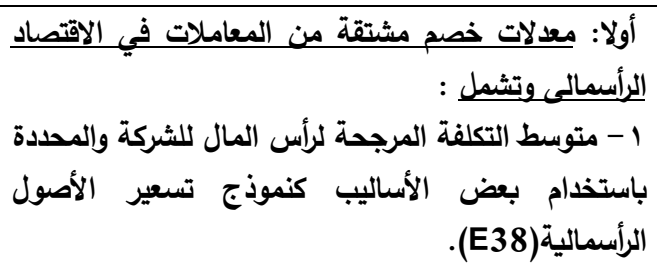 \\
\hline ) & $\ldots$ & r,vq & \&, IV & r - سعر الاقتراض المتزايد للشركة(E39). \\
\hline , AAr( (') & , , . & $r, v \vee$ & $\varepsilon, r$. & r- أسعار الاقتراض السائدة فى السوق(E40). \\
\hline , & a & r, & $r, \wedge v$ & 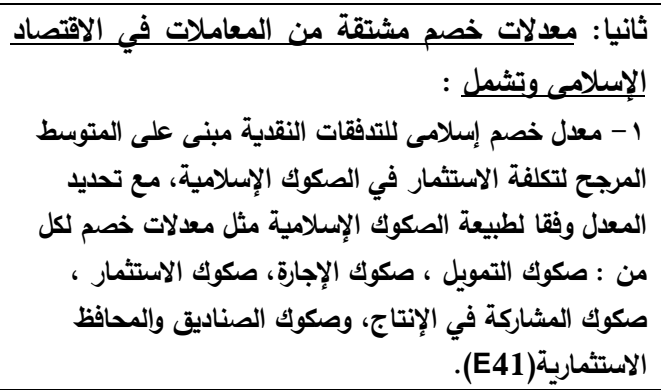 \\
\hline., $819(0)$ & $\cdot, .91$ & $r, v_{1}$ & r,94 & 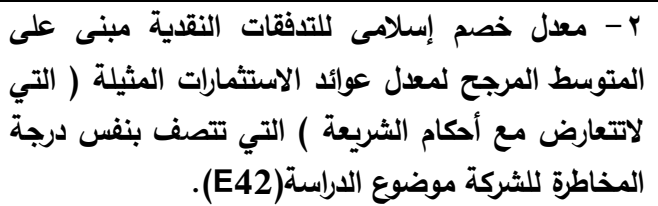 \\
\hline 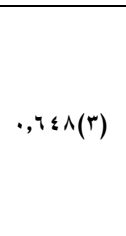 & .,..9 & r, ro & $\{, \cdot r$ & 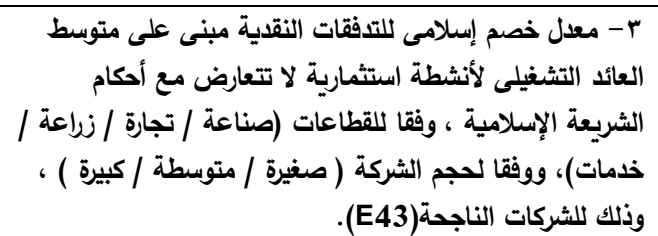 \\
\hline
\end{tabular}

ب- إن نتائج اختبار Discriminant Analysis بجدول رقم (r) تثير إلى عدم وجود اختلاف متمايز ذات دلالة إحصائية بين عينتى الدراسة بشأن بدائل اختيار المعدل المستخدم فى خصم صافى التدفقات

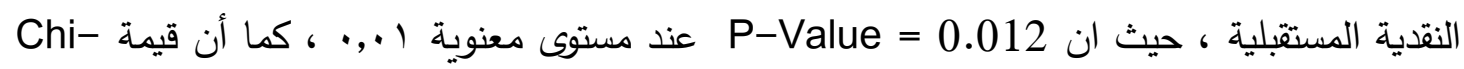

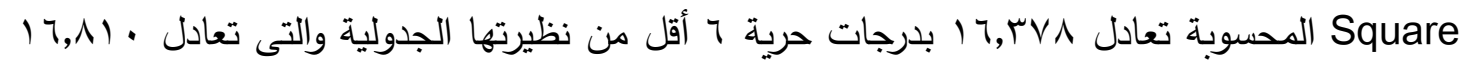

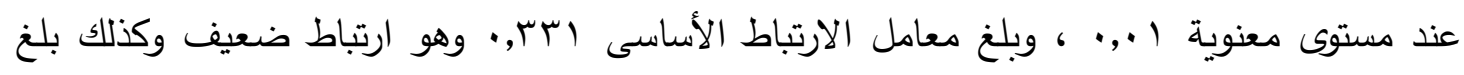
معامل Wilks' Lambda ما قيمته . 9.,. • مما يدل على عدم وجود اختلاف متمايز بين العينتين. 
وتوضح قيم معاملات الارتباط التجميعية للمجموعات بالجدول السابق رقم (V) ترتيب المتغيرات

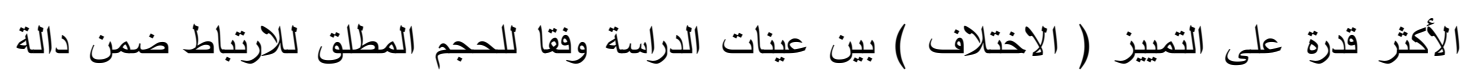

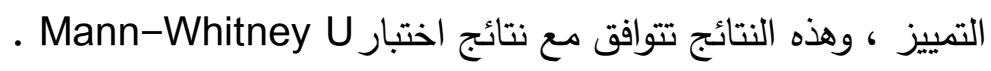

وبناءً على ما تقدم ، يمكن قبول الفرض الخامس للبحث والذى يقضى بأنه لاتوجد اختلافات ذات

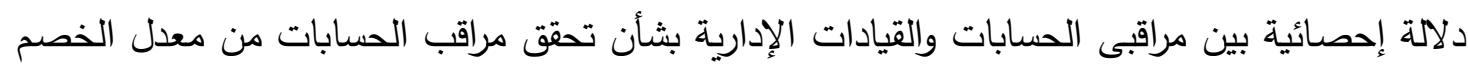

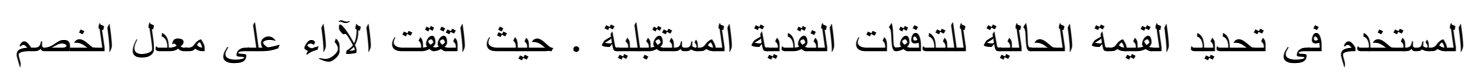

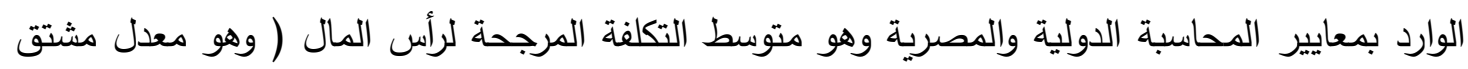

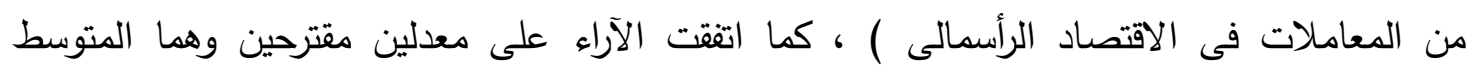

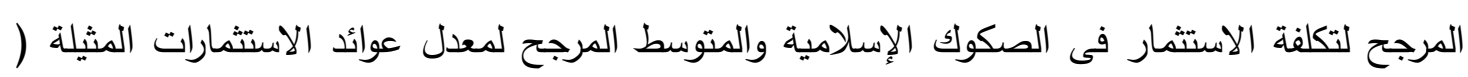
وهما من المعدلات المشتقة من المعاملات فى الاقتصاد الإسلامى ).

وبناء على ما قدمته هذه الدراسة بجانبيها النظرى والميدانى بثأن إمكانية مراجعة القيمة الحالية

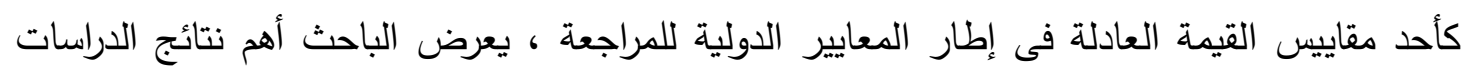

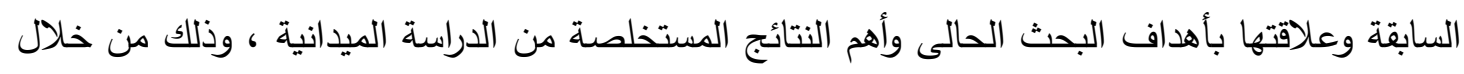
الثكل التالى :

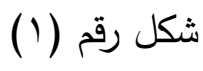


علاقة نتائج الدراسات السابقة بأهداف البحث ونتائج الدراسة الميدانية

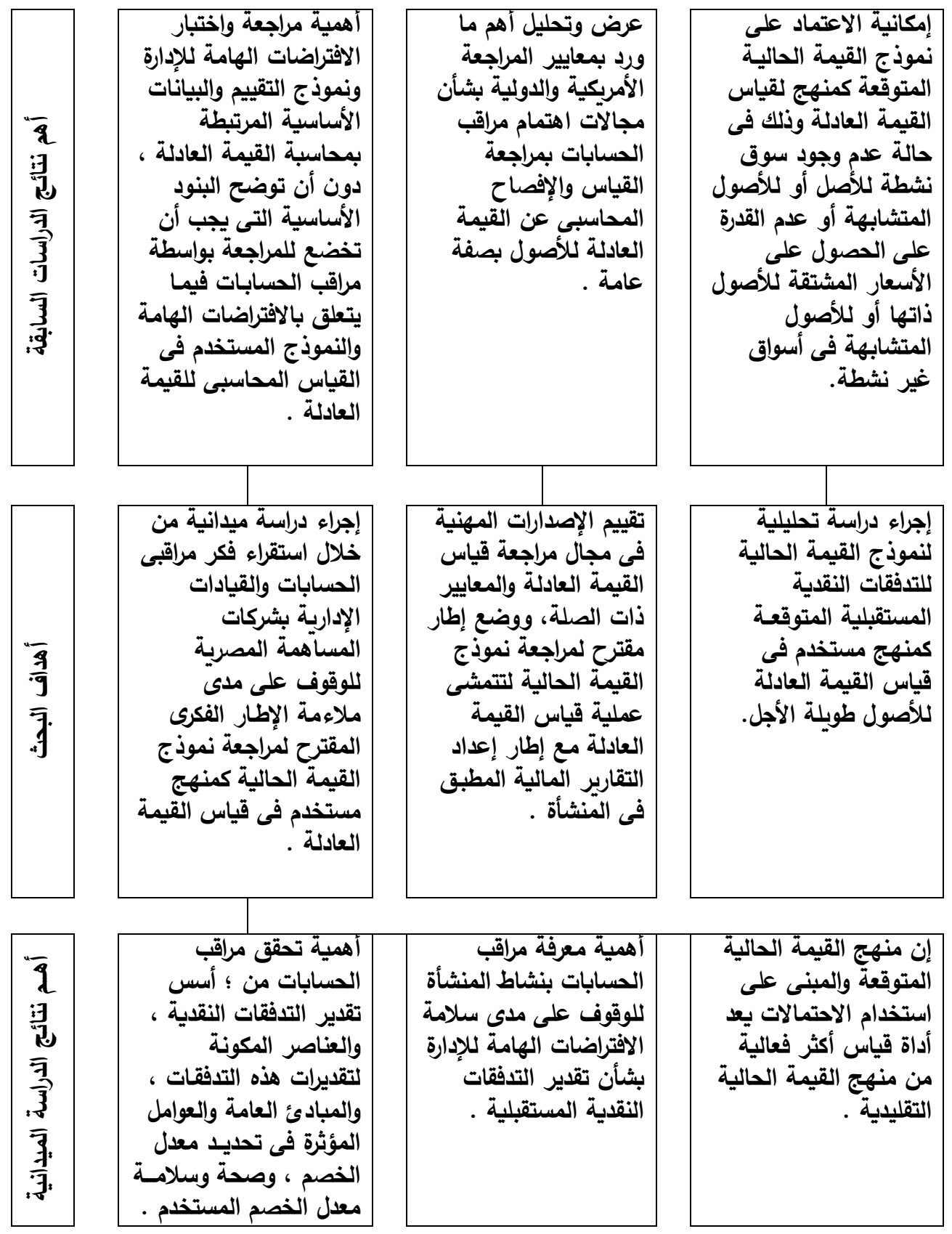

سادسا : نتائج وتوصيات البحث 
خلصت الدراسة إلى العديد من النتائج المرتبطة بالدراسة الميدانية واختبارات الفروض وعدد من التوصيات يوجزها الباحث على النحو التالى : 1/ 1/ نتائج البحث :

يمكن للباحث عرض أهم النتائج المرتبطة بالدراسة الميدانية واختبار فروض البحث على النحو التالى : 1- أهمية معرفة مراقب الحسابات بنشاط المنثأة للوقوف على مدى سلامة الافتراضات الهامة للإدارة

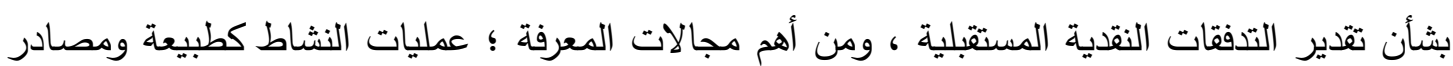
الإيراد وظروف السوق وإدارة العمليات الإنتاجية والعملاء الرئيسيين والموردين الهامين ، وتوثيق الافتراضات الهامة للإدارة ، والأساليب المستخدمة لتطبيق وتطوير الافتراضات ، وظروف الصناعة

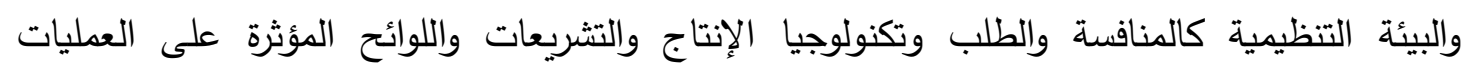
الإنتاجية والسياسات الحكومية المؤثرة على أنشطة المنشأة ، ومدى استعانة الشركة بعمل الخبراء ، وتواصل مراقب الحسابات مع المسئولين عن الحوكمة بثأن قياس القيمة العادلة ، وفحص الأداء المالى له وغير المالى بما فى ذلك من تحليل المنافسين وتقارير التنبؤ والموازنات ونمو الإيرادات ץ- أهمية تحقق مراقب الحسابات من أسس تقدير التدفقات النقدية المستقبلية وتشمل ؛ إعداد التدفقات النقدية على نحو متسق مع القوائم المالية التاريخية وباستخدام مبادئ محاسبية مناسبة ، وتقييم المصادر الداخلية والخارجية المؤيدة لافتراضات الإدارة ، وتقييم ما إذا كانت الافتراضات مبنية على خطط مسبقة ، وان تقدير التدفقات قد تم باستخدام معدل نمو ثابت أو متجها للانخفاض فى السنوات التالية ، وعدم التهات تجاوز معدل النمو متوسط معدل النمو للمنتجات أو الصناعات أو السوق الذى يستخدم فيه الأصل ، ومتابعة الدراسات الخاصة بإمكانية دخول المنافسين للسوق وتقييد النمو • ז- إن منهج القيمة الحالية المتوقعة والمبنى على استخدام الاحتمالات يعد أداة قياس أكثر فعالية من منهج القيمة الحالية التقليدية والمبنى على وضع تقدير وحيد لكل من التدفقات النقدية ومعدل أو سعر الخصم

ع - إن صافى التدفقات النقدية المتوقع تحصيلها من بيع الأصل أو التصرف فيه فى نهاية عمره الإنتاجى ، وكذلك استخدام معدل خصم مناسب للتدفقات النقدية المستقبلية بالعملة الأجنبية وترجمة القيمة الحالية باستخدام سعر الصرف الفورى فى تاريخ حساب القيمة العادلة ، يعدان من أهم العناصر التى يجب ان تخضع للفحص بواسطة مراقب الحسابات .

ه- أهمية تحقق مراقب الحسابات من المبادئ العامة لتحديد معدل أو سعر خصم التدفقات النقدية المستقبلية ، وتثمل أهم هذه المبادئ ما يلى: هربئ 
- أن تظهر أسعار الفائدة المستخدمة لتخصيم التدفقات النقدية والافتراضات المتفقة مع الافتراضات المتأصلة في التدفقات النقدية . أنعان - أن تعكس معدلات الخصم مجموعة من النتائج الممكنة وليس فقط قيمة الحد الأدنى والحد الأقصى

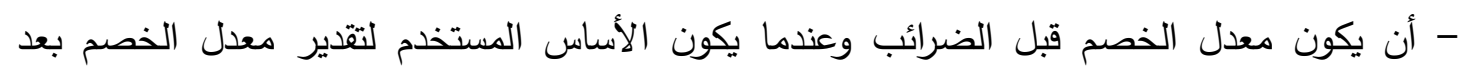
الضرائب يتم تعديل هذا الأساس ليظهر المعدل أو السعر قبل الضرائب التزاما بمعايير المحاسبة المصرية .

؟- إن القيمة الزمنية للنقود للفترات حتى نهاية العمر الإنتاجى للأصل تعد من أهم العوامل المؤثرة فى تحديد معدل خصم صافى التدفقات النقدية المستقبلية ، والتى يجب ان تكون محل دراسة وفحص الإس بواسطة مراقب الحسابات .

V- أهمية تحقق مراقب الحسابات من معدل خصم صافى التدفقات النقدية المستقبلية، والذى يؤثر بشكل مباشر على استتاج القيمة الحالية لتلك التدفقات ، ومن بين معدلات الخصم التى اتفق عليها مراقبى الحسابات والقيادات الإدارية بشأن إمكانية استخدامها ما يلى:

- متوسط التكلفة المرجحة لرأس المال للمنشأة والمحدة باستخدام نموذج تسعير الأصل الرأسمالى ـ

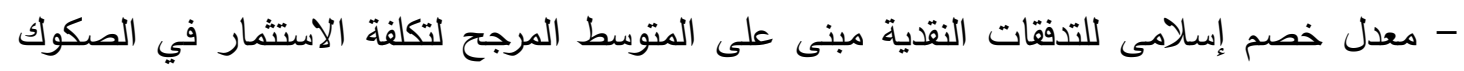
الإسلامية ، مع تحديد المعدل وفقا لطبيعة الصكوك الإسلامية مثل معدلات خصم لصكوك التمويل

والإجارة والاستثمار والمشاركة في الإنتاج وصكوك الصناديق والمحافظ الاستثمارية .

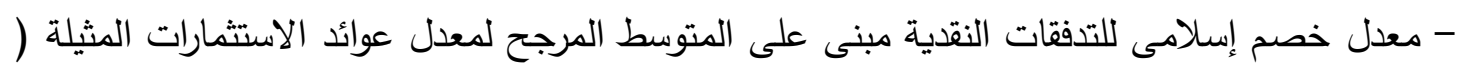
التي لا تتعارض مع أحكام الثريعة ) التي تتصف بنفس درجة المخاطرة للمنشأة موضوع الدراسة .

\section{: r/r توصيات البحث}

بناءً على ما ورد بنتائج البحث ، يرى الباحث أن بيئة الأعمال المصرية فى حاجة إلى إصدار معيار

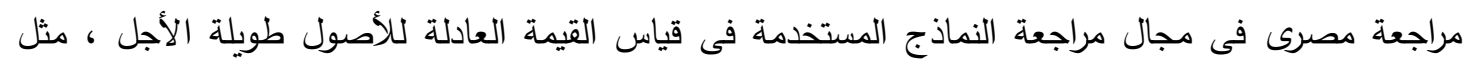

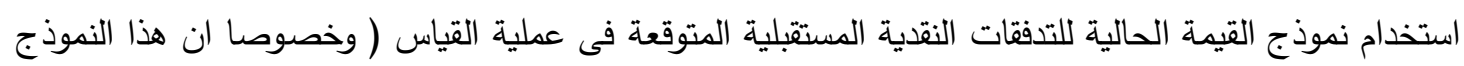
قد تم طرحه بثكل أساسى كمنهج لقياس القيمة العادلة فى حالة اضمحلال قيمة الأصول بمعيارى المحاسبة

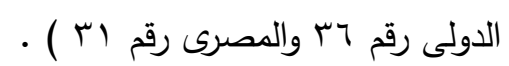
ويتاول معيار المراجعة المقترح إصداره توفير إرشادات لمراقبى الحسابات فيما يتعلق بمهام المراجعة الخاصة

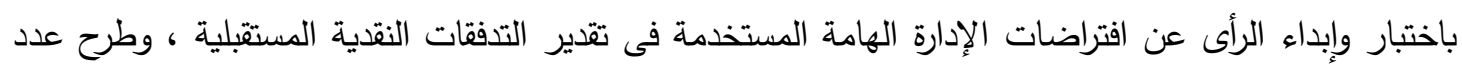

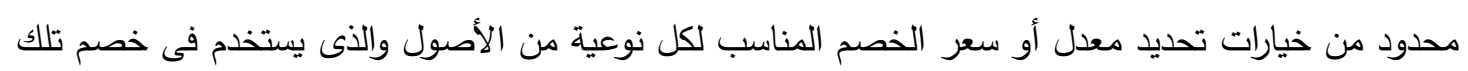


التدفقات ـ كما يتناول المعيار توفير إرشادات بثأن إمكانية قيام مراقبو الحسابات بعمل تقديرات مستقلة للقيمة العادلة باستخدام نموذج القيمة الحالية لإثبات صحة وملاءمة قياسات القيمة العادلة . ويجب أن يوفر المعيار إرشادات لمراقبى الحسابات بشأن التحقق من أسس تقدير التدفقات النقدية

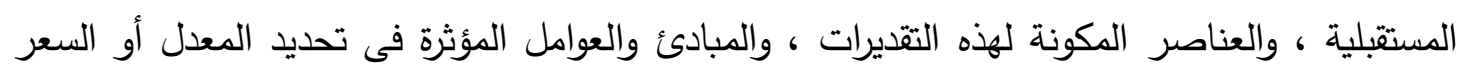
المستخدم فى خصم صافى التدفقات النقدية المستقبلية ـ وذلك فى إطار منهج القيمة الحالية المتوقعة والمبنى على استخدام الاحتمالات .

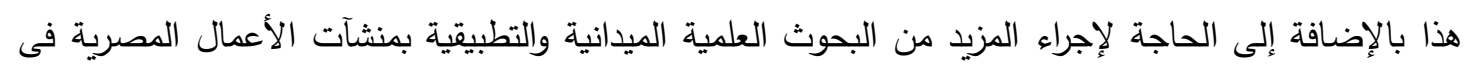
مجال المراجعة لنموذج القيمة الحالية للتدفقات النقدية المستقبلية المتوقعة كمدخل لقياس القيمة العادلة للأصدول

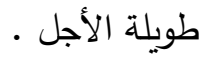

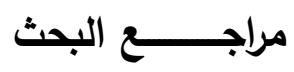


1- د.حسين محمد سححان ، "نحو استخدام مؤشرات مالية إسلامية فى تتييم المشروعات الاقتصادية "،

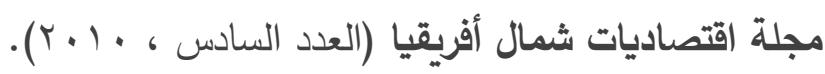

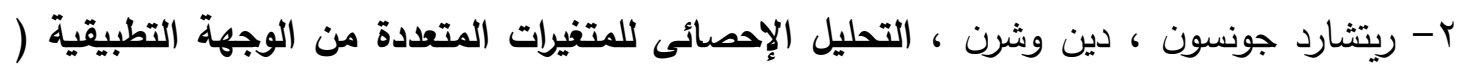

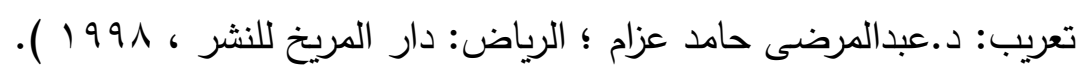

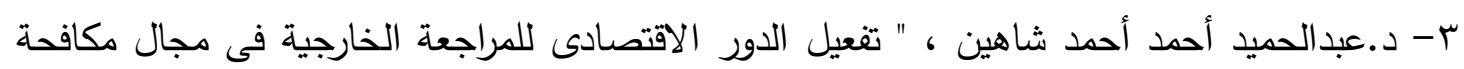

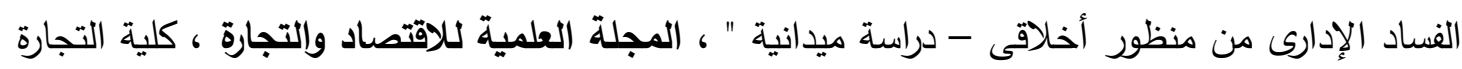

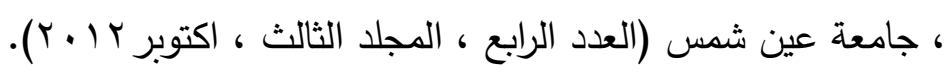

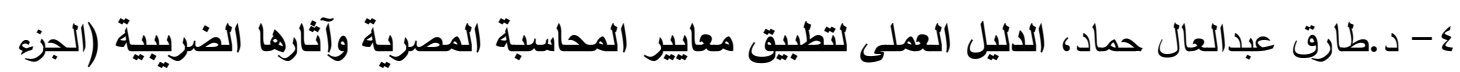

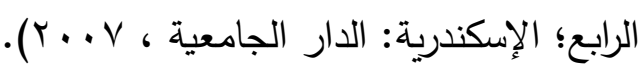

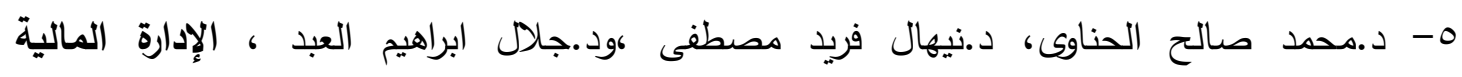

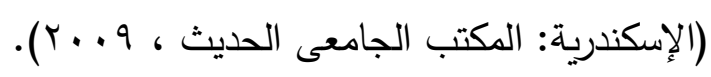
7- د.ناصر نور الدين عبد اللطيف ، "أثر اختلاف بدائل القياس المحاسبى للقيمة العادلة لاستثمارات

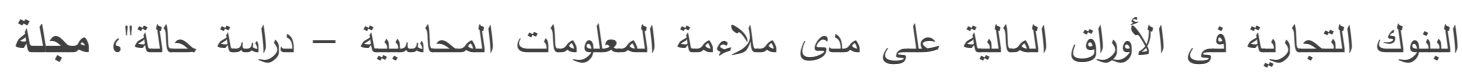

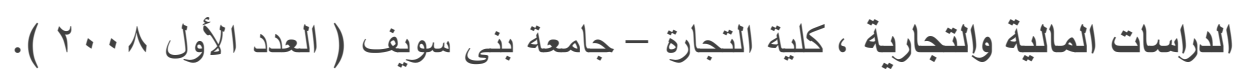

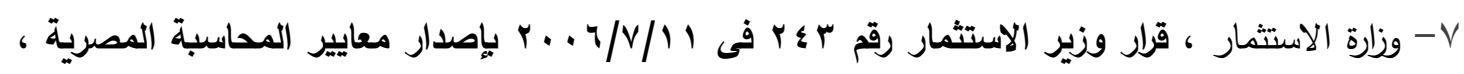

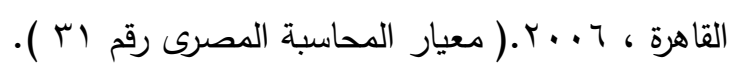

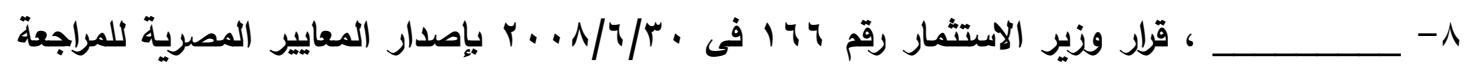

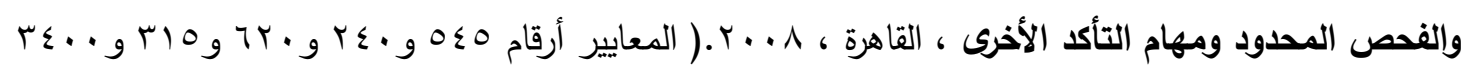

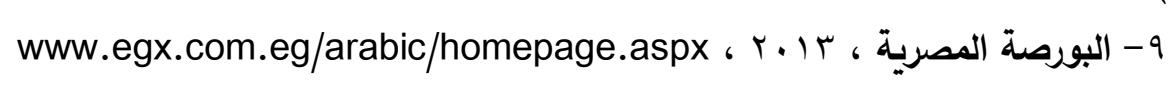


1- American Institute of Certified Public Accountants (AICPA), "Auditing fair value measurement and disclosures", SAS NO.101, AICPA, 2003.

2- Backof, A.G, Carpenter, T.D. and Thayer, J., "Auditing fair value estimates: The effect of management's supporting evidence on auditors' Detection of Aggressive Assumptions", 2012, www.darden.virginia.edu/

3- Bell, T.B., and Griffin,J.B., " Commentary on auditing high-uncertainty fair value estimates", Auditing: A Journal of Practice and Theory, 31 (1), January 2012 ,PP. 147-155.

4- Bratten, B., Gaynor, L.M., McDaniel, L.S., Montague, N.R. and Sierra, G.E., "The audit of fair values and other estimates: The effects of underlying environmental, task, and auditor-specific factors" Auditing: A Journal of Practice \& Theory, Forthcoming, September 2012

5- Carmichael, D., " The PCAOB and the social responsibility of the independent auditor", Accounting Horizons, Vol. 18, No. 2,2004, pp. 127133

6-Carmichael, S., Hummels,H., Klooster, A.T. and Luijk,H.V., " How ethical auditing can help companies compete more effectively at an international level ", The Institute of Chartered Accountants of India,Vol.1,February2011,www.kochiicai.org/admin/newsletter

7- Carpentier, C., Labelle, R., Laurent, B. and Suret, J.M., "Does fair value measurement provide satisfactory evidence for audit ? The case of high tech valuation” September 17, $2008 \quad$ http://ssrn.com/ sol3/papers. cfm?abstract-id=1269743

8- Don, H., saudagaran, S. M. and Thomas, W.B., "Property plant and equipment : The next step in M.S. fair value accounting", 2002, http://papers.ssrn. comid $=\mathbf{3 1 2 1 5 0}$

9- Ehrhardt, M. C. and Brigham, E. F., "Financial management: Theory and practice" South-Western, Thirteenth Edition, Australia, 2011. 
10- Ellison, S.L., Barwick, V.J. and Frrant, T.J., "ractical statistics for the analytical scientist" London: WK RSC Publishing, 2009.

11- Fama,E.F. and French,K.R., "The Capital Asset Pricing Model: Theory and Evidence", Journal of Economic Perspectives, Vol. 18, No. 3, Summer 2004 .

12- Financial Accounting Standards Board (FASB),"Using cash flow information and present value in accounting measurements", FASB,SFAS NO.7,2000.

$13-$ "Fair Value Measurements", FASB, SFAS No. 157, 2006

14- Grego, M. J. and Zollo, R. A., "Auditing fair value measurements and disclosures", Commercial Lending Review, November 2003.

15- Griffith, E.E., Hammersly, J.S. and Kadous, K., "Auditing complex estimates: Understanding the process used and problems encountered", Working Paper, University of Georgia, 2012.

16- Humphrey, C., Loft, A. and Woods, M., "The global audit profession and the international financial architecture: Understanding regulatory relationships at a time of financial crisis, Accounting, Organizations and Society, Vol. 34, 2009, pp. 810-825.

17- Independent Pricing and Regulatory Tribunal, "Review of method for determining the WACC: Dealing with uncertainty and changing market خطأ! مرجع الارتباط التشعبي غير صالح.

18- International Accounting Standards Board (IASB), "Fair value measurement guidance converges", IFRS 13 , 2011, ERNST \& YOUNG, 2011, www.ey.com/IFRS

19- International Auditing and Assurance Standards Board (IAASB), "Challenges in auditing fair value accounting estimates in the current market environment", IFAC, October 2008, www.ifac.org/download/ staff_audit_practice_alert.pdf 
Auditing Accounting Estimates, Including Fair Value Accounting Estimates, and Related Disclosures", IFAC, 2009.

21-International Federation of Accountants (IFAC), "Auditing fair value measurement and disclosures", IFAC.ISA 545, 2004.

22- Johnson, S., "PCAOB: Can Auditors Handle Fair Value?", June7,2007, www.cfo.com/article.cfm/9319788

23- Kaplan, R.S. \& Norton, D.P., Translating strategy into action : The Balanced Scorecard (Boston : Harvard Business School Press, 1996) . 24 , " Trans forming the Balanced Scorecard from performance measurement to strategic management : part 1 ", Accounting Horizons (Vol. 15 , No. 1, March 2001).

25- King, A. M., Fair value for financial reporting (New Jersey: John Wiley \& Sons, 2006).

26- Kohlbeck, M., "An analysis of recent events on the perceived reliability of fair value measures in the banking industry", Barry Kaye College of Business, 2008, http://ssrn.com/abstract=1117728

27- Kumarasiri,J., "Auditors' perceptions of fair-value accounting: Developing country evidence" International Journal of Auditing, Vol. 15, No. 1,2011, pp. 66-87.

28- Maksymov, E., Nelson, M.W., Kinney, W.R., "Effect of procedure frame, procedure verifiability, and audit efficiency pressure on planning audits of fair values" July 4, 2012, www.american.edu/ 29- Marza, D.G., " Trust and dialogue : Theoretical approaches to ethics auditing ", journal of business ethics, 2005.

30- McConnell, D.K. \& Banks, G.Y., " Expanded guidance for auditor fraud detection responsibilities ", The CPA Journal , No.6, June 2003.

31- Mclaney, E., J. Pointon, M. Thomas and Tucker, J., "Practitioners' perspectives on the UK cost of capital", The European Journal of Finance, Volume 10,2004,PP.123-138.

32- Menelaides, S.L., Graham, L.E. and fischbach, G., "The auditor's approach to fair value", Journal of Accountancy, June 2003,www.aicpa.org/PUBS/jofa/jun2003/ 
33- Pannese, D. and Delfavero, A., "Fair value accounting: Affect on the auditing profession", The Journal of Applied Business Research, Vol. 26, No. 3 , May/June 2010.

34- Public Company Accounting Oversight Board (PCAOB), Auditing fair value, Standing Advisory Group Meeting, September 8-9, 2004 , www.pcaobus.org

$35-$ , Auditing Accounting Estimates and Fair value measurements, Standing Advisory Group Meeting, June 21,2007, www.pcaobus.org

$36-$ Auditing fair value measurements and using the work of a specialist, Standing Advisory Group Meeting, October 14-15,2009, www.pcaobus.org

37- Reamer, F.G., " Conducting an ethics audit ", Social work today,vol.7.No.1,Jan./Feb. 2007, http://www.socialworktoday.com/ 38- Ryan, S. G., "Fair value accounting: understanding the issues raised by the credit crunch", Council of Institutional Investors, July 2008. 39-Troung, G., Partington, G., and Peat, M., "Cost of capital estimation and capital budgeting practice in Australia, Australian Journal of Management, Volume 33, No. 1,June 2008, pp 95-121, www.stieykpn.acid/ 
بيان عينة شركات المساهمة الموجه لها قائمة الاستقصاء

\begin{tabular}{|c|c|}
\hline اسم الشركــــــــــة & 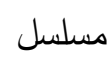 \\
\hline بنك قناة السويس & 1 \\
\hline بنك فيصل الإسلامى - مصر & r \\
\hline الإسكندرية للأدوية والصناعات الكيماوية & r \\
\hline العربية للَّدوية والصناعات الكيماوية " & $\varepsilon$ \\
\hline مينا فارم للأدوية والصناعات الكيماوية & 0 \\
\hline المصرية الدولية للصناعات الدوائية- إيبيكو & 7 \\
\hline بنك الثركة المصرفية العربية الدولية & $\mathrm{v}$ \\
\hline البنك الأهلى سوستيه جنرال & $\wedge$ \\
\hline القاهرة للاستثمار والتتمية العقارية & 9 \\
\hline بنك الاتحاد الوطنى - مصر & 1. \\
\hline المصرية للاتصالات & 11 \\
\hline زهراء المعادى للاستثمار والتعمير & it \\
\hline القاهرة للإسكان والتعمير & ז \\
\hline البنك التجارى الدولى (مصر) & $1 \varepsilon$ \\
\hline مصرف أبو ظبى الإسلامى - مصر & 10 \\
\hline أوراسكوم للإنشاء والصناعة & 17 \\
\hline المهن الطبية للأدوية ل & iv \\
\hline النيل للأدوية والصناعات الكيماوية & 11 \\
\hline ممفيس للأدوية والصناعات الكيماوية & 19 \\
\hline السادس من اكتوبر للتتمية والاستثمار سوديك & $r \cdot$ \\
\hline الجيزة العامة للمقاولات والاستثمار العقارى & r) \\
\hline الحديد والصلب المصرية & rt \\
\hline البنك المصرى الخليجى & rt \\
\hline السويدى اليكتريك & $r \leq$ \\
\hline البنك الوطنى المصرى & ro \\
\hline
\end{tabular}

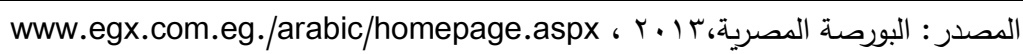

\section{ملحق رقم (r)}




\section{قائمة استقصــــــاء}

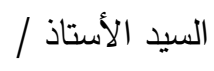

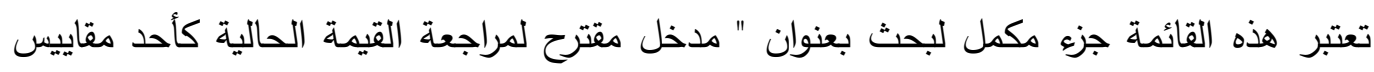

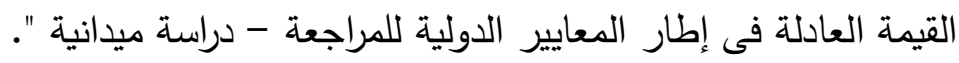

وتهدف هذه القائمة إلى استقراء فكر الممارسين من مراقبى الحسابات ، والقيادات الإدارية المعنية بالقياس

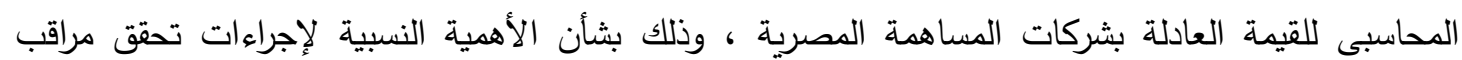

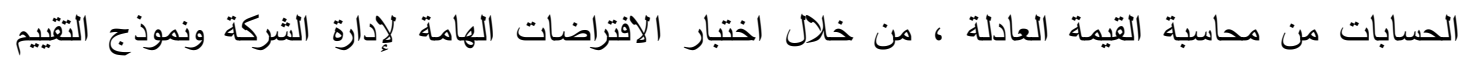

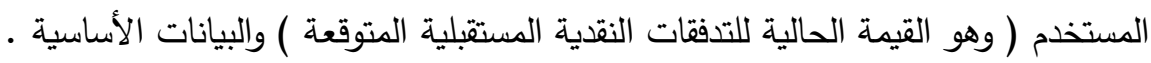

ولتحقيق ما تقدم تتتاول القائمة تحقق مراقب الحسابات من محاسبة القيمة العادلة باستخدام نموذج القيمة الحالية للتدفقات النقدية المستقبلية المتوقعة ، من الجوانب التالية :

1 - ـ مجالات المعرفة بنشاط الشركة لتحديد كافة الافتراضات الهامة لتقدير التدفقات النقدية.

r- ب أسس تقدير التدفقات النقدية المستقبلية.

r- العناصر المكونة لتقديرات التدفقات النقدية المستقبلية.

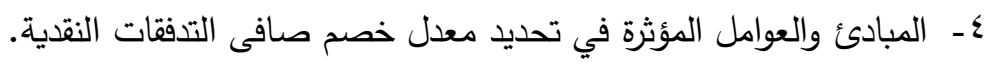

ـ - معدلات الخصم المتاحة.

ويتقدم الباحث لسيادتكم بخالص الثكر والتقدير سلفا لتفضلكم بالمعاونة الصادقة والمخلصة لاستيفاء

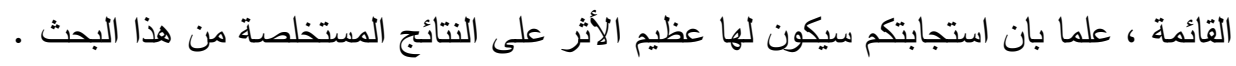

$$
\text { الباحث }
$$

د. عبد الحميد احمد احمد شاهين

أستاذ مساعد المحاسبة والمراجعة

كلية التجارة - جامعة مدينة السادات 


\begin{tabular}{|l|r|}
\hline & مدؤهل \\
\hline & \\
\hline
\end{tabular}

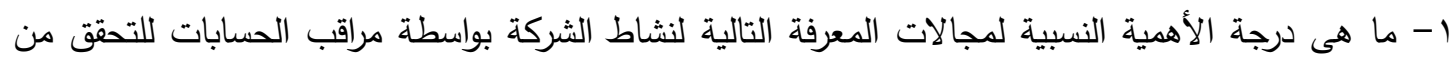
قيام إدارة الشركة بتحديد كافة الافتراضات الهامة المطلوبة لتقدير التدفقات النقدية المستقبلية :

\begin{tabular}{|c|c|c|c|c|c|}
\hline \multicolumn{5}{|c|}{ المقياس والأوزان الترجيحية } & \multirow{2}{*}{ 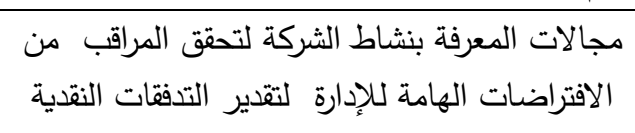 } \\
\hline 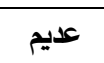 & قليل & متوسط & هام & هام & \\
\hline الأهمية & الأهمية & الأهمية & & جدا & المستقبلية \\
\hline 1 & r & $r$ & $\varepsilon$ & • & \\
\hline & & & & & التدققات النقطية. الرقابة ذات الصلة على نظام إعداد تقديرات \\
\hline & & & & & التدفقات النقدية. \\
\hline & & & & & والعملاء والموردين. النشاط والمرتبطة بالإيراد والسوق والإنتاج \\
\hline & & & & & ؛ - توثيق الافتراضات الهامة للإدارة. . \\
\hline & & & & & 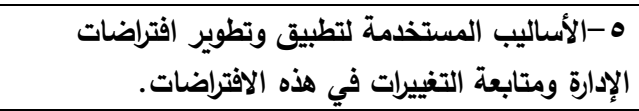 \\
\hline & & & & & 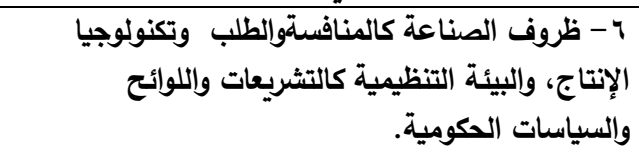 \\
\hline & & & & & تقديرات التدفقات النقدية. \\
\hline & & & & & 1الحوكمة بثأن قياس مراقب القيمة العادلة. بالمسئولين عن \\
\hline & & & & & 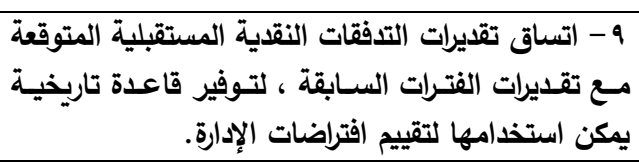 \\
\hline & & & & & 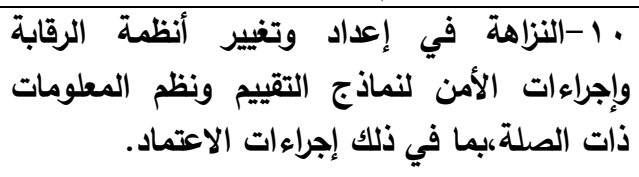 \\
\hline & & & & & 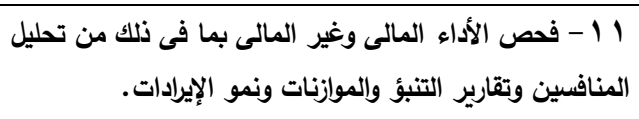 \\
\hline
\end{tabular}

ץ- ما هى درجة الأهمية النسبية للبنود التالية لحصول مراقب الحسابات على أدلة كافية وملائمة عن أسس تقدير التذفقات النقدية المستقبلية : المقياس والأوزان الترجيحية 


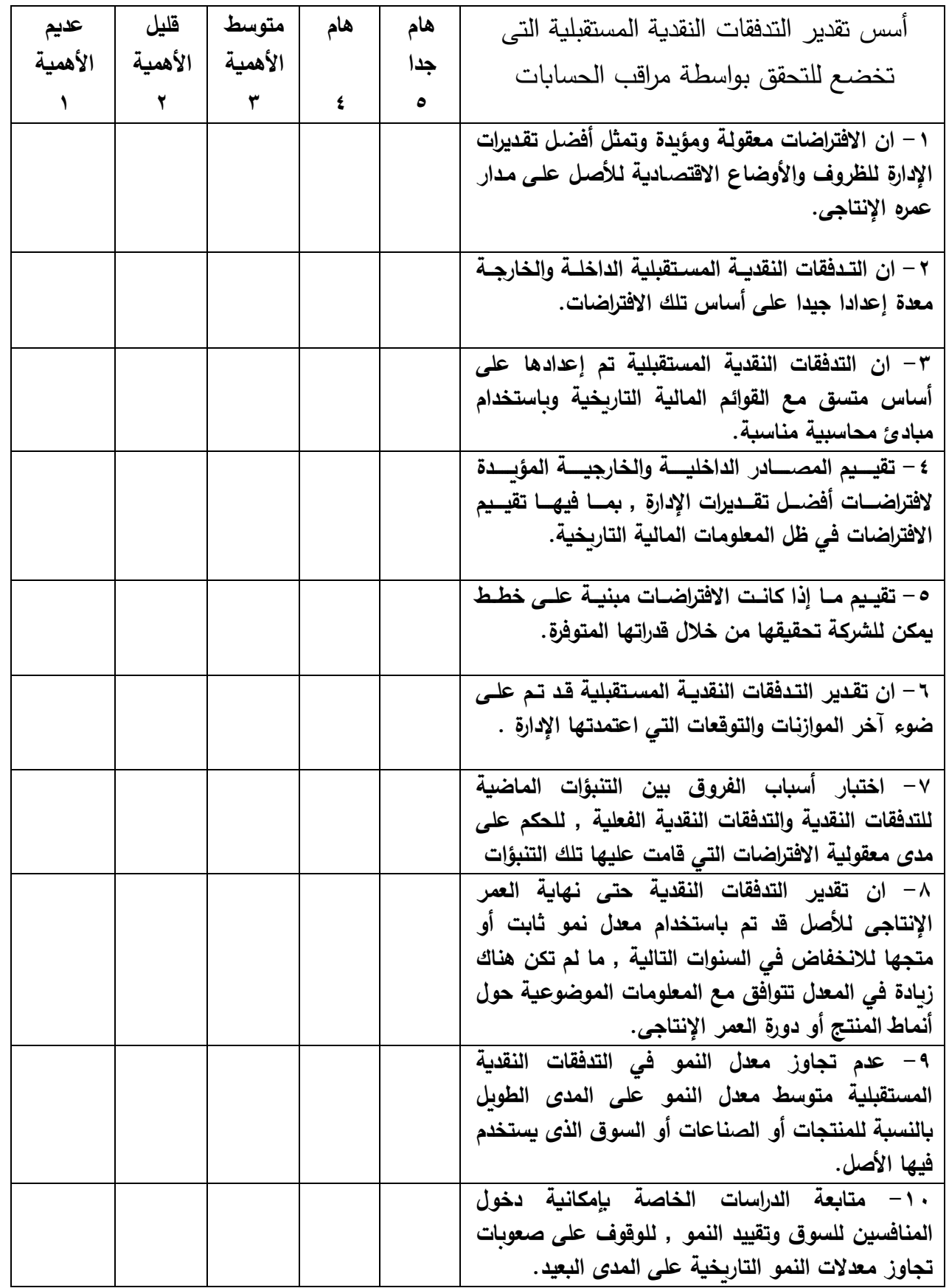

ץ- ما هى درجة الأهمية النسبية للبنود التالية لتحقق مراقب الحسابات من سلامة العناصر المكونة لتقديرات

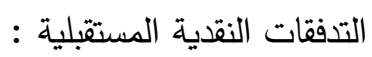

\begin{tabular}{|c|c|c|c|c|c|}
\hline \multicolumn{5}{|c|}{ المقياس والأوزان الترجيحية } & \multirow{4}{*}{ المستقبلية التى تخضع المكونة لتقديرات التذفقات النقدية } \\
\hline عديم & قليل & متوسط & هام & هام & \\
\hline الأهمية & الأهمية & الأهمية & & جدا & \\
\hline 1 & r & $r$ & $\varepsilon$ & 0 & \\
\hline
\end{tabular}




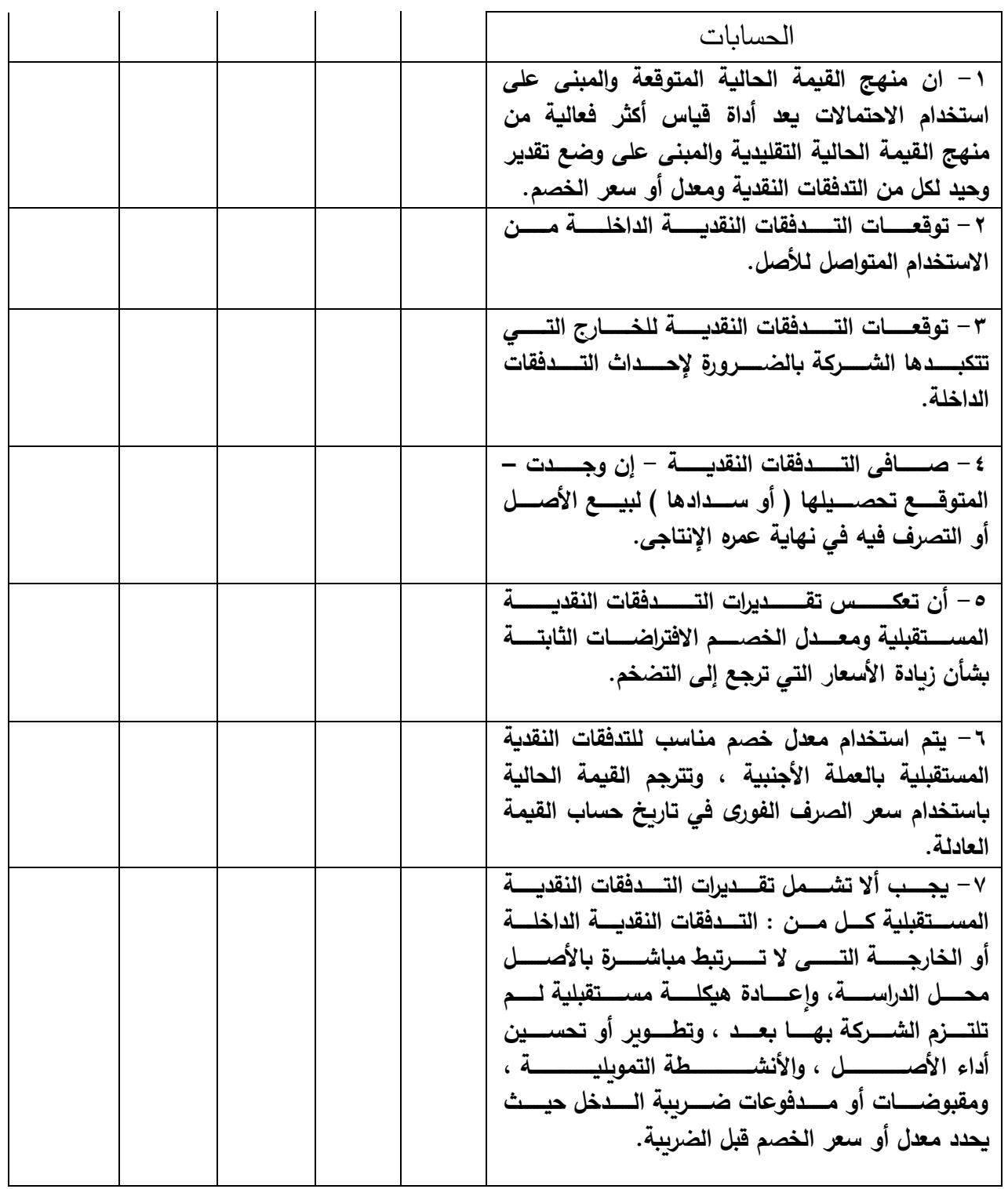

ع - ما هى درجة الأهمية النسبية للبنود التالية لتحقق مراقب الحسابات من المبادئ العامة والعوامل المؤثرة فى تحديد معدل خصم التدفقات النقدية المستقبلية.

\begin{tabular}{|c|c|c|c|c|c|}
\hline \multicolumn{5}{|c|}{ المقياس والأوزان الترجيحية } & \multirow{4}{*}{ 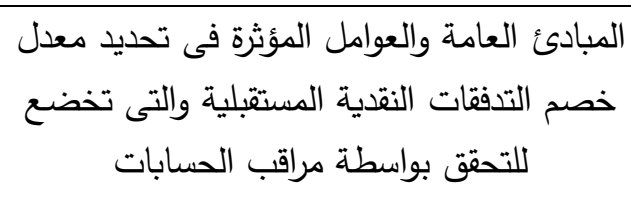 } \\
\hline عديم & قاليل & متوسط & هام & هام & \\
\hline 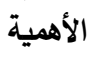 & 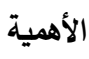 & 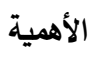 & & جدا & \\
\hline 1 & $r$ & $r$ & $\varepsilon$ & - & \\
\hline
\end{tabular}




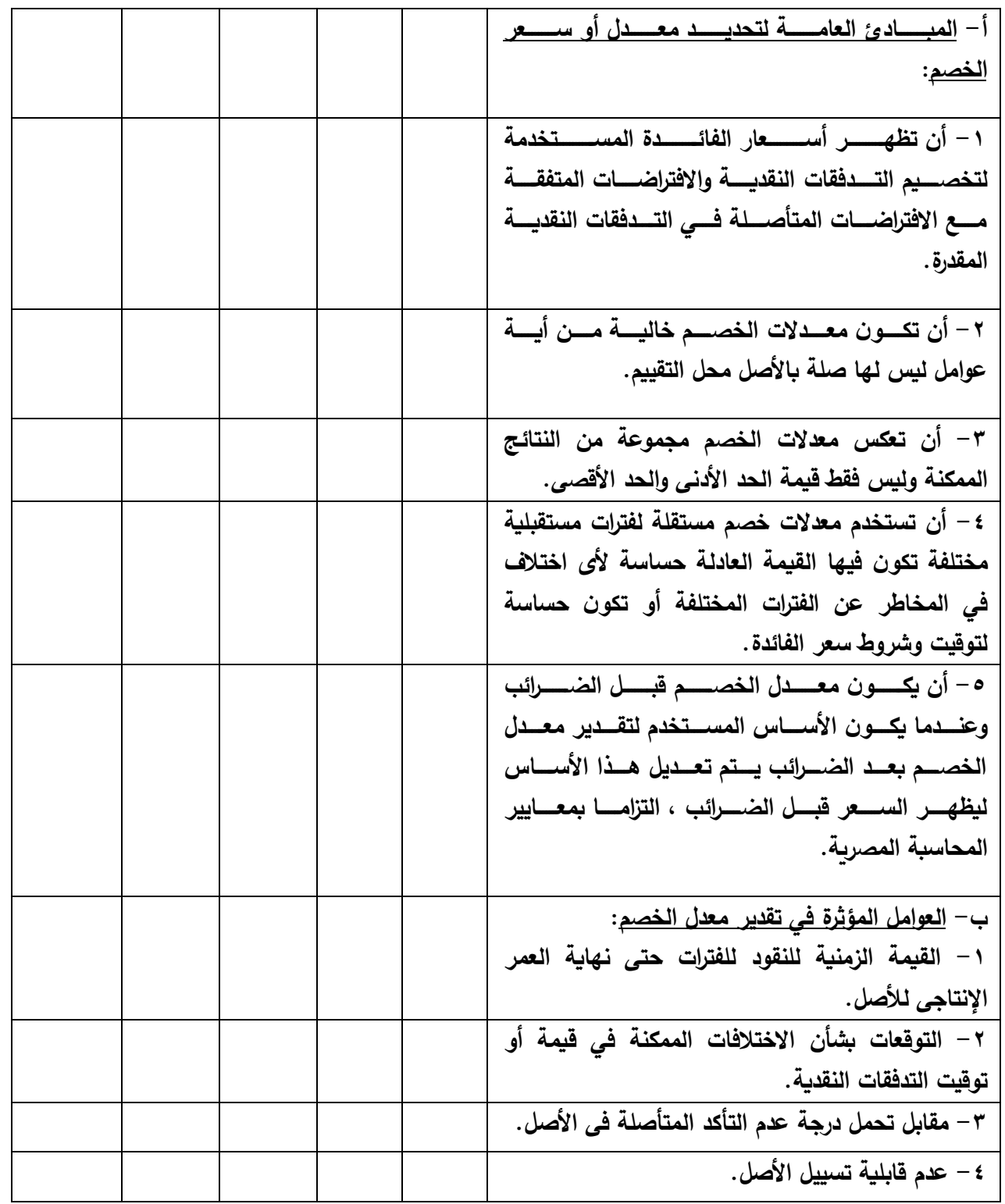

0- ما هى درجة الأهمية النسبية للمعدلات التالية لتحقق مراقب الحسابات من صحة وسلامة المعدل المستخدم فى خصم صافى التدفقات النقدية المستقبلية.

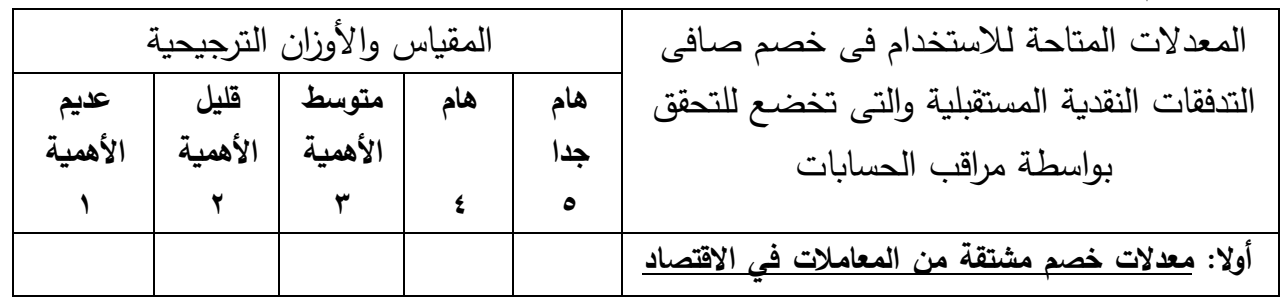




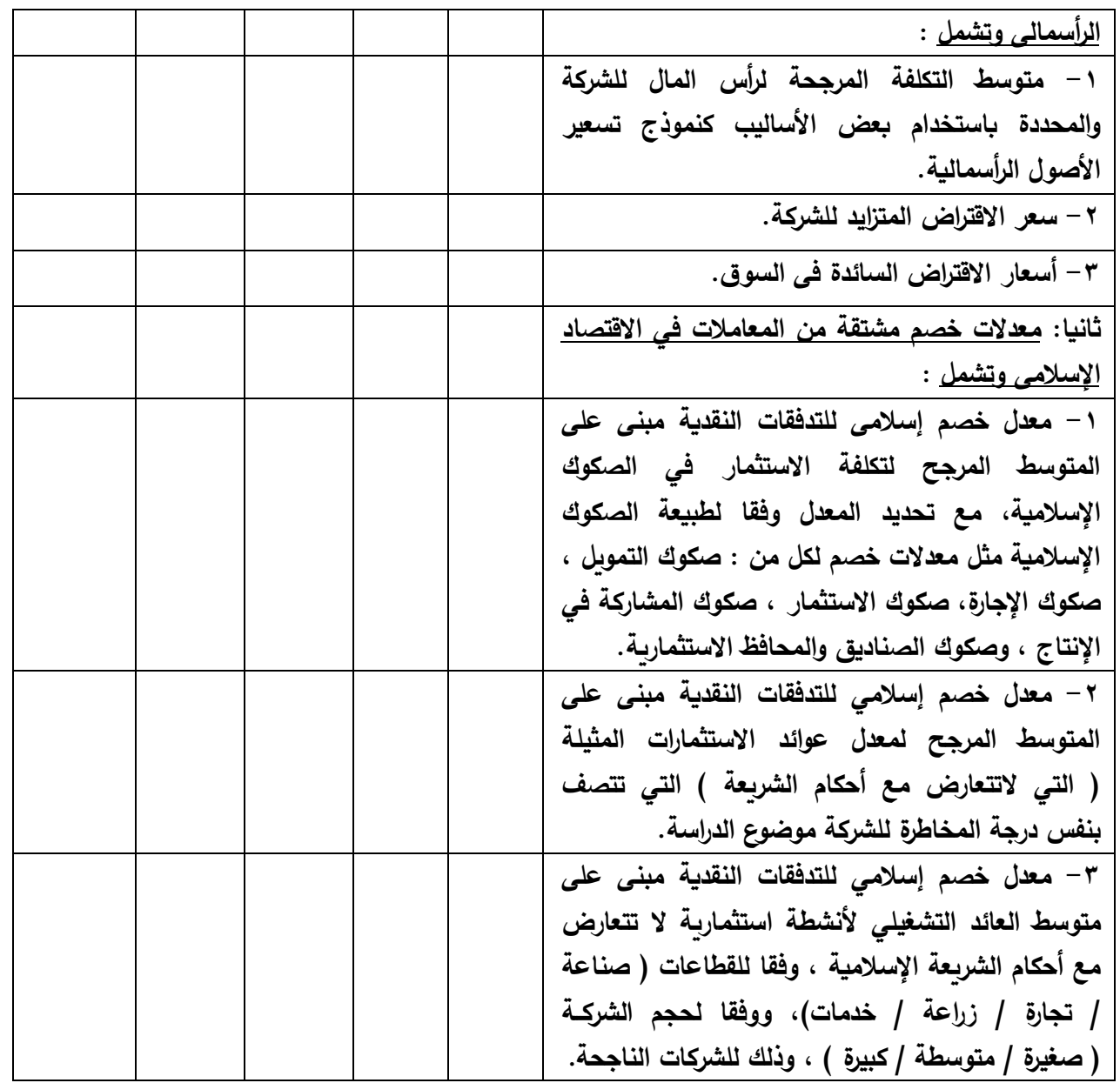

